\title{
Managing work-based postgraduate medical education in clinical departments
}

Citation for published version (APA):

Malling, B. V. G. (2011). Managing work-based postgraduate medical education in clinical departments. [Doctoral Thesis, Maastricht University]. Universitaire Pers Maastricht. https://doi.org/10.26481/dis.20110701bm

Document status and date:

Published: 01/01/2011

DOI:

10.26481/dis.20110701bm

Document Version:

Publisher's PDF, also known as Version of record

\section{Please check the document version of this publication:}

- A submitted manuscript is the version of the article upon submission and before peer-review. There can be important differences between the submitted version and the official published version of record.

People interested in the research are advised to contact the author for the final version of the publication, or visit the DOI to the publisher's website.

- The final author version and the galley proof are versions of the publication after peer review.

- The final published version features the final layout of the paper including the volume, issue and page numbers.

Link to publication

\footnotetext{
General rights rights.

- You may freely distribute the URL identifying the publication in the public portal. please follow below link for the End User Agreement:

www.umlib.nl/taverne-license

Take down policy

If you believe that this document breaches copyright please contact us at:

repository@maastrichtuniversity.nl

providing details and we will investigate your claim.
}

Copyright and moral rights for the publications made accessible in the public portal are retained by the authors and/or other copyright owners and it is a condition of accessing publications that users recognise and abide by the legal requirements associated with these

- Users may download and print one copy of any publication from the public portal for the purpose of private study or research.

- You may not further distribute the material or use it for any profit-making activity or commercial gain

If the publication is distributed under the terms of Article $25 \mathrm{fa}$ of the Dutch Copyright Act, indicated by the "Taverne" license above, 


\section{Managing work-based postgraduate medical education in clinical departments}


The research reported here was carried out at

\section{Mastricht University in Leaming!}

in the school of Health Professions Education

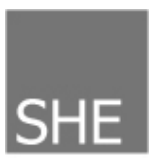

The research studies of this thesis were supported financially by the KUL-fund for quality improvement in postgraduate medical education, Aarhus County and by the Scientific Funds of Viborg and Aalborg County respectively.

Copyright, Bente Malling, Aarhus, Denmark, 2011

Print: Datawyse, Universitaire Pers Maastricht

Cover illustration: Gitte Skovgaard, Aarhus University Hospital, Denmark

ISBN 9789461590718 


\title{
Managing work-based postgraduate medical education in clinical departments
}

\author{
Dissertation \\ to obtain the degree of Doctor at Maastricht University, \\ on the authority of the Rector Magnificus, Prof. dr. G. P. M. F. Mols, \\ in accordance with the decision of the Board of Deans, \\ to be defended in public on Friday the $1^{\text {st }}$ of July 2011 , at 16:00 hours \\ by
}

Bente V. G. Malling

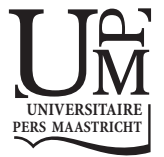




\section{Supervisor}

Prof. dr. A. J. J. A. Scherpbier

\section{Co-supervisor}

Prof. dr. C. Ringsted, University of Copenhagen, Denmark

\section{Assessment Committee}

Prof. dr. R. Koopmans (chairman)

Dr. J. van Dalen

Prof. dr. T. Dornan, University of Manchester, United Kingdom

Dr. D. Østergaard, Danish Institute for Simulation, Denmark

Prof. dr. C. van der Vleuten 
"When you have a great and difficult task, something perhaps almost impossible, if you only work a little at a time, every day a little, suddenly the work will finish itself" (Baroness Karen Blixen). 



\section{Table of contents}

1 Introduction 9

2 What is the role of the consultant responsible for postgraduate 29 education in the clinical department?

B Malling, AJJA Scherpbier \& C Ringsted

Published in Medical Teacher, 2007; 29: 471-477

3 Educational climate seems unrelated to leadership skills of clinical consultants responsible of postgraduate medical education in clinical departments

B Malling, LS Mortensen, AJJA Scherpbier \& C Ringsted

Published in BMC Medical Education, 2010; 10:62

4 Effects of multi-source feedback on developmental plans for leaders of postgraduate medical education

B Malling, T Bonderup, L Mortensen, C Ringsted \& AJJA Scherpbier

Published in Medical Education, 2009; 43: 159-167

5 Combining a leadership course and multi-source feedback has no effect 75 on leadership skills of leaders in postgraduate medical education. An intervention study with a control group

B Malling, L Mortensen, T Bonderup, A Scherpbier \& C Ringsted

Published in BMC Medical Education, 2009; 9:72

6 Issues of governance in postgraduate medical education. A curriculum analysis

B Malling, D Davis, A Scherpbier \& C Ringsted

Submitted to Advances in Health Sciences Education, January 2010

7 Discussion

8 Summary

9 Samenvatting (Summary in Dutch) 135

10 Acknowledgements 143

$\begin{array}{lll}11 \text { Appendices } & 147\end{array}$

12 Curriculum vitae 153 

CHAPTER 1

Introduction 
The issue of this thesis is the management of postgraduate medical education (PGME) in clinical departments. PGME has a long tradition of apprenticeship learning and the optimal way of learning the medical profession is considered to be through participation in patient treatment (1) alongside with support and supervision from senior doctors $(2-4)$, supplemented with theoretical and practical courses.

Postgraduate medical education has tight bonds to hospitals and other health care organisations. Although both under- and post-graduate education takes place in various health care organisations, the main part of under-graduate medical education takes place in universities or medical schools, which are academic institutions designed for education and research. Contrary to this, PGME mainly takes place in hospitals characterised by complex organisations with competing missions and values (5 - 9). About 100 years ago Flexner described that research was the primary mission of medical schools, from which education and good patient treatment would emerge (10). Later patient treatment was ranked highest followed by education and research $(5,6)$. However, some have perceived the core mission of hospitals as first of all teaching the next generation of physicians, secondly to conduct groundbreaking research and finally provide high-quality care to patients $(8,9)$. No matter how you perceive the tripartite mission of hospitals, the awareness that education has to be prioritized is growing $(7,11)$, and it is becoming obvious that effective education - like research and patient treatment - cannot be achieved without leadership and management $(6,8,11$ - 17).

Hospital departments are complex workplaces where it is difficult to make an exact plan for educating young physicians (trainees). The working schedule is often tentative and frequently changed at short notice due to emergencies and unforeseeable incidents. Due to the complexity of the clinical departments and the workbased nature of PGME there are many stakeholders in the organisation of PGME (18 - 22). These stakeholders all contribute to the complexity in the leadership of PGME in clinical departments. Thus the responsibilities and obligations in managing PGME in clinical departments are many (6), and the appointment of leaders of PGME in clinical departments has been described in many countries $(20,23,24)$.

Hospitals and other health care organisations involved in PGME face major challenges such as demands for efficiency, high quality and high patient safety, and a shift towards increased ambulatory and outpatient care. As a result the patientpopulation in the wards, traditionally the foundation of specialist training has changed $(6,7,25,26)$. Combining these challenges with the increasing number of postgraduate trainees and the continuously growing specialization of university hospitals has made the inclusion of non-university hospitals in specialist training necessary. Finally, the changing male/ female ratio of students, the changes in attitudes towards the job and the lowering of working hours have made it necessary to change educational practice (6 - 8). 
To comply with society's need for well-educated doctors conducting high quality and safe patient care, major reforms in PGME introducing outcome-based education and in-training assessment have been initiated in most countries (18, 27 - 29). In turbulent times with many organisational changes, leadership is essential (30 34). Thus, managing medical education has become a major issue and leadership in medical education has achieved increasing attention (11- 16, 35 - 38).

Skills and attributes of effective leaders of health care, medical school deans, and clerkship directors have been described (39-45). There is no reason to believe that the expectations of leadership skills of PGME leaders in clinical departments are any different. However, we do not know much about these educational leaders, their job, or their management abilities. Therefore this thesis sets out to explore leadership and management of PGME in the complex world of clinical departments. The studies are conducted in a Danish context, and they focus on the consultant responsible for education in the clinical department (CRE). The job of the CRE bears much resemblance with the job of a site director or programme director.

The thesis is structured around three concepts in the management of PGME in clinical departments: the task, the leader and the context. The task is to manage PGME through introduction, implementation, administration and quality assurance of curricula defined by authorities. The leader is the person who carries out the management and leadership of PGME in the clinical department (the CRE). The context includes the clinical department as a working place and a professional organisation, the culture and human relations in the department and the concept of outcome-based education.

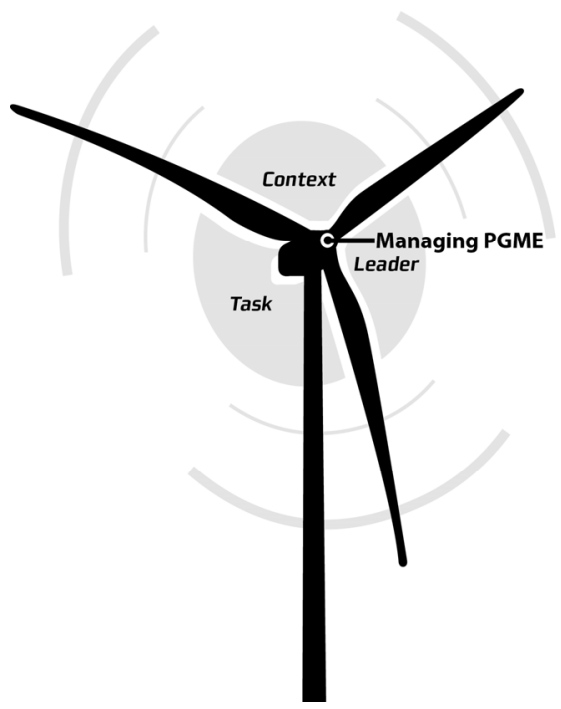


This introduction presents the theoretical background for the task, the leader and the context. At the end of the introduction the research questions are presented with an outline of the studies included in the thesis. In the section "The task" the concept of leadership as a process of influencing others to understand and agree about what needs to be done and how to do it will be described. The CREs function on the mid-level manager level and in the studies his role, position and influence in the clinical department will be explored. The taxonomy in leadership will be presented and the mid-level managers' primary functions will be discussed. In the section "The leader" the leadership skills and performance of CREs are investigated together with the effect of leadership development initiatives. The physician as leader will be discussed and various initiatives to develop leadership skills are presented. Finally in the section "The context" the characteristics of the clinical department as a professional organisation are discussed. In the studies the relation between patient care and the outcome-based PGME in relation to the clinical workplace is discussed. The culture and the human relations in clinical departments with relation to educational obligations are explored. Finally, in the last section of the thesis the context is broadened from this micro-level (clinical department) to macro-level comprising the very complex context of the PGME as a whole.

\section{The task}

\section{Job description}

The leader of PGME in clinical departments, in this thesis represented by the CRE, has many duties $(18,24)$. As an administrator of PGME in the clinical departments, he takes care of planning and administration of the various educational courses. The many changes in the organization of health care and the introduction of outcomebased education and in-training assessment make it necessary that he can exhibit leadership (30 - 34). Thus, he must have the technical skills and knowledge on how to introduce and implement changes, like the major reform on PGME, he is supposed to implement in the clinical departments right now. Especially in professional organisations like hospital departments, the mastery of change management is an important requisite, since professional organizations are particularly reluctant to changes (46). In change processes the CREs must possess human skills like cooperation, communication, coaching and emotional intelligence (39-41) in order to work through others to make the various initiatives run smoothly in the clinical department with its many stakeholders.

Thus the CRE must be able to manage both administration and changes. This is in alignment with the traditional perception that managerial skills are divided into management skills and leadership skills. Management skills are defined as the ability 
to cope with complexity, its practices and procedures (administration), and leadership skills involving ability to cope with change (34). However, elaboration on the ability to cope with change has revealed three perspectives or dimensions concerning leadership skills: 1 ) task-oriented behavior or technical skills which refer to the proficiency in specific methods, processes and techniques as a leader; 2) relationoriented behaviour or human skills which include the ability to work with and through people to meet goals; and 3) citizenship behaviour which is professionalism regarding interpersonal, organisational and job/task performance, often including change-oriented behaviour $(33,47)$. Scullen et al. (47) has described a four-factor model consisting of technical skills, human skills, citizenship behavior and administrative skills. The CREs' obligations, tasks and duties described above fit well into this four-factor model, and the taxonomy provided by Scullen et al. (47) will be applied in this thesis.

The job-description for a CRE, provided by the Danish National Board of Health, comprises all the obligations described above (24). However, the extent to which the CREs possess and use technical skills, human skills, citizenship behavior and administrative skills in practice is unknown.

\section{The concept of leadership}

Knowledge about the kind of leadership exerted by CREs is scarce. In the past century various leadership models and theories have evolved and developed over time $(32,33)$. From focusing on the "natural born" leader to a perception that leadership can be learned and that leadership evolves in the individual through self-awareness and a learning approach to experience supplemented with the establishment of personal relations $(48,49)$. Day \& Harrison even takes the evolvement further to describe leadership as a shared property of a social system including interdependencies among individuals, teams and organisations involving roles and influences depending upon the situation (50). This perception is shared with Fullan (51), who describes the pervasive leadership as "slow learning and knowing in context with others at all levels in the organisation".

Likewise, there have been many definitions of leadership over the years. In this thesis the definition provided by Yukl (33) will be used. He described leadership as "The process of influencing others to understand and agree about what needs to be done and how to do it, and the process of facilitating individual and collective efforts to accomplish shared objectives" (33). By using Yukl's definition of leadership in this thesis it is not intended to ignore the fact that leadership can be and is defined in other ways. And it is well acknowledged that the definition of leadership is constantly undergoing changes. 
It has not been investigated what kind (s) of leadership models CREs use, how the CREs are educated to take on the leadership role or how the CREs' leadership position is perceived by the CREs or by stakeholders in PGME.

\section{Level of management}

Traditionally, managers are divided into high-level managers, mid-level managers and low-level managers $(33,46)$. In the organisation of PGME, high-level managers make long-ranging plans, formulate policies, modify organisational structures, and initiate new procedures. These initiatives come from various institutions like specialist societies, medical associations, national boards of health $(18,19,27,29,52$ - 54) or accreditation bodies $(20-23,28,55,56)$. The CREs in clinical departments can be perceived as mid-level managers primarily concerned with interpreting and implementing policies and programs, and mediating changes in the clinical department regarding PGME $(23,24,57)$. However, CREs can make long-ranging plans and perform all the managerial roles of a high-level manager inside his department. Thus, he is a mid-level manager in the extended perception expressed by Mintzberg (46). The clinical supervisors in the department perform the duties of a low-level manager like structuring, coordinating and facilitating work activities, and they usually spend time on patient treatment, training, scheduling work, and monitoring trainees' performance.

While the role and responsibilities of the clinical teachers and the supervisors have been extensively investigated, we know very little about the perceived roles and responsibilities of the CREs in practice.

\section{The leader}

To be appointed as CRE you have to be a specialist in a field of medicine. However, it might be questioned if being a specialist of a domain of medicine is enough to fulfil the many obligations of a CRE. However, the absence of managerial and leadership competencies has been described among physicians who hold key leadership positions (58). Few physicians, who become leaders in academic medicine, aspire to, plan for or seek training in leadership (59) and often these leaders have gained their leadership competencies through painful and time-consuming experiences (49).

At first glance physicians ought to be excellent leaders by the way they are trained to handle complex, (clinical) problems and deal with emotional and stressfull situations (39). But at the same time physicians have been trained to handle one case at a time and physician leaders are more aligned to their disciplines and the profession than to their organisation $(15,39,59)$. Leaders, however, have to de- 
velop a more systemic view and understanding of organisations in order to succeed $(39,50,60)$.

Effective leaders in academic healthcare possess knowledge of leadership, skills like enabling others to act, consensus-building, conflict resolution, capacity to respond to rapid changes and a strong sense of other-directedness like listening, learning, coaching and mentoring, as well as competences such as emotional intelligence $(39,40,41)$ together with a team-oriented mindset $(42)$. The same qualities were stressed in a literature review on desired characteristics of medical school deans (43). Regarding directors of educational programmes, there is a growing awareness that they need to develop their leadership role and not simply concentrate on managing educational resources and applying rules and regulations (61). Hence suggestions have been made to include leadership development in medical school $(42,59)$. Recently, clerkship directors have been reported to meet expectations of leadership skills to a high degree $(62,63)$. However, little is known of whether CREs live up to expectations regarding leadership skills.

\section{Development of leaders}

Many have described how development of the individual leader's managerial skills is a prerequisite of leadership $(15,31-33,50,58,64-66)$. It is widely accepted that leadership can be learned through experience, formal education (courses), personal development and net-working $(9,15,16,33,40,49,50,67-70)$.

Experience as a leader is a necessary but not sufficient way of developing leadership skills $(48,49,66,69)$. Improvement of leaders' performance can be achieved through leadership courses or other educational initiatives $(9,15,33,50,68)$. However, to be efficient the content of leadership courses should relate to the organization the leaders work in $(32,33,50,66,69)$. Finally, personal development is regarded by many as an essential part of the development of leadership skills $(50,66$, $68)$. Some even regard it the most important initiative $(47,70)$.

Personal development is related to experience but it can be more efficiently targeted by various initiatives like multi-source feedback (MSF), coaching and mentoring $(15,66,70)$. Multi-source feedback is a popular and widely used method to initiate personal development $(15,33,66,70$ - 74). Multi-source feedback processes are intended to make leaders aware of strengths and weaknesses, to initiate reflections on how to improve own performance, and to form the basis for a personal development plan $(33,50,70,73)$. Besides initiating personal development, some have found that MSF processes were well-suited for evaluating performance of leaders $(33,50,73)$.

Leadership skills can be gained through various initiatives and many authors have recommended a combination of methods $(15,50,66,69)$. Thus, McKimm used the combination of MSF, coaching and leadership courses in the FDTL leadership 
program (15). Mintzberg advocates for the use of personal development combined with leadership courses rooted in daily work through projects in your own organisation or through simulations (69). This recommendation is in agreement with others $(50,66)$.

Longitudinal studies of leadership program outcomes using comparative groups are exceedingly rare in academic medicine (75). Saleh et al., however, showed how a public health leadership training program improved participants' leadership skills judged by self-assessment of competences (76). Beneficial impact on the participants and their careers have been described following leadership programs specifically designed for leaders in medical education at under-graduate level $(14,75)$. The CRE faces a complex leadership role as a mid-level manager in regard to both PGME and clinical services and thus might need leadership training that relates to his specific position in the clinical department. However, the effect of leadership development initiatives focused on leaders of PGME in clinical departments (CRE) has not been described.

\section{The context}

In this thesis the context will be investigated at two levels: 1) the micro-level represented by the clinical department, where PGME takes place, and 2) the macro-level which deals with the influence from government, universities and hospital administrations on the management of PGME.

\section{Clinical departments are professional bureaucracies}

Clinical departments are complex work-places with a mixed mission (patient care, research and education) and many stakeholders. From a theoretical point of view hospital departments are professional bureaucracies (46). A professional bureaucracy or organisation is characterized by having a large percentage of professional or academic staff - in the hospitals, the physicians. The primary coordinating mechanism is standardisation of skills. The nature and quality of skills are decided and evaluated by the profession itself. They typically include work-based learning, which contributes to make physicians identify more with the profession than with the organisation he practices in. Characteristically the professionals' services are in great demand in society and the professionals claim their right to autonomy. The only control physicians accept is the control from the "profession" (scientific societies) itself or from "other professionals" (other physicians) (46).

Another characteristic of professional organisations is that leaders are often chosen due to their individual achievements (research, clinical skills) - rather than their leadership skills $(9,15,39,58,59,77)$. The physician leader is leading other 
professionals who also favour autonomy and independence, and who resist being told what to do. They are brought up with the ideology of academic freedom (31), and their achievements have brought them personal status and given them power positions $(31,39,78)$. Physicians thus face fundamental dilemmas: they want freedom to practice their profession, but freedom is gained only at the price of administration, however, they tend to delegate paperwork to administrators and by doing so they lose power. Power in professional structures, like hospitals, flow to those professionals, who care to devote effort in doing administrative instead of professional work, but only as long as the other professionals believe they serve their interests (46). The physician as a leader fall between two chairs - the collegial professional world where he is a peer and a colleague, a team-member and a clinical expert, and the leadership world where he has to make decisions that involve his colleagues (49). Rigid hierarchical and bureaucratic structures with long traditions are inherent in professional academic organisations $(9,39)$. Another characteristic of these organizations is the reactionary forces, which makes them less suitable and slow to adopt changes $(8,9,39,46)$.

Regarding PGME the implementation of reforms comprising outcome-based education and in-training assessment seems to be a slow process. It is characteristic that the changes made have predominantly been structural, while changes in teaching principles and practice have not (yet?) been manifested as measurable changes $(79,80-84)$, which is not an unfamiliar feature in change processes $(33,34,85)$. The reluctance to changes in professional organizations like hospitals might be one reason for slow implementation of reforms in PGME. However, other contributing factors need to be explored and investigated.

\section{The organisation of PGME at a wider level}

In many countries (United States, Canada, United Kingdom) the universities or medical schools play a substantial role in PGME (20 - 22). In the United States (US) the prevalent organisational models are partnerships where the open clinical service delivery system forms alliance with a university / medical school. "General partnerships" where the university or medical school is the dominant partner, and "limited partnerships" where the clinical service delivery system is the dominant partner have been developed (86). Besides partnerships allegedly $30 \%$ of health care organisations in the US have adopted a "single ownership" model where the clinical service is owned or controlled by the university / medical school $(86,87)$. In Canada the "single ownership" model predominates (20). In European countries

"unlinked partnership" dominates. In the United Kingdom (UK) the universities are involved in PGME through deaneries (22), while in most other European countries PGME is not the business of the universities. In these countries other parties like 
national boards of health (UK, Denmark, France) or medical associations (Norway) are responsible for PGME $(18,19,22,88)$.

The differences in the organisations in various countries are probably defined by history and national values rather than by a robust base of evidence, and furthermore organisations shift over time due to external influences $(85,86,88)$. The models described are archetypes and a mix of the models is probably more likely to be found than a pure form of any of the models (86).

Hospitals, on the other hand, are managed through a kind of hospital administration, which is not necessarily linked to the administration of PGME. Decisions on the management of PGME seem to be made by outside bodies compared to the decisions regarding the actual work in the hospitals that PGME depends so heavily on. In this way, there seems to be two parallel organisations or lines, one for PGME and the other for clinical service. How this seemingly split line of governance influences the management of PGME at departmental level has not been described in the literature.

\section{Organisational culture and educational climate}

In PGME a part of the organisational culture, the educational climate in the clinical departments, has achieved increasing attention, since it is perceived to have major influence on how trainees learn and perform $(1,3,4,89)$. However, the concept educational climate has been used indiscriminately with culture, environment or learning context (90). Nevertheless, all of these concepts include the same elements: 1) atmosphere (89-91), 2) the connection and personal relation with colleagues $(4,36,91), 3)$ openness to questions, and 4) appropriate supervision and feedback $(3,4,91)$. Sometimes the concept educational climate also covers the working conditions and planning of the work to ensure that trainees learn and develop clinical skills $(89,91,92)$.

The organisational culture is closely connected to leadership, and although all employees take part in developing the culture in a department, the leaders are in a position to deliberately influence the culture (85). The CRE can influence the educational climate by prioritising and attending to a variety of activities in the department (6) and by role-modelling. Hence, a positive relation between leadership skills of the CRE and the quality of the educational climate might be expected. However, this inference cannot be drawn from the current literature on PGME.

\section{Outcome-based education in clinical departments}

The international trend in PGME comprises the introduction of outcome-based education with in-training assessment. The implementation of this educational reform is one of the duties of a CRE. 
However, there seems to be problems with implementation of outcome-based education (79, 80, 82 - 84, 93-95). The structural changes are well-implemented while the cultural aspects and assumptions around clinical training remain unchanged $(79-81,83,94,95)$. Especially the implementation of in-training assessment causes troubles $(79,82)$, although it has been documented that in-training assessment can be successfully implemented $(96,97)$.

The incomplete implementation has been ascribed to poor staff development $(85,94)$, common resistance to change (52) and a culture not ready for change (94). However, whether these problems could be related to the concept of outcomebased education in combination with the complex world of PGME, or if they are an indication of the leadership skills of the CREs, or his possibility to exert leadership, has not been investigated.

\section{Summary}

Postgraduate medical education takes place in a complex arena, and is undergoing major reforms with the introduction of out-come based education and in-training assessment. At the same time society, health care and the clinical departments where PGME takes place continuously undergo changes. Leaders in PGME therefore have to be able to cope with a constantly changing environment. In clinical departments a leader of PGME (CRE) therefore has been appointed in many countries. However, how he is managing his job of leading PGME in practice is not well described. Neither has it been investigated how his leadership competence is perceived by colleagues or how influential he is in the clinical department. It is known that various developmental initiatives like leadership courses and personal development can improve leadership skills. However, whether this applies to CREs has not been investigated. Finally, the interaction between PGME and clinical service needs to be explored further. The purpose of this thesis was to explore how PGME is managed in clinical departments. Below the research questions and the studies included in this thesis are outlined.

\section{Research Questions}

This thesis focuses on the challenges in the management of PGME in clinical departments. The overall research question was:

- What characterises leadership and management of PGME in clinical departments?

From the overall research question, five sub-questions were generated on the previously mentioned aspects: the task, the leader and the context. 


\section{The task}

The duties and responsibilities of a CRE are very similar to the function of mid-level managers $(33,57)$. However, one thing is a description of tasks, duties and responsibilities, another thing is what is actually happening. The first study therefore aims at describing what tasks and duties the CRE really carries out, and how the position as CRE is perceived by various stakeholders.

Research question 1: What is the role and position of the consultant responsible for postgraduate medical education and what is expected from him concerning tasks and responsibilities, qualifications, influence and prestige?

With the definition of leadership used in this thesis follows an expectation that the CRE as leader of PGME has influence on how education is carried out in the clinical department. The educational climate is perceived to have major influence on how trainees learn and perform $(3,4,89)$. The organisational culture, according to Schein (85), is closely connected to leadership and leaders are in a position to deliberately influence the culture (85). Hence, a positive relation between leadership skills of the CRE and the quality of the educational climate might be expected.

Research question 2: What is the relation between the educational climate in the clinical department and the leadership skills of the consultant responsible for education?

\section{The leader}

The purpose of multi-source feedback (MSF) processes is primarily to initiate personal development (73). However, MSF is also well suited for evaluating managerial performance $(33,74)$. Multi-source feedback provides physicians with quality improvement data about competencies like medical expertise, communication skills, collegiality, psychosocial and administrative skills, when used in medical settings (71). In a MSF process your own performance ratings are compared to ratings from your superior, peers, and subordinates (73). Multi-source feedback processes are intended to increase awareness of strengths and weaknesses, to initiate reflections on how to improve performance, and to form the basis of a personal developmental plan (73). Areas in need of improvement are identified through low ratings or gaps e.g. differences in self-ratings and ratings made by others $(33,73)$. An MSF instrument specifically designed for CREs was developed, since MSF instruments already developed did not include all responsibilities and tasks of a leader of PGME $(74,98)$.

Research question 3: To which extent are the areas in need of improvement (low ratings or gaps) identified by MSF responses from young doctors-in-training, con- 
sultants, heads of departments, and CREs used in the development plans of PGME leaders in clinical departments?

Although it has recently been questioned, it is still the general opinion that education of leaders results in improvement of leaders' performance $(9,15,33,66)$, especially if the content of the leadership courses relates to the organisation the leader works in $(9,33,69)$. In organisations outside health care it has been suggested to combine leadership courses with MSF or other initiatives supposed to initiate personal development in coherence with development of the organisation $(50,66)$. A leadership course was developed for CREs based on an assessment of needs.

Research question 4: What is the effect of a leadership course following a MSF procedure compared to MSF alone especially regarding development of leadership skills over time?

\section{The context}

It is well-known that the context in which you exert your leadership has major influence on the impact of your leadership $(31,33,34,46,99)$. It has likewise been described that the effect of both MSF-processes and courses is influenced by context (MSF: 73, 100; Courses: 76, 101 - 103). However, both the content of what you are supposed to lead and the context in which you lead influences the possibilities to exert leadership. The final research question dealt with the context in which PGME takes place.

Research question 5: What characterises the governance of PGME? What underlying assumptions and epistemologies are reflected in the content and organisation of outcome-based education curricula on paper? What characterises the curricula in use, enabling factors and barriers?

The five research questions all relate to the way PGME is managed in clinical departments. However, answering these five questions only disclose a fragment of the complexity surrounding management of PGME in clinical departments. They may constitute the foundation for other similarly relevant questions. These questions and suggestions for further research will be addressed in the concluding section of the thesis. 


\section{Context of the study: the organisation of PGME in Denmark}

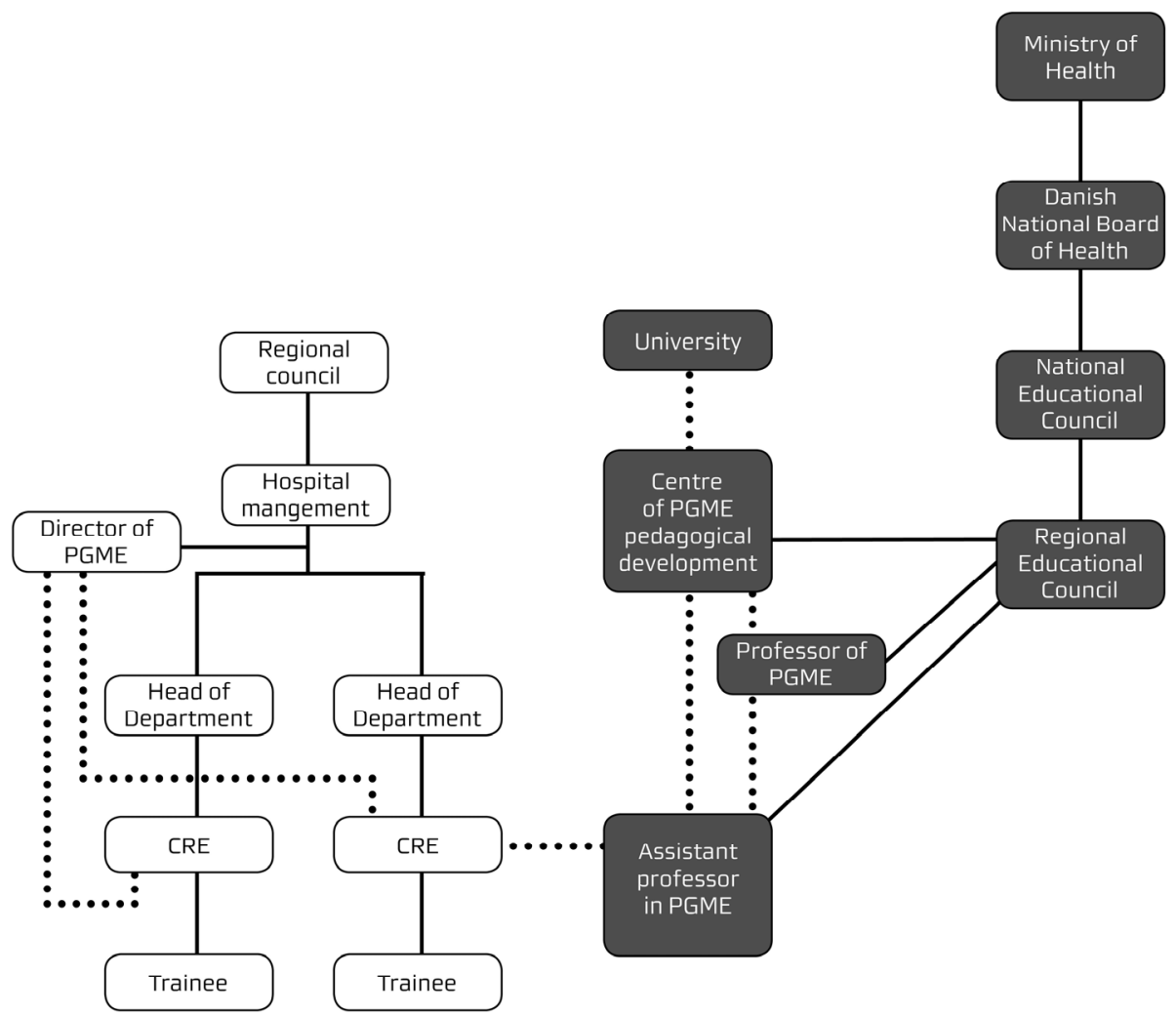

Figure 1. The organisation of postgraduate medical education (PGME) in Denmark. The white boxes represent the service line and the gray boxes the educational line. Dotted lines show loose or unclear connection. CRE = consultant responsible for education.

The research project was conducted in Denmark and the Danish organisation of PGME is shown in Figure 1. In Denmark, PGME is governed by the Ministry of Health through the Danish National Board of Health (DNBH) (gray boxes). The DNBH sets rules and regulations and issues authorisations. The universities manage the undergraduate medical education, but are not involved in PGME. However, the professor in PGME and his faculty has some connection to the university, expressed by the dotted line. The content (learning objectives) for PGME is defined by the specialist societies in collaboration with the DNBH and training takes place in specified trainee-jobs. There are three educational regions in DK: North, South and East. In each region there is a Regional educational council managing PGME.

In the service line (white boxes), the regional councils manage the hospitals. Each clinical department is managed by the head of department (MD) and a nursing officer (RN). In clinical departments having PGME it is mandatory to appoint one 
consultant responsible for education - the CRE. The tasks and responsibilities of a CRE were laid down by the DNBH in 1998 (24). The CRE must be a certified specialist in his field. Besides this no qualifications are needed. However, he is encouraged to seek qualifications in education and educational leadership. The CRE can appoint one of the trainees to be educational coordinator and delegate various educational tasks like planning educational activities and introducing new trainees to this educational coordinator, or the tasks can be delegated to the clinical teachers, the other consultants in the department.

In Denmark we do not have postgraduate deans nor program directors as we know it from other countries. However, many hospitals have a director of PGME, who manages PGME at the hospital and takes care of all specialties represented in the hospital. The CRE's refer to this director of PGME and in the North educational region through the assistant professor in PGME to the educational council. In the other regions the CRE refers directly to the educational council. The educational council refers through the national educational council to the DNBH.

\section{Structure of the thesis}

The research questions in this thesis are addressed through the five individual studies shown in Table 1. The studies are presented in the chapters two through six. Since the thesis is based on scientific journal articles some repetition and overlap in the description of background and theories across the chapters is inevitable.

Table 1. Outline of the studies included in the thesis. Methods indicated in italics.

\begin{tabular}{|c|c|c|}
\hline \multirow[t]{4}{*}{ The task } & The role of the CRE & Chapter 2 \\
\hline & Focus group interviews & \\
\hline & Educational culture / leadership relation & Chapter 3 \\
\hline & Questionnaire study & \\
\hline \multirow[t]{4}{*}{ The leader } & Personal development through multi-source feedback (MSF) and & \\
\hline & through a combination of MSF and a leadership course & Chapters 4 and 5 \\
\hline & Development of MSF instrument & \\
\hline & Intervention study with control group & \\
\hline \multirow[t]{3}{*}{ The context } & Issues of governance and the relation between curriculum on & \\
\hline & paper and curriculum in practice & Chapter 6 \\
\hline & Curriculum analysis & \\
\hline
\end{tabular}




\section{References}

1. Teunissen PW, Scheele F, Scherpbier AJJA, van der Vleuten CPM, Boor K, van Luijk SF \& van DiemenSteenvoorde JAAM. How residents learn: qualitative evidence for the pivotal role of clinical activities. Med Educ, 2007; 41, 763-770.

2. Kilminster SM \& Jolly BC. Effective supervision in clinical practice settings: a literature review. Med Educ, 2000; 34: 827-840.

3. Hoff TJ, Pohl H \& Bartfield J. Creating a learning environment to produce competent residents: the roles of culture and context. Acad Med, 2004; 79, 532-540.

4. Kendall ML, Hesketh EA \& Macpherson SG. The learning environment for junior doctor trainingwhat hinders, what helps? Med Teach, 2005; 27, 619-624.

5. Souba WW. Academic medicine's core values: What do they mean? J Surg Res, 2003; 115: 171-173.

6. Beauchamp RD. The changing roles of a surgical department chair. Adapting to a changing environment. Arch Surg, 2005; 140, 258-263.

7. Cooke M, Irby DM, Sullivan W \& Ludmerer KM. American medical education 100 years after the Flexner report. N Eng J Med, 2006; 355: 1339-1344.

8. Cohen JJ. Leadership for medicine's promising future. Acad Med, 1998; 73: 132-37.

9. Lobas JG. Leadership in Academic Medicine: Capabilities and conditions for Organizational success. Am J Med, 2006; 119: 617-21.

10. Flexner A. Medical Education in the United States and Canada: a report to the Carnegie Foundation for the advancement of Teaching. New York: The Carnegie Foundation for the Advancement of Teaching; 1910.

11. Klinge B. Leadership in academic institutions: raising the value of teaching. Med Educ, 2000; 34: 201-02.

12. Steinert Y. Faculty development in the new millennium: key challenges and future directions. Med Teach, 2000; 22: 44-50.

13. Benor DE. Faculty Development, teacher training and teacher accreditation in medical education: Twenty years from now. Med Teach, 2000; 22: 503-12.

14. Steinert Y, Nasmith L, McLeod PJ \& Conochie L. A Teaching Scholars Program to Develop Leaders in Medical Education. Acad Med, 2003; 78: 142-49.

15. McKimm J. Developing tomorrow's leaders in health care education. FDTL4 Leadership development programme. Special report No 5. Case studies in leadership in medical education; 2004.

16. Hill F \& Stephens C. Building leadership capacity in medical education: developing the potential of course coordinators. Med Teach, 2005; 27, 145-49.

17. The Open University, Centre for Education in Medicine. Evaluation of the reforms to higher specialist training, 1996-1999, Final Report. Joint Centre for Education in Medicine, London. Walton Hall, Milton Keynes; 2001.

18. The Danish Ministry of Health. Fremtidens speciallæge. Betænkning fra speciallægekommissionen. Betænkning nr. 1384. ["The future Specialist”. Report and recommendation on specialist training. Report no. 1384]. DNBH Publications. 2000. In Danish.

19. Legeforeningen. Generelle bestemmelser for specialist utdanningen. [Specialist training for physicians in Norway]. 2005. Retrieved from the Web august 2006. http:// www.legeforeningen.no

20. Royal College of Physicians and Surgeons of Canada. General standards applicable to the university and affiliated sites. 2007. Retrieved January 6, 2010 from www.rcpsc.medical.org

21. Accreditation Council for Graduate Medical Education. Common Programme Requirement. July 2007. Retrieved January 2010 from www.acgme.org.

22. Postgraduate Medical Education and Training Board (PMETB). Generic standards for training. 2008. Retrieved January 6, 2010 www.gmc-uk.org.

23. Accreditation Council for Graduate Medical Education, ACGME. Program director guide to the common programme requirements. 2008. Retrieved from the Web January 2010. www.acgme.org 
24. The Danish National Board of Health. Vejledning og evaluering i den lægelige videreuddannelse. Struktur, retningslinier og ansvarsfordeling. [Guidance and evaluation in the training of specialists in Denmark. Structure, instructions and division of responsibilities]. DNBH Publications. 1998. In Danish.

25. Souba WW. Academic medicine and the search for meaning and purpose. Acad Med, 2002; 77: 139144.

26. Whitcomb ME . Redesigning clinical education: a major challenge for Academic Health Centers. Acad Med, 2005; 80: 615-616

27. Leach DC. A model for GME: shifting from process to outcomes. A progress report from the Accreditation Council for Graduate Medical Education. Med Educ, 2004; 38, 12-14.

28. Postgraduate Medical Education and Training Board (PMETB). Educating tomorrow's doctors Future models of medical training; medical workforce shape and trainee expectations. 2008. Retrieved August 8, 2009 from www.gmc-uk.org .

29. Frank JR. The CanMEDS 2005 Physician Competency Framework. Better standards, Better physicians. Better care. Ottawa: The Royal College of Physicians and Surgeons of Canada. 2005. Retrieved 10 January 2010 from www.rcpsc.medical.org

30. Gale R \& Grant J. AMEE Guide No. 10: Managing change in a medical education context: guidelines for action. Med Teach, 1997; 19: 239-49.

31. Souba WW. New ways of understanding and accomplishing leadership in academic medicine. J Surg Res, 2004; 117: 177-186.

32. McKimm J \& Swanwick T. Educational Leadership. Understanding Medical Education Series. ASME; 2007.

33. Yukl G. Leadership in organizations, $6^{\text {th }}$ Ed. Upper saddle River, New Jersey: Pearson Education Inc.; 2006.

34. Kotter P. What leaders really do. Boston: Harvard Business School Press; 1999.

35. Bland CJ, Starnaman S, Wersal L, Moorhead-Rosenberg L, Zonia S \& Henry R. Curricular change in medical schools: How to succeed. Acad Med, 2000; 75: 575-594.

36. Parsell G \& Bligh J. Encouraging educational leadership. Med Educ, 2000; 34: 199-200.

37. Davis $\mathrm{MH} \&$ Harden RM. Leadership in education and the strategy of the dolphin. Med Teach, 2002; 24, 581-582.

38. World Federation for Medical Education. Postgraduate Medical Education. WFME Global Standards for Quality Improvement. WFME Office, University of Copenhagen, Denmark; 2003.

39. Naylor CD. Leadership in academic medicine: reflections from administrative exile. Clin Med, 2006; 6: 488-492.

40. Golemann D. Leadership that gets results. Harv Bus Rev, 2000; 78: 78-90.

41. Empey D, Peskett S \& Lees P. Medical Leadership. BMJ, 2002; 325: S191.

42. Gunderman R\& Kanter SL. Educating physicians to lead hospitals. Perspective. Acad Med, 2009; 84: 1348-1351.

43. Rich EC, Magrane D L\& Kirch DG. Qualities of the medical school dean: Insights from the literature. Acad Med, 2008; 83: 483-487.

44. Wong JG, Fagan M \& Pinsker J. Expectations of and for the medical director of the resident's ambulatory clinic. Am J Med, 2001; 111: 84 - 87,

45. Pangaro L, Fincher RM, Bachicha J, Gelb D, Brodkey A, Morgenstern B, Chumley-Jones H \& Sachdeva AK. Expectations of and for the clerkship directors: a collaborative statement from the alliance for clinical education. Teach Learn Med, 2003; 15: 217-222.

46. Mintzberg H. The structuring of organizations. Upper Saddle River, NJ: Prentice-Hall, Inc.; 1979.

47. Scullen SE, Mount MK \& Judge TA. Evidence of the construct validity of developmental ratings of managerial performance. J Appl Psych, 2003; 88: 50-66.

48. Heiferts RA. Leadership without easy answers. Cambridge, MA: Harvard University Press, 1994.

49. Simpson J \& Calman K. Making and preparing leaders. Med Educ, 2000; 34: 211-15. 
50. Day DV \& Harrison MM. A multilevel, identity-based approach to leadership development. Hum Res Manag Rev, 2007; 17: 360-373.

51. Fullan M. Leading in a culture of change. San Fransisco: Jossey-Bass; 2001.

52. Frank JR \& Danoff, D. The CanMEDS initiative: implementing an outcome-based framework of physician competencies. Med Teach, 2007; 29: 642-647.

53. Association of American Medical Colleges. AAMC policy guidance on graduate medical education: Assuring quality patient care and quality education. Acad Med, 2003; 78: 111-116.

54. Department of Health, Social Services and Public Safety. Modernising medical careers - the next steps. 2004. Retrieved January 2010 from www.dh.gov.uk/publications .

55. Postgraduate Medical Education and Training Board. Preparing doctors for the future: about PMETB. 2007. Retrieved January 2010 from www.pmetb.org.

56. Royal College of Physicians and Surgeons of Canada. Programme Directors Handbook. 2009. Retrieved January 2010 from www.rcpsc.org.edu .

57. Gleeson D \& Shain F. Managing ambiguity: between markets and managerialism - a case study of "middle" managers in further education. Sociol Rev, 1999; 47: 461-490.

58. Schwartz RW \& Pogge C. Physician leadership is essential to the survival of teaching hospitals. Am J Surg, 2000; 179: 462-468.

59. Daugherty RM. Leading among leaders: the dean in today's medical school. Acad Med, 1998; 73: $649-653$.

60. Carroll JS \& Edmondson AC. Leading organisational learning in health care. Qual Saf Health Care, 2002; 11: 51-56.

61. Bordage G, Foley R \& Goldyn S. Skills and attributes of directors of educational progammes. Med Educ, 2000; 34: 206-210.

62. Durning SJ, Papp KK, Pangaro LN \& Hemmer P. Expectations of and for internal medicine clerkship directors: How are we doing? Teach Learn Med, 2007; 19: 65-69

63. Margo K, Gazewood J, Jerpbak C, Burge S \& Usatine R. Clerkship directors' characteristics, scholarship, and support: a summary of published surveys from seven medical specialties. Teach Learn Med, 2009; 21: 94-99.

64. Freedman AM. Swimming upstream: The challenge of managerial promotions. In RB Kaiser (Ed.). Filling the leadership pipeline (pp 25-44). Greensboro, NC: Centre for Creative leadership; 2005.

65. Leonard HS. When leadership development fails managers: Addressing the right gaps when developing leadership. In RB Kaiser (Ed.). Filling the leadership pipeline (pp 66-84). Greensboro, NC: Centre for Creative leadership; 2005.

66. Quatro SA, Waldman DA \& Galvin BM. Developing holistic leaders: Four domains for leadership development and practice. Hum Res Manag Rev, 2007, 17: 427-41.

67. Hollenbeck GP \& Hall DT. Self-confidence and leader performance. Org Dyn, 2004; 33: 254-69

68. Rooke D \& Torbert WR. The seven transformations of leadership. Harv Bus Rev, April 2005: 67-76.

69. Mintzberg H. The manager's job: folklore and facts. Harv Bus Rev, March-April 1990: 163-176.

70. Day DV. Leadership development: A review in context. Lead Quart, 2001; 11: 581-613.

71. Lockyer J, Violato C \& Fidler H. Likelihood of change: a study assessing surgeon use of multisource feedback data. Teach Learn Med, 2003; 15: 168-174.

72. Sargeant J, Mann K, Sinclair D, Van der Vleuten CPM \& Metsemakers J. Challenges in multisource feedback: intended and unintended outcomes. Med Educ, 2007; 41: 583-591.

73. Bracken DW, Timmreck CW \& Church AH. Eds. The handbook of multisource feedback. The comprehensive resource for designing and implementing MSF processes. San Fransisco: Jossey-Bass Inc.; 2001.

74. National Health Service. NHS Leadership Qualities Framework. www.nhsleadershipqualities.nhs.uk [Accessed 3 January 2008] 
75. Dannels SA, Yamagata H, McDade SA, Chuang YC, Gleason KA, McLaughlin JM, Richman RC \& Morahan PS. Evaluating a leadership program: a comparative, longitudinal study to assess the impact of the executive leadership in academic medicine (ELAM) program for women. Acad Med, 2008; 83: 488-495.

76. Saleh SS, Williams D \& Balougan M. Evaluating the effectiveness of public health leadership training: The NEPHLI experience. Am J Public Health, 2004; 94: 1245-49.

77. Souba WW. The new leader: new demands in a changing, turbulent environment. J Am Coll Surg, 2003; 197: 79-87

78. Van Rensburg T \& Prideaux G. Turning professionals into managers using multisource feedback. J Manag Dev, 2006; 25: 561-71.

79. Bayer, M. Speciallægeuddannelse i Danmark - en empirisk undersøgelse af tendenser inden for speciallægeuddannelsen efter implementeringen af den nye speciallægeuddannelse. [Specialist training in Denmark - an empirical analysis of tendencies in specialist training after implementation of the new reform]. København, Danmarks Pædagogiske Universitets forlag. 2007. In Danish.

80. Dehn $\mathrm{P}$, Nielsen $\mathrm{CH}$, Larsen $\mathrm{K} \&$ Bayer $\mathrm{M}$. Implementering af speciallægereformens syv roller. [Implementing the seven roles of the specialist training reform]. UfL, 2009; 171/19: 1580-1584. In Danish.

81. Mortensen L, Malling B, Ringsted C \& Rubak S. What is the impact of a national postgraduate medical specialist education reform on the daily clinical training 3.5 years after implementation? A questionnaire study. BMC Med Educ, 2010, 10: 46.

82. Swing SR. The ACGME outcome project: retrospective and prospective. Med Teach, 2007; $29: 648$ 654.

83. Agius SJ, Willis SC, McArdle PJ \& O'Neill PA. Managing change in postgraduate medical education: still unfreezing? Med Teach, 2008; 30: e87-e94.

84. Didwania A, McGaghie WC, Cohen E \& Wayne DB. Internal medicine residency graduates' perception of the systems-based practice and practice-based learning and improvement competencies. Teach Learn Med, 2010; 22: 33-36.

85. Schein EH. Organizational culture and leadership. $3^{\text {rd }}$ Ed. San Francisco: Jossey-Bass; 2004.

86. Culbertson RA, Goode LD \& Dickler RM. Organizational models of medical School relationships to the clinical enterprise. Acad Med, 1996; 71: 1257-1274.

87. Weiner BJ, Culbertson R, Jones RF \& Dickler R. Organizational models for medical school - clinical enterprise relationships. Acad Med, 2001; 76: 113-124.

88. Seguin C \& Hodges B. Educating doctors in France and Canada: are the differences based on evidenceor history? Med Educ, 2005; 39: 1205-1212.

89. Cross V, Hicks C, Parle J \& Field S. Perceptions of the learning environment in higher specialist training of doctors: implications for recruitment and retention. Med Educ, 2006; 40: 121-128.

90. Genn JM. AMEE Medical Education Guide No. 23 (Part 2): Curriculum, environment, climate, quality and change in medical education - a unifying perspective. Med Teach, 2001; 23: 445-454.

91. Roff S, McAleer S \& Skinner A. Development and validation of an instrument to measure the postgraduate clinical learning and teaching educational environment for hospital-based doctors in the UK. Med Teach, 2005; 27: 326-331.

92. Schwartzstein RM, Huang GC \& Coughlin CM. Development and implementation of a comprehensive strategic plan for medical education an an academic medical center. Acad Med, 2008; 83: 550 559.

93. Davis DJ, Skaarup AM \& Ringsted C. A pilot survey of junior doctor's confidence in tasks related to broad aspects of competence. Med Teach, 2005; 6: 548-552.

94. Harden RM. Outcome-based education - the ostrich, the peacock and the beaver. Med Teach, 2007; 29: 666-671.

95. Tsouroufli M \& Payne H. Consultant medical trainers, modernising medical careers (MMC) and the European time directive (EWTD): tensions and challenges in a changing medical education context. BMC Med Educ, 2008; 8: 31. 
96. Ringsted C, $\varnothing$ stergaard D \& Van der Vleuten CPM. Implementation of a formal in-training assessment programme in anaesthesiology and preliminary results of acceptability. Acta Anaesth Scand, 2003; 47: 1196-1203.

97. Skjelsager K, Malling B, Bested KM, Østergaard HT, Ravn L, Østergaard D \& Ringsted C. Implementering af nationalt kompetenceprogram. [The implementation of a national in-training assessment program]. UfL, 2008; 170/44: 3557-3561. In Danish.

98. Royal College of physicians and surgeons of Alberta - Physician Achievement Review Program. http/ www.par-program.org [Accessed 31 January 2008]

99. Souba WW. The leadership dilemma. J Surg Res, 2007; 138: 1-9.

100. Smither JW, London M \& Reilly RR. Does performance improve following multisource feedback? A theoretical model, meta-analysis, and review of empirical findings. Pers Psych, 2005; 58: 33-66.

101. Brinkerhoff RO. The success case method. Find out quickly what's working and what's not. San Fransisco: Berrett-Kohler Publishers Inc.; 2003.

102. Tannenbaum SI \& Yukl G. Training and development in work organizations. Annu Rev Psychol, 1992, 43: 399-441.

103. Cochrane L, Olson CA, Murray S, Dupuis M, Tooman T \& Hayes S. Gaps between knowing and doing: Understanding and assessing the barriers to optimal health care. J Contin Educ Health Prof, 2007; 27: 94-102. 


\section{CHAPTER 2}

\section{What is the role of the consultant responsible for postgraduate education in the clinical department?}

Published in Medical Teacher, 2007; 29: 471-477.

B Malling, AJJA Scherpbier \& C Ringsted. 


\section{Abstract}

Background: The organisation of specialist training is complex and involves many clinical departments. The position of consultants responsible for education (CRE) in specialist training at department level is poorly defined in the literature.

Aims: The aim of the study was to explore expectations of stakeholders concerning the role and position of a CRE in specialist training.

Method: The role and position of the CRE was explored using focus group and semistructured individual interviews.

Results: Knowledge of tasks and responsibilities was limited in all stakeholders except among CREs. The expectations of stakeholders to the CRE varied according to their position in the hospital hierarchy. In general terms the CRE was expected to assume overall responsibility for specialist training, promote a positive educational climate and secure quality of specialist training along with numerous administrative tasks. All interviewees expressed a wish for a strong leader at the same time they did not consider the position of the CRE influential.

Conclusion: Along with improved information about the role of the CRE, formal education, proper job-descriptions and clear leadership in the organisation concerning specialist training might increase the influence and power of CREs. 


\section{Introduction}

The organisation of postgraduate clinical training has changed in the past twenty years. Previously, postgraduate training mainly took place at a few large university hospitals. Internationally the tendency has moved towards extending the postgraduate training period and expanding training facilities to include non-university hospitals. The rising number of postgraduate trainees and the continuously growing specialization in university hospitals has increased the need to include nonuniversity hospitals in specialist training.

The organisation of specialist training is complex and includes many stakeholders, among these the universities, deaneries, scientific societies, medical associations, the hospital owners (trusts), trainers and the trainees. The overall responsibility for specialist training can be placed at the universities through deaneries alone or through deaneries in collaboration with either the scientific societies (United Kingdom) or the national specialist college (Canada). It can be placed in the hands of the medical association (Norway) or a national board of health (Denmark) (1-4).

The more dispersed organisational model has made it necessary to coordinate specialist training. In US a local site director is responsible for coordination and quality of training (5). In Norway and Denmark local councils at hospital level are responsible $(3,4)$. In Denmark, it is a requirement to have a consultant responsible for education (CRE) at each clinical department conducting specialist training (6). In many ways the CRE corresponds to a residency programme director in US and Canada.

The question is what is expected from a person who is responsible for education at department level? Wong et al. (2001) described the expectations of and to the medical director of the resident's ambulatory clinic (7). Among the essential skills were administrative skills, skills in providing supervision and feedback, being approachable and able to communicate. Desirable competencies were medical expert skills, leadership skills, negotiating skills and interpersonal skills. To some extend the expectations to and responsibilities of the medical director in ambulatory clinics are probably the same for the CRE in specialist education. However, the organisation of a clinical department can be much more complex including wards, operating rooms and outpatient clinics. The question is if all stakeholders hold the same expectations to a CRE and are aware of his/her actual responsibilities.

In this study the role and position of a CRE at departmental level was investigated by means of a qualitative exploration of the expectations of stakeholders concerning tasks and responsibilities, qualifications, influence and prestige. 


\section{Context of the study}

In Denmark the Danish National Board of Health (DNBH) defines the number and types of medical specialties and the number of trainees for each specialty. The counties own the hospitals and the number of training positions are negotiated with the counties. In Denmark we do not have postgraduate deans or programme directors.

The DNBH issues guidelines and makes rules and regulations. The outcome of specialist education is defined by the scientific societies in collaboration with the DNBH. Postgraduate training takes place in specified trainee positions. At department level one consultant, the CRE, is responsible for specialist training. Appointment of a CRE is mandatory for all departments offering specialist training programmes. The tasks and responsibilities, laid down by the the DNBH 1998, are shown in Table $1(6,8)$. The CRE has to be a certified specialist. The CRE can appoint one of the junior doctors to be education coordinator and delegate various educational tasks like planning educational activities and introducing new trainees, or the tasks can be delegated to the clinical supervisors.

Table 1. The responsibilities and tasks of a consultant responsible for education at department level According to the Danish National Board of Health (1998).

- Make, revise and assure use of the department education programmes, based on national blue-prints

- Make, revise and assure use of introduction programmes

- Monitor and participate in the evaluation of the trainees through appraisal meetings

- Approve and monitor use of the individual learning plans, worked out by the trainee and the clinical supervisor

- Appoint and supervise the clinical supervisors and teachers in the department

- Keep up-dated on all individual educational courses in the department and report to the authorities (hospital owners, county and DNBH)

- Initiate, develop, plan, supervise and participate in relevant educational activities in the department

- Secure the overall quality of the education in the department

- Inspire trainees to do research

- Convey internal and external educational offers - meetings, congresses and courses

- Organise the work in the department to assure all trainees get the proper education

- Delegate educational tasks to the clinical teachers, the trainees etc

- Be advisory in the trainee's further career planning, education and training

- Manage problem trainees

\section{Methods}

The opinions of the CREs role, position, qualifications and influence were studied among stakeholders in specialist training in a cross-sectional, descriptive, qualitative study design. Focus group interviews and semi-structured telephone interviews 
were conducted among stakeholders from an academic hospital and a county hospital, respectively.

Focus group interviews are particularly suited to explore knowledge, attitudes and experience on a subject well known to the interviewees (9). Since hierarchy in a mixed group can affect data (9), we used homogenous groups. The participants represented different educational roles, i.e. junior doctors, junior doctors/education coordinators, consultants and CREs from a university hospital and a county hospital, and from different specialties. All participants received a letter, inviting them to participate in a focus group interview. Participants were included consecutively. Six focus group interviews were conducted with four to seven participants in each group. In all 33 doctors from 14 different departments and specialties participated in the group interviews.

Since it was not considered possible to recruit enough hospital directors and heads of departments to establish focus groups, semi-structured interviews were used to explore their points of views. Eight department heads and the hospital directors of the two hospitals were invited to participate in a semi-structured telephone interview. Two department heads and one hospital director responded and participated.

Confidentiality was guaranteed and participants were assured that it would be impossible to trace back the findings to individual participants, departments or hospitals.

\section{Procedure}

The first author made an interview guide for the discussions in the focus groups and the telephone interviews (Table 2). The questions in the guide concerned the CRE's tasks, position and influence - including suggestions to enhance prestige and influence in the department. In order to assure content validity drafts of the interview guides were circulated to two informed colleagues asking for comments and possible improvements. After incorporating any improvements, the guides were referred back for further comments. After each focus group interview the guides were discussed and re-phrased if necessary.

The focus groups were moderated by a researcher experienced in focus group interviews but not involved in this study. The first author acted as co-moderator and conducted the telephone interviews. The focus groups and telephone interviews were tape-recorded and transcribed verbatim. 
Table 2. Question guide used for focus group interview in the group of CREs.

1. Arrival and introduction

2. What tasks do you see as CRE tasks - and what are the most important tasks for a CRE?

3. How are these tasks incorporated in the working schedule in your department?

4. Please describe a situation showing your influence as a CRE?

5. Are there areas where you - as a CRE - do not have the influence that you think you should have? describe with an example.

6. On a scale from 1 to 10 where 10 is the most prestigious job a doctor can have and 1 is the least prestigious - please place these consultants (a scale is placed on the table and 8 different sorts of consultants - like a consultant responsible for open heart surgery, a head of a department, a professor, a CRE, a consultant with night duty etc - are written on small pieces of paper to be placed on the scale). Please discuss why you choose this order of precedence.

7. What could make the CRE improve his position?

8. If you were to develop a future education for CREs - which themes would you suggest to be part of this education?

9. SUMMARY

10. Do you have supplementary comments on the education, qualifications or position of a CRE?

11. Are there any areas in the work of a CRE that we have not covered in our questions - that you would like to comment on?

Supplementary questions:

1. What would in your opinion make it attractive to apply for a job as a CRE?

2. If the job being a CRE was a fulltime job - how would it be possible to keep up with the medical expertise?

3. Why did you choose to be CRE?

4. Some have said that the fact that there is an appointed CRE in a department may make the other senior doctors feel less responsible for educating their younger colleagues - please comment on this statement?

The question guides for the other focus groups and in the semi-structured interviews covered the same themes - but were slightly rewritten according to the attendants in the groups.

\section{Analysis}

The first author analysed the interviews using deductive or framework analysis (10). A set of hypothetical categories derived from the research questions were formed. During the analysis the new categories that emerged from the interviews were incorporated into the final set of codes and categories and main themes and concepts were thus identified. After the analysis was performed one interview was reviewed by an independent researcher for consistency. Since there was good overall agreement between researchers no changes in the categories were made.

\section{Results}

After the first three focus group interviews, few new themes emerged and the last group discussion did not add any new themes at all, which indicated that a point of saturation was reached (11). The results are presented according to participants' 
level of training and position. The analysis yielded four major themes: 1) Tasks and responsibilities, 2) Influence, 3) Job prestige and 4) Actual qualifications and suggestions for improvement of the role and position of a CRE.

Results are presented according to the four themes.

\section{Tasks and responsibilities}

The expectations to the CRE regarding responsibilities and tasks are shown in Table 3. The various groups of participants had different outlooks on the tasks.

Table 3. Tasks and responsibilities of a consultant responsible for education expressed by various stakeholders, arranged according to the official duties laid down by the Danish National Board of Health (DNBH) in 1998. X means that the task or responsibility was mentioned by the focus group or in the semistructured interview.

\begin{tabular}{|c|c|c|c|c|c|c|}
\hline Task as defined by DNBH & $\begin{array}{l}\text { Hospital } \\
\text { Director }\end{array}$ & $\begin{array}{l}\text { Head of } \\
\text { Department }\end{array}$ & Consultants & CRE & $\begin{array}{l}\text { Educ } \\
\text { coord* }\end{array}$ & $\begin{array}{l}\text { Junior } \\
\text { doctors }\end{array}$ \\
\hline $\begin{array}{l}\text { Make, revise and assure use of the } \\
\text { department education programmes }\end{array}$ & $x$ & $x$ & $x$ & $x$ & $x$ & $x$ \\
\hline $\begin{array}{l}\text { Make, revise and assure use of introduc- } \\
\text { tion programmes }\end{array}$ & $x$ & $x$ & $x$ & $x$ & $x$ & $x$ \\
\hline $\begin{array}{l}\text { Monitor and participate in the evalua- } \\
\text { tion of the trainees }\end{array}$ & & & & $x$ & & \\
\hline $\begin{array}{l}\text { Approve and monitor use of the individ- } \\
\text { ual learning plans }\end{array}$ & & & & $x$ & $x$ & \\
\hline $\begin{array}{l}\text { Appoint and supervise the clinical super- } \\
\text { visors and teachers }\end{array}$ & & & $x$ & $x$ & $x$ & $x$ \\
\hline $\begin{array}{l}\text { Keep up-dated on all individual educa- } \\
\text { tional courses }\end{array}$ & & & $x$ & $x$ & $x$ & $x$ \\
\hline $\begin{array}{l}\text { Initiate, develop, plan, supervise and } \\
\text { participate in relevant educational } \\
\text { activities in the department }\end{array}$ & $x$ & $x$ & $x$ & $x$ & $x$ & $x$ \\
\hline $\begin{array}{l}\text { Secure the overall quality of the educa- } \\
\text { tion and training in the department }\end{array}$ & & & & $x$ & $x$ & $x$ \\
\hline Inspire trainees to do research & & & & $x$ & & \\
\hline $\begin{array}{l}\text { Convey internal and external educational } \\
\text { offers }\end{array}$ & & & & $x$ & $x$ & \\
\hline $\begin{array}{l}\text { Organise the work in the department to } \\
\text { ensure all trainees' education }\end{array}$ & $x$ & $x$ & $x$ & $x$ & $x$ & $x$ \\
\hline Delegate educational tasks & & & & $x$ & $x$ & \\
\hline $\begin{array}{l}\text { Be advisory in the trainee's further } \\
\text { career-planning and education }\end{array}$ & & & & $x$ & $x$ & \\
\hline Take care of problem trainees & & & $x$ & $\mathrm{x}$ & $\mathrm{x}$ & $\mathrm{x}$ \\
\hline
\end{tabular}

* Educ. coord: Educational coordinators are senior postgraduate trainees in specialist training who have co-ordinating tasks for the training programme. 
All groups shared the view of the CRE as a leader of educational matters, who sets the agenda and fosters a positive climate for education in the department, delegates teaching, initiates, coaches and organises. Only the group of CREs was able to mention all the tasks and responsibilities as listed by the DNBH.

The expectations to the CRE changed according to the position of the stakeholder in the hospital hierarchy. The hospital director expected the CRE to know all about education and training and that the CRE would focus on longterm goals and outline the educational strategy in the department. The heads of department had a more pragmatic view, wishing the CREs to take care of planning and at the same time be visionary within the field of education.

The consultants expected the CRE to take care of logistics and perceived specialist training as a shared responsibility among all consultants in the department. However, taking care of problematic trainees was believed to be the sole responsibility of the CRE.

The CRE together with the junior doctors / education coordinators believed it was very important to take initiatives to improve education, to ensure quality and to implement new methods. The other groups put the administration related to the training programme high on the CRE priority list. One group of consultants thought administration should be on top of the list:

Basically he must assure that there are training possibilities in the department, make sure they are planned and carried out - this is first priority. If he wants to then he might also inspire the use of new methods

Knowing relatively little about the CREs tasks, the junior doctors gave a rather vague description:

You do not have any impression of what he is doing - I wonder if some kind of job description exists?

The main concern of the junior doctors was that the CRE should look after their educational interests and they wanted him/her to be aware of their individual training needs. They also considered an open attitude and approachability important. The consultants, the two groups of junior doctors and the CRE group agreed that the CRE should be well informed about all trainees in the department.

All groups expressed that being a CRE was a huge job with many responsibilities and tasks. At the same time they found it difficult to describe the actual tasks and responsibilities of a CRE - it was difficult for them to describe what they meant by supervise, motivate and "take care" of educational matters.

Their knowledge of the duties of a CRE was superficial and expressed in overall terminology. 


\section{Influence}

According to the hospital director the CRE obtains influence since the responsibility for education has been delegated to him. The heads of department consider education as a mutual responsibility between him and the CRE. Concerning delegation of power they believe all initiatives must be made in cooperation.

The other groups describe the influence of a CRE as depending on the person holding the position and how the job is carried out. One consultant group expressed:

He gets the influence he wants - if he is very active and outgoing he will be allowed to do many things

This does not mean unlimited influence according to another consultant group:

I do not know exactly what his influence on education is. We do not see him as a person making decisions

The junior doctors do not see him as influential since he is not the head of the department. The CRE described their influence in this way:

You have the responsibility - but that is all you have, you do not get any influence or power

The young doctors wanted a strong leader that "gets proposals through". The consultants were divided in their point of view. Some wanted a strong person with clout and some a person drafting proposals for others to take decisions. All interviewees agreed that it is not an attractive position. The consultants said:

I do not think it is that attractive to be a CRE. As you know consultants do not compete to get the post

\section{Prestige}

Both the hospital director and heads of departments saw the job as prestigious. They agreed that the prestige of a CRE is dependent on the person holding the position. If the CRE is highly esteemed for his medical knowledge he does not have less prestige if he works with education too. The CRE, actively working with education, is capable of giving the job more prestige. Another important aspect providing prestige is the management's ability to create a culture where education is considered important.

The youngest doctors had yet another view:

I would say the prestige is low, this is something you are ordered to do

The other groups mentioned the way you are appointed to do the job. Someone has to do it - and often you point at the youngest consultant in the department. 


\section{Actual qualifications and suggestions for improvement of the role and position of a CRE}

The six CREs in this study all lived up to qualifications set by DNBH (6). One third had attended a basic leadership course for consultants. All had participated in a 3-day "Training the Trainer"- course.

All groups thought that working with education should be prioritized in the department in line with doing medical research or being a highly specialised clinician. They suggested that working with medical education should count in your career. To make it a position involving more power and prestige the job should be more formalised with a job-description of compulsory qualifications. Other suggestions for improvement of the function were setting up a course to ensure the CRE gained the proper qualifications, higher salary, reduced night-time duties and allocated time to do the work.

\section{Discussion}

Knowledge of the responsibilities and tasks of a CRE was scarce among stakeholders. At the same time the perception of the role and position of a CRE was influenced by the stakeholders' position in the hospital hierarchy.

All stakeholders wanted the CRE to be the leader of education at department level - and all requested a clearer definition of the job including qualifications. However, a job description already exists - made by the DNBH in 1998 (6). Only the group of CREs themselves were able to list all responsibilities and tasks mentioned in the job description. Lack of knowledge of tasks and responsibilities may be connected to the lack of prestige and power of the position.

\section{Qualifications of a CRE}

The interviewees suggested setting up a course to qualify the CRE. Since the CRE has many tasks similar to what Challis (12) calls a staff developer, such a course might be inspired by staff development programs. Among others Steinert (13) has described how leadership and management should be part of the courses offered in order to keep up with needs (13-18).

However, it is questionable whether a course could reduce the lack of prestige and power in the position. This study clearly shows that a visionary leader of education is requested, a person who introduces new methods to improve education and the educational climate. Attending a course might not be enough to introduce changes in culture, especially not if the tasks of a CRE are unclear to stakeholders as this study shows. 


\section{The tasks and the responsibility}

The necessity of clear responsibilities of leadership and administration in specialist training is stated as one area in the global standards for quality improvement in specialist training by the World Federation for Medical Education (WFME) (19). WFME also points out that the responsibility for organising, coordinating, managing and assessing the individual training setting and the training process must be clearly stated. Since more training sites and more departments are involved in specialist training we need to ensure that this responsibility is clear to all stakeholders in specialist training. Our interviews showed that stakeholders in specialist training have different views on governance and administration of specialist training at department level. All stakeholders were able to list a number of administrative tasks but had difficulty in describing the leadership role of a CRE apart from describing it in superficial and vague terminology. According to Kotter (20), leaders have to cope with both management and leadership. He describes management as coping with complexity, its practices and procedures while leadership means coping with change. Although leadership is ill defined most definitions involve a process whereby intentional influence is exerted by one person over others to guide structure and facilitate activities and relationships in a group or organisation (21). Using this overall definition of leadership the interviewees in our study asked for more leadership and less administration. They wanted the CRE to lead the way, to inspire, to motivate - but also to get things done.

\section{The culture}

Despite a clear job description by the DNBH (6), the role and position of a CRE is still ill defined by the surroundings. Various stakeholders describe how the CRE is able to strengthen the position through his work as CRE by managing the role well. Being able to cope with changes and manage both the role of a manager and a leader might give a clue to appointing the right person for this job. Rogers have described how both the Porter/Mazlow need-priority and Herzberg two-factor models of motivation to become a leader can be used to identify candidates that become good leaders with the right education (22). However the motivation to become a CRE is low - it is not an attractive position. A more deliberate selection combined with clear goal-oriented education will create better leaders of specialist training at department level.

Dependency of others and how others perform is characteristic of the leadership role (20). At a hospital department the CRE is not only dependent on people he/she does not control. The CRE navigates in a complex system with interdependent hierarchical chains: the educational, the clinical and the institutional hierarchy. Even if a CRE is given formal leadership of specialist training he is dependent on the culture in the department. Giving the leadership to the CRE and at the same time 
describing a system where all consultants have mutual responsibility to secure the education in the department puts the CRE in a vague position from the start. Leadership is also about cooperation - but if cooperation means that the CRE can make suggestions that the other consultants will consider to support makes it difficult if not impossible to take the lead.

\section{Strengths and limitations of the study}

The strength of the study is that although a fixed number of focus groups were planned the point of saturation was actually reached. It would have strengthened the study if more than two department heads and one hospital director had agreed to participate. Although many stakeholders were interviewed representatives for the scientific societies and the DNBH were not invited to participate. They might have provided even further perspectives to the questions raised in this study. The participants in this study may have more than average knowledge of specialist training and the role of a CRE, since they responded to the invitation to participate. The results may thus have a positive angle. Limiting the analysis to only one person might have influenced the results since objectivity could not be guaranteed.

\section{Conclusion}

The traditional hierarchy still exists in a clinical department no matter how well we educate leaders of specialist training. This study showed that there are various opinions on the role and position of a CRE and how he or she manages the leadership of specialist training at department level.

It was suggested that a specific course on leadership in specialist training should be designed. It is a question if this is enough to secure both power and influence or if other initiatives need to be taken. One initiative could be job description including compulsory qualifications in both management and leadership. Moreover clear lines of leadership could be established along with selection of the right candidates. Before taking these steps it might be necessary to inform all stakeholders in specialist training about the role and position of a CRE. 


\section{References}

1. The Royal College of Physicians and Surgeons of Canada. General standards of Accreditation. 2002. Retrieved from the Web August 2006. http:// www.rcpsc.medical.org

2. Postgraduate Medical Education and Training Board (PMETB), 2006. Strategy document: 2006-2010. Retrieved from the Web August 2006. http:// www.pmetb.org.uk

3. Legeforeningen. Specialist training for physicians in Norway 2005. Retrieved from the Web august 2006. http:// www.legeforeningen.no

4. The Danish National Board of Health. Report and recommendation on specialist training. Report no. 1384. "The future Specialist". DNBH Publications; 2000. In Danish.

5. Accreditation Council for Graduate Medical Education (ACGME), 2007. Retrieved from the web April 2007. http:// www.acgme.org

6. The Danish National Board of Health. Guidance and evaluation in the training of specialists in Denmark. DNBH Publications; 1998. In Danish.

7. Wong JG, Fagan M \& Pinsker J. Expectations of and for the medical director of the resident's ambulatory clinic. Am J Med, 2001; 111: 84-87.

8. The Danish Ministry of Health. Report evaluating specialist training. Report no.1183. DNBH Publication;. 1989. In Danish.

9. Kitzinger J. Introducing focus groups. BMJ, 1995; 311: 299-302.

10. Pope C, Ziebland S \& Mays N. Qualitative research in health care: Analysing qualitative data. BMJ, 2000; 320: 114-116.

11. Morgan DL. Planning focusgroups. Thousand Oaks, CA, Sage; 1998.

12. Challis M. Building an effective program for clinical teachers: the role of the staff developer. Med Teach, 2001; 23: 270-275.

13. Steinert Y. Faculty development in the new millennium: key challenges and future directions. Med Teach, 2000; 22: 44-50.

14. Benor DE. Faculty development, teacher training and teacher accreditation in medical education: twenty years from now. Med Teach, 2000; 22: 503-512.

15. Grant J. Evaluation of the reforms to higher specialist training, 1996-1999. Final Report. The Open University Centre for Education in Medicine, Walton Hall, Milton Keynes; 2001.

16. Pololi L, Clay MC, Lipkin MJR, Hewson M, Kaplan C \& Frankel RM. Reflections on integrating theories of adult education into a medical school faculty development course. Med Teach, 2001; 23: 276283.

17. Steinert Y, Nasmith L, McLeod PJ \& Conochie L. A teaching scholars program to develop leaders in medical education. Acad Med, 2003; 78: 142-149.

18. Hill F \& Stephens C. Building leadership capacity in medical education: developing the potential of course coordinators. Med Teach, 2005; 27: 145-149.

19. World Federation for Medical Education. Postgraduate Medical Education. WFME Global Standards for Quality Improvement. WFME Office, University of Copenhagen, Denmark; 2003.

20. Kotter JP. What leaders really do. Boston: Harvard Business School Press; 1999.

21. Yukl G. Leadership in organizations, $6^{\text {th }}$ Ed. Upper Saddle River: Pearson, Prentice Hall; 2006.

22. Rogers J. Aspiring to leadership - identifying teacher-leaders. Med Teach, 2005; 27: 629-633. 



\section{CHAPTER 3}

\section{Educational climate seems unrelated to leadership skills of clinical consultants responsible of postgraduate medical education in clinical departments}




\begin{abstract}
Background: The educational climate is crucial in postgraduate medical education. Although leaders are in the position to influence the educational climate, the relationship between leadership skills and educational climate is unknown. This study investigates the relationship between the educational climate in clinical departments and the leadership skills of clinical consultants responsible for education.
\end{abstract}

Methods: The study was a trans-sectional correlation study. The educational climate was investigated by a survey among all doctors (specialists and trainees) in the departments. Leadership skills of the consultants responsible for education were measured by multi-source feedback scores from heads of departments, peer consultants, and trainees.

Results: Doctors from 42 clinical departments representing 21 specialties participated. The response rate of the educational climate investigation was moderate 52 $\%(420 / 811)$, Response rate was high in the multisource-feedback process $84.3 \%$ (420/498). The educational climate was scored quite high mean 3.9 (SD 0.3) on a five-point Likert scale. Likewise the leadership skills of the clinical consultants responsible for education were considered good, mean 5.4 (SD 0.6) on a seven-point Likert scale. There was no significant correlation between the scores concerning the educational climate and the scores on leadership skills, $r=0.17(p=0.29)$.

Conclusions: This study found no relation between the educational climate and the leadership skills of the clinical consultants responsible for postgraduate medical education in clinical departments with the instruments used. Our results indicate that consultants responsible for education are in a weak position to influence the educational climate in the clinical department. Further studies are needed to explore, how heads of departments and other factors related to the clinical organisation could influence the educational climate. 


\section{Background}

Postgraduate medical education (PGME) is a work-based education where learning and teaching takes place in a clinical context. On the one hand the young doctor (trainee) is under education and on the other hand he is a member of the staff in the clinical department. The clinical departments face the challenge of creating an educational environment that is supportive and learning-oriented (1) and at the same time meeting the demands from society to deliver efficient clinical services and research $(2,3)$. A common feature in PGME is the need for supervision and feedback among trainees and for being engaged in the responsibility for patients (4, 5). Furthermore, trainees need to be appreciated and valued as team members (5). The challenge is to find a proper balance between involving trainees in patient treatment, and at the same time ensure patient safety and meet demands for a high production (6). As the educational climate is perceived to have major influence on how trainees learn and perform, the quality of the educational climate has received increasing attention in the literature on $\operatorname{PGME}(1,5,7)$.

However, the concept educational climate has been used indiscriminately with culture, environment or learning context (8). Nevertheless, all of these concepts include the same elements: atmosphere (7-9), the connection and personal relation with colleagues $(5,9,10)$, openness to questions and appropriateness of supervision and feedback $(1,5,9)$, and eventually the working conditions and organisation of the work $(5,7,9)$. The educational climate may differ considerably across clinical departments. Hence, in order to be able to change the educational climate, it is relevant to find out who contributes to this climate and to the specific ways of behavior and "living" in the clinical departments.

The organisational culture, according to Schein (11), is closely connected to leadership. Although all employees take part in developing the culture in a department, the leaders are in a position to deliberately influence the culture (11). In PGME leaders can influence the educational climate by prioritising and attending a variety of activities in the department (2) and by role-modelling. Various authors have described the "good physician leader" as a necessity to the survival of teaching hospitals $(10,12-14)$. And since the responsibilities and obligations in managing PGME in the clinical departments are many, and has become a growing business (2), the nomination of leaders of PGME in clinical departments has been introduced in many countries (15-18).

However, we do not know much of these educational leaders in PGME. In a previous study on the clinical consultant responsible for education (CRE) in clinical departments, we found that stakeholders expected the CRE to develop and improve the educational climate (19), which is in accordance with the description of desired competencies for a leader of PGME provided by Wong et al. (14). They also indicated that structure of the educational program in the department was a necessary 
but not sufficient prerequisite for the educational climate. The CREs were expected to take the lead regarding educational matters (19) and stakeholders perceived the CREs to have fairly good administrative and leadership skills (20). Hence, a positive relation between leadership skills of the CRE and the quality of the educational climate might be expected. Likewise, a positive relation between the CRE's administrative skills and the organisation of the daily clinical work could be expected. However, this inference cannot be drawn from current literature on PGME.

The purpose of this study was to explore the relationship between the educational climate in clinical departments and leadership skills in clinical consultants responsible for PGME.

\section{Methods}

The study was a trans-sectional correlation study on the relationship between the educational climate in clinical departments and leadership performance of CREs. The unit of analysis is the clinical department.

\section{Context of the study}

Postgraduate medical education in Denmark is governed by the Danish National Board of Health. For clinical departments participating in PGME, it is mandatory to nominate one of the clinical consultants in the department to be leader of PGME in the department (CRE). The CRE has responsibility for a highly diverse group of trainees undergoing a number of different PGME programs at each clinical department. At the same time the position of a CRE is an important link between the administrative line and the educational line as shown in Figure 1. The CRE manages PGME in the clinical department and has both administrative and leader responsibilities ranging from organising the work in the department to assure all trainees get the proper education, through monitoring the evaluation of the trainees, to appointing and supervising the clinical teachers and supervisors in the department. 


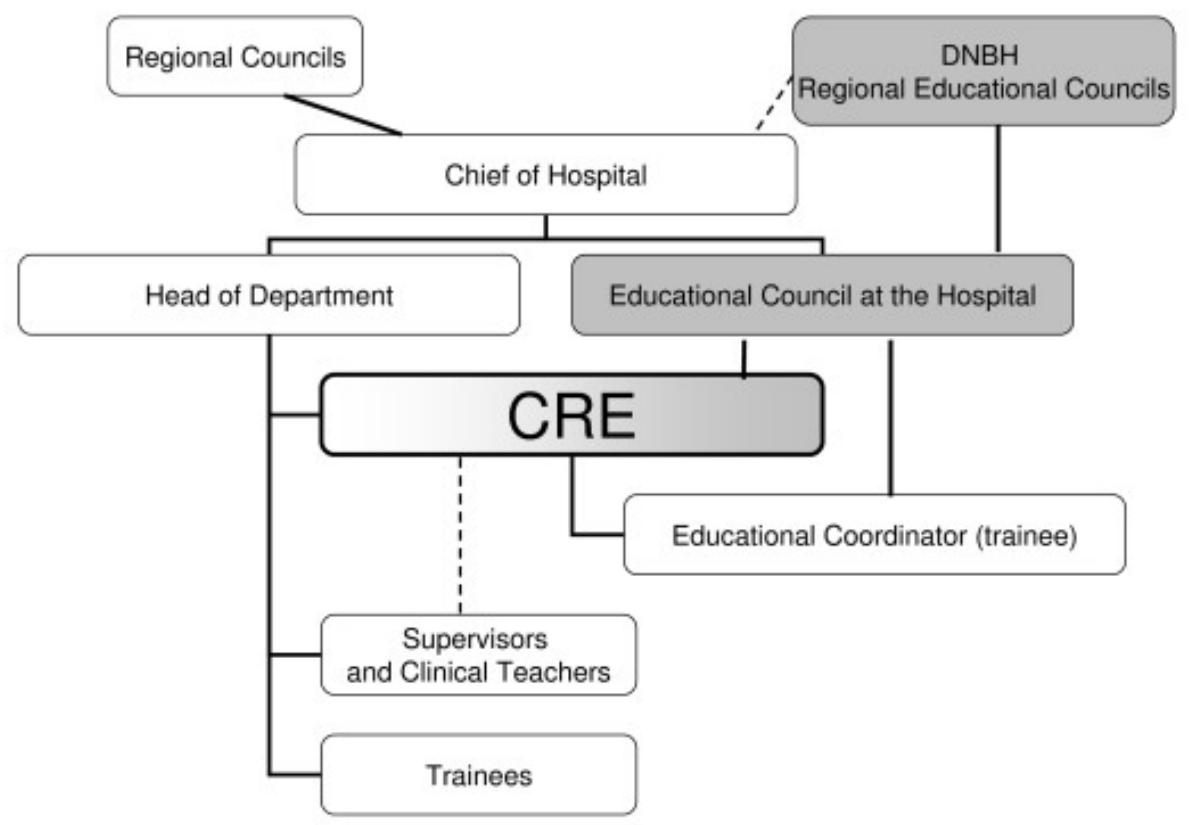

Figure 1. Postgraduate medical education in Denmark - Organisational diagram.

The organisation of postgraduate medical education (PGME) in Denmark. The Danish National Board of Health sets rules and regulations regarding PGME. These are brought into effect by the Regional Educational councils. Postgraduate medical education takes place in the clinical departments which are managed by the Regional councils through the Chief of the Hospital. The Consultant responsible for education (CRE) is the pivotal link between the administrative and the educational line. The educational line is shown in gray boxes and the administrative line in white boxes.

\section{Participants}

This investigation took place in the Northern Educational Region in Denmark. This region covers one third of the country and includes both university and nonuniversity hospitals. CREs from clinical departments with more than three consultants in addition to the head of the department and more than three trainees were eligible for inclusion.

CREs who had previously participated in a leadership course for CREs were excluded as they were included in another study also collecting multi-source feedback (MSF) data. Thus, a total of 79 CREs and their departments were eligible for inclusion. All participants were contacted by phone and informed about the study, the questionnaire on the educational climate and the MSF procedure. All gave informed consent. Confidentiality was guaranteed and participants were assured that it would be impossible to trace findings to individual participants, clinical departments or hospitals. The study was presented to the ethical committee for Viborg and Aalborg County. In our jurisdiction studies of this kind do not need approval. 


\section{Questionnaire on the educational climate}

Various instruments have been introduced to measure educational climate in PGME $(9,21)$. We chose a previously validated Danish instrument, derived from the Postgraduate Hospital Educational Environment Measure (PHEEM) instrument $(9,21)$. In this study we adjusted the instrument to comprise answers from all doctors in the department, thus including both specialists and trainees. The assumption was that all doctors in a department have an opinion about the educational climate (11). The questionnaire comprised 36 statements divided into three main areas concerning the educational climate: 1) Learning opportunities, 2) Supervision and feedback, and 3) Organisation of work. A five-point Likert scale was used ( 1 = "totally disagree" and $5=$ "totally agree" or best score). An e-mail based electronic system (Enalyzer ${ }^{\circledR}$ ) was used to collect data.

\section{MSF on leadership skills}

Multi-source feedback is a widely accepted tool for measuring leadership skills (2224). In this study we used an MSF instrument previously developed to specifically evaluate leadership skills of CREs (20). Multi-source feedback scores were collected from heads of department, consultants and trainees (20). The MSF instrument comprised 69 statements divided into four categories: 1) Technical skills, referring to the proficiency in specific leadership methods and processes ; 2) Human skills, including the ability to work with and through people to meet goals; 3 ) Citizenship behaviour referring to professionalism regarding interpersonal, organisational and job/task performance; 4) Administrative skills, involving knowledge of the planning, organizing and coordinating of tasks (20). Leaders' skills are normally perceived as twodimensional with a leadership dimension and a management dimension. Accordingly, the statements in technical skills, human skills and citizenship behavior comprise leadership skills while administrative skills refer to management. Each statement was scored on a seven-point Likert scale ( 1 = "not at all" and 7 = "always" or best score). The option "not able to answer" was provided. The CRE chose at least three consultants and three trainees in the department to secure anonymity in addition to the head of department. Enalyzer ${ }^{\circledR}$ was used to collect data

\section{Statistics}

Mean scores of educational climate and MSF were calculated. If an item score was missing it was replaced by a mean of all other scores in the same category from the same respondent, provided that more than half of the items in the category were scored. If scores on more than half of the items were missing the respondent was excluded from further analysis. Separate mean scores were calculated for each of the three categories in the educational climate questionnaire, and separated into 
mean score from specialists and from trainees. Similarly, separate mean scores were calculated for the two overall categories "leadership skills" and "management skills" in the MSF procedure.

The overall educational climate score and scores for the three categories in the educational climate questionnaire were correlated to the overall MSF scores and the scores for leadership skills and management skills, respectively using Pearsson's correlation coefficient. Scores from trainees and specialists were compared using Oneway ANOVA. A p-value $<0.05$ was considered significant.

Descriptive statistics were used to examine whether characteristics of study sample were comparable to the background population. For this purpose the departments were categorised according to specialty type into 1) cognitive specialties (internal medicine and subspecialties, paediatrics, dermatology, oncology, psychiatry and neurology), 2) surgical specialties (surgery, orthopaedic surgery, urology, gynaecology, ophthalmology, otology, thoracic surgery, vascular surgery, brain surgery) and 3) technical specialties (anaesthesiology, radiology, all laboratory specialties).

\section{Results}

Figure 2 show how the 154 eligible departments in the Northern Educational Region in Denmark resulted in a study population of 56 departments.

The number of consultants responsible for postgraduate medical education in clinical department (CRE) included in the multi-source feedback process (MSF) and the number of departments included in the measurement of the educational climate including response rates (RR).

Participants represented 21 of the 36 specialties in Denmark. The distribution between cognitive, surgical and technical departments in the study population did not reflect the background population mainly because many of the technical specialty departments (especially the laboratory departments) were too small to participate in the MSF procedure (Table 1). The proportion of cognitive and surgical departments was the same in the study group compared to the background population. 


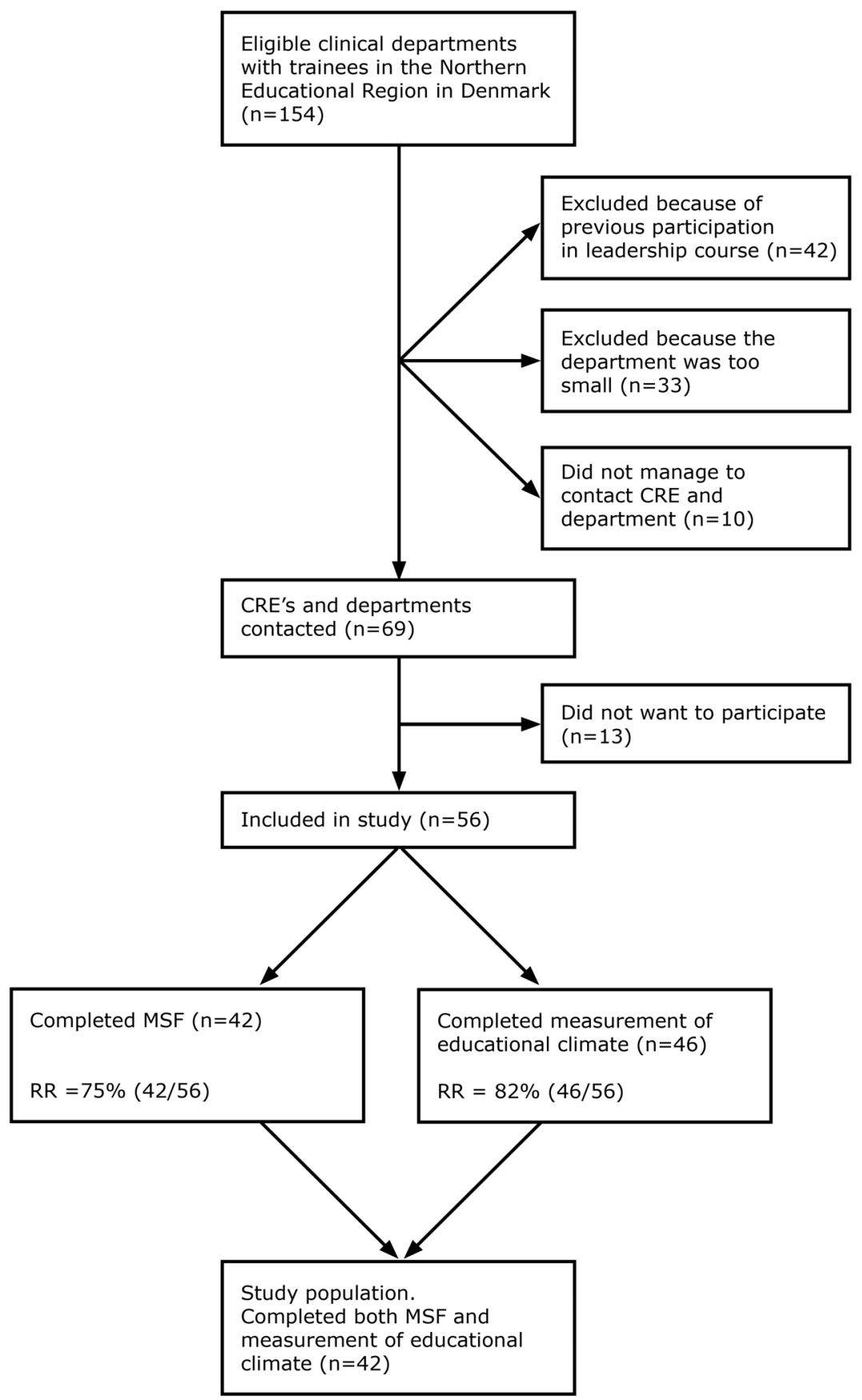

Figure 2. Study population. 
Table 1. Distribution of clinical departments according to specialty in the total population, study sample and excluded departments in actual numbers and percentages of the total sum. Cognitive specialties include internal medicine and subspecialties, paediatrics, dermatology, oncology, psychiatry and neurology. Surgical specialties include surgery, orthopaedic surgery, urology, gynaecology, ophthalmology, otology, thoracic surgery, vascular surgery and brain surgery. Technical specialties include anaesthesiology, radiology and all laboratory specialties.

\begin{tabular}{lcccc}
\hline & $\begin{array}{c}\text { Specialties } \\
\text { Cognitive }\end{array}$ & Surgical & Technical & Total \\
\hline Eligible clinical departments & $60(39 \%)$ & $48(31 \%)$ & $46(30 \%)$ & 154 \\
Excluded - previous leadership course & $13(31 \%)$ & $16(38 \%)$ & $13(31 \%)$ & 42 \\
Excluded - department too small & $9(27 \%)$ & $5(15 \%)$ & $19(58 \%)$ & 33 \\
Included in study & $27(48 \%)$ & $21(38 \%)$ & $8(14 \%)$ & 56 \\
\hline
\end{tabular}

An average of ten doctors answered the questionnaire on the educational climate in the department. The response-rate was 52\% (420/811). In the MSF-process each CRE had ten respondents on average (a total of 420 respondents answered the MSF). The response rate was high $84.3 \%$ (420/498). Mean educational climate and MSF scores are shown in Table 2.

There was no significant correlation between total mean scores of the educational climate and the MSF scores, $r=0.17, p=0.29$. Similarly, there were no significant correlations between the three categories of the educational climate and leadership skills or administrative skills of the leader of PGME in the clinical department for neither the trainees nor the specialists score on the educational climate. Pearson's correlation coefficients varied between $0.29(p=0.07)$ and $0.03(p=0.87)$. 
Table 2. Total mean scores with (SD) and range for a multi-source feedback (MSF) process in clinical consultants responsible for education in clinical departments and a survey on the educational climate among all doctors in the same departments are provided. The MSF scores are divided into two categories: leadership and management skills. The scores on the educational climate are divided into three categories: learning opportunities, supervision and feedback and organization of work. On the educational climate the total scores, trainees' and specialists' scores are provided. *Statistically significant difference between scores from trainees and specialists $(p=0.02)$.

\begin{tabular}{|c|c|c|}
\hline & Mean (SD) & Range \\
\hline \multicolumn{3}{|c|}{ Multi-source feedback (max score $=7$ ) } \\
\hline Total score & $5.4(0.6)$ & $4.2-6.3$ \\
\hline Leadership performance & $5.5(0.6)$ & $4.2-6.3$ \\
\hline Management skills & $5.2(0.6)$ & $4.2-6.3$ \\
\hline \multicolumn{3}{|c|}{ Educational climate $(\max$ score $=5$ ) } \\
\hline \multicolumn{3}{|l|}{ Total score* } \\
\hline All doctors in department & $3.0(0.3)$ & $3.0-4,5$ \\
\hline Trainees & $3.8(0.3)$ & $3.2-4.6$ \\
\hline Specialists & $4.0(0.3)$ & $2.6-4.5$ \\
\hline \multicolumn{3}{|l|}{ Learning opportunities* } \\
\hline All doctors in department & $3.8(0.3)$ & $3.3-4.4$ \\
\hline Trainees & $3.7(0.3)$ & $2,6-4,2$ \\
\hline Specialists & $3.9(0.3)$ & $2.9-4.5$ \\
\hline \multicolumn{3}{|l|}{ Supervision and feedback* } \\
\hline All doctors in department & $3.8(0.3)$ & $2.6-4.7$ \\
\hline Trainees & $3.7(0.3)$ & $2.8-4,9$ \\
\hline Specialists & $3.9(0.3)$ & $2.3-4,5$ \\
\hline \multicolumn{3}{|l|}{ Organisation of work } \\
\hline All doctors in department & $4.2(0.3)$ & $3.2-4.7$ \\
\hline Trainees & $4.1(0.3)$ & $3.6-4.7$ \\
\hline Specialists & $4,2(0.4)$ & $2,7-4,8$ \\
\hline
\end{tabular}

\section{Discussion}

Surprisingly, this study did not show a significant correlation between the educational climate in clinical departments and the leadership performance of the CRE. There could be various explanations for this finding including both internal and external validity threats.

Firstly, the scores on the educational climate were quite high with a mean score of 3.9 (SD 0.3) on a five-point Likert scale. Moreover, MSF scores on leadership performance were quite high with a mean value of 5.4 (SD 0.6) on a seven-point Likert scale. Both results might indicate an instrumentation bias. However, the 
scores on the educational climate in our study varied from 3.0 and 4.5. An educational climate score of 3.0 should be considered a low score, since there is a tendency to get positive scores in measurements of educational climate $(25,26)$. Likewise, respondents in MSF procedures are known to give high scores on MSF (20, 22). The scores on leadership performance ranged between 4.2 and 6.3. A score of 4.2 indicates a rather low leadership performance. The instruments therefore are both able to separate high performers from lower performing CREs and good from a less positive educational climate.

The response rate was moderate $52 \%$ (420/811) on the questionnaire on the educational climate and might pose a threat to the validity of these results. In average we got response from ten doctors from each department, which is enough to get a reliable measurement of the educational climate (27).

Finally, we chose to calculate a total MSF score for all respondents. When measuring leadership performance through an MSF procedure you usually separate the respondents into subgroups according to their position in the organisation. Many studies have shown that you perceive the leaders' performance differently according to your position in the organisation (head of department, peer consultant and trainee) (22). However, in a previous study we have shown that there were only minor differences between the scores of various respondent groups on a MSF process in CREs in clinical departments (20).

The rather high average score in educational climate and MSF scorings might indicate a positive selection bias. However, we excluded the departments where CREs had previously voluntarily signed up for a leadership course and most probably represented the most enthusiastic CREs in the region. Moreover, our study sample included 56 departments covering CREs and departments from a whole region in the country and comprising both university and non-university hospitals in addition to representing many specialties. Even with the lower representation of technical specialties in our study population compared to the background population we feel confident that the results reflect the population in general. Especially since the ratio between the cognitive and surgical specialty departments was the same in the study and the background population. The MSF instrument was developed in a way that only doctors could be invited as respondents. Extending the respondent groups to other staff groups in the department might be considered in future studies in order to achieve a more equal representation of specialties.

In summary, although we acknowledge limitations to our study these do not fully account for our findings. Therefore other explanations to the lack of relation between educational climate and CREs leadership skills might be speculated, including organisational issues of PGME.

In one way PGME relates to a parallel organisation outside the organisation of hospitals and other health care organisations where PGME takes place $(6,28)$. PGME is governed by outside bodies like a national boards of health (United King- 
dom, Denmark) $(15,29)$, the Accreditations Councils (USA) (17), specialist societies (Canada) (18) or the union (Norway) (30). Contrary to this the CRE refers to the head of department in administrative matters. This unclear line of reference combined with an unclear task description may contribute to the CRE's low impact (19). The hospitals are run administratively through the heads of departments. This places the CRE in a position as middle manager primarily concerned with interpreting and implementing policies and programs from the educational bodies or places him as a low-level manager supposedly engaged in structuring, coordinating and facilitating work activities (24). In a previous study we have shown that the CRE is expected to manage a whole range of administrative duties (19), among them ensuring that trainees are exposed to the clinical situations they are supposed to learn from. Structuring the learning opportunities and processes is very important in clerkship education $(31,32)$, and there is reason to believe that it might be even more important in PGME, where involvement, participation and interpersonal relations are so fundamental (33). Since stakeholders in PGME found that the CRE masters the administrative duties well(19), we would have expected a relation between the organisation of work and management skills of the CRE. Finding no relation might reflect that the CRE have limited influence on the planning of daily work schedules. Both CREs and stakeholders have suggested the development of a specific leadership course for CREs to strengthen their position (19). However, if the CRE is in a weak position to influence the working organisation and educational climate these initiatives may be in vain (34).

CREs might be fairly good leaders but acting in a system that makes it difficult to be perceived as a leader of education and creator of the educational culture. Additionally, the educational climate might be so mixed up in the work environment that maybe focus should be on the working culture instead of isolating the educational climate. This would involve asking other staff groups about their perception of the working culture in the clinical departments.

To further explore factors that influence the educational climate it might be relevant to focus on the leadership performance of the administrative heads of the clinical departments. In particular how the head of the department prioritises PGME and attends to the educational mission in the department. This might have significant influence on the CRE's possibility to excert leadership of education and fulfil expectations (24).

\section{Conclusion}

Our results indicate that there is no relationship between the educational climate in clinical departments and the leadership performance of educational leaders of PGME in the department. The separated administrative and educational lines of 
reference in PGME might explain this lack of relation. Future studies should focus on exploring how administrative leaders of clinical departments and perhaps other factors related to the clinical organisation influence the educational climate. 


\section{References}

1. Hoff TJ, Pohl H \& Bartfield J. Creating a learning environment to produce competent residents: the roles of culture and context. Acad Med, 2004; 79, 532-540.

2. Beauchamp RD. The changing roles of a surgical department chair. Adapting to a changing environment. Arch Surg, 2005; 140: 258-63.

3. Naylor CD. Leadership in academic medicine: reflections from administrative exile. Clin Med, 2006; 6 (5): 488-492.

4. Bleakley A. Pre-registration house officers and ward-based learning: a "new apprenticeship" model. Med Educ, 2002; 36: 9-15.

5. Kendall ML, Hesketh EA \& Macpherson SG. The learning environment for junior doctor trainingwhat hinders, what helps? Med Teach, 2005; 27, 619-624.

6. Schwartzstein RM, Huang GC \& Coughlin CM. Development and implementation of a comprehensive strategic plan for medical education an academic medical center. Acad Med, 2008; 83: 550 559.

7. Cross V, Hicks C, Parle J \& Field S. Perceptions of the learning environment in higher specialist training of doctors: implications for recruitment and retention. Med Educ, 2006; 40: 121-128.

8. Genn JM. AMEE Medical Education Guide No. 23 (Part 2): Curriculum, environment, climate, quality and change in medical education - a unifying perspective. Med Teach, 2001; 23: 445-454.

9. Roff S, McAleer S \& Skinner A. Development and validation of an instrument to measure the postgraduate clinical learning and teaching environment for hospital-based doctors in the UK. Med Teach, 2005; 27: 326-331.

10. Parsell G \& Bligh J. Encouraging educational leadership. Med Educ, 2000; 34: 199-200.

11. Schein EH. Organizational culture and leadership. $3^{\text {rd }}$ Ed. San Francisco: Jossey-Bass; 2004.

12. Schwartz RW \& Pogge C. Physician leadership is essential to the survival of teaching hospitals. Am J Surg, 2000; 179: 462-468.

13. Souba WW. The new leader: new demands in a changing, turbulent environment. J Am Coll Surg, 2003; 197: 79-87

14. Wong JG, Fagan M \& Pinsker J. Expectations of and for the medical director of the resident's ambulatory clinic. Am J Med, 2001; 111: 84 - 87,

15. The Danish Ministry of Health. Report and recommendation on specialist training. Report no. 1384. "The future Specialist". DNBH Publications; 2000. In Danish.

16. The Danish National Board of Health. Guidance and evaluation in the training of specialists in Denmark. DNBH Publications; 1998. In Danish.

17. Accreditation Council for Medical Education, ACGME. Program director guide to the common programme requirements. 2008. Retrieved from the Web August 2008. www.acgme.org

18. Royal college of Physicians and Surgeons of Canada. General standards applicable to the university and affiliated sites. 2007. Retrieved January 6, 2010 from www.rcpsc.medical.org

19. Malling B, Scherpbier, AJJA \& Ringsted C. What is the role of the consultant responsible for postgraduate education in the clinical department? Med Teach, 2007; 29: 471-77.

20. Malling B, Bonderup, T, Mortensen L, Ringsted C \& Scherpbier AJJA. Effect of multi-source feedback on developmental plans for leaders of postgraduate medical education. Med Educ, 2009; 43: 159167.

21. Aspegren K, Bastholt L, Bested KM, Bonnesen T, Ejlersen E, Fog I et al. Validation of the PHEEM instrument in a Danish hospital setting. Med Teach, 2007; 29: 498-500.

22. Bracken DW, Timmreck CW \& Church AH. Eds. The handbook of multisource feedback. The comprehensive resource for designing and implementing MSF processes. San Fransisco: Jossey-Bass Inc.; 2001.

23. National Health Service. NHS Leadership Qualities Framework. www.nhsleadershipqualities.nhs.uk [Accessed 3 January 2008] 
24. Yukl G. Leadership in organizations. 6th ed. Upper Saddle River, New Jersey: Pearson Education Inc.; 2006.

25. Cassar K. Development of an instrument to measure surgical operating theatre learning environment as perceived by basic surgical trainees. Med Teach, 2004; 26: 260-264.

26. Clapham M, Wall D \& Batchelor A. Educational environment in intensive care medicine - use of Postgraduate Hospital Educational Environment Measure (PHEEM). Med Teach, 2007, 1-8.

27. Boor K, Scheele F, van der Vleuten CPM, Scherpbier AJJA, Teunissen PW \& Sijtsma K. Psychometric properties of an instrument to measure the clinical learning environment. Med Educ, 2007; 41: 92 99.

28. Weiner BJ, Culbertson R, Jones RF \& Dickler R. Organizational models for medical school - clinical enterprise relationships. Acad Med, 2001; 76: 113-124.

29. Postgraduate medical education and training board PMETB. Strategy document: 2006-2010. www.gmc-uk.org .

30. Legeforeningen. Specialist training for physicians in Norway 2005. Retrieved from the Web august 2006. http:// www.legeforeningen.no

31. Durak HI, Vatansever K, van Dalen J \& Van der Vleuten C. Factors determining students' global satisfaction with clerkships: an analysis of a two year students' ratings database. Adv Health Sci Educ, 2008; 13: 495-502.

32. Van der Hem-Stockroos HH, Daelmans HE, van der Vleuten CPM, Haarman HJ \& Scherpbier AJ. A qualitative study of constructive clinical learning experience. Med Teach, 3002; 25: 120-126.

33. Teunissen PW, Scheele F, Scherpbier AJ, van der Vleuten CPM, Boor K, van Luijk SJ et al. How residents learn: qualitative evidence for the pivotal role of clinical activities. Med Educ, 2007; 41: 763770.

34. Malling B, Mortensen L, Bonderup T, Scherpbier AJJA \& Ringsted C. Combining a leadership course and multi-source feedback has no effect on leadership skills of leaders in postgraduate medical education. An intervention study with a control group. BMC Med Educ, 2009; 9: 72. 



\section{CHAPTER 4}

\section{Effects of multi-source feedback on developmental plans for leaders of postgraduate medical education}

Published in Medical Education, 2009; 43: 159-167.

B Malling, T Bonderup, L Mortensen, C Ringsted \& AJJA Scherpbier. 


\begin{abstract}
Objectives: Multi-source feedback (MSF) is a widely used developmental tool for leaders in organisations including those dealing with health care. This study was performed to examine the effect of an MSF process on developmental plans made by leaders of postgraduate medical education (PGME) in clinical departments.
\end{abstract}

Methods: An MSF instrument was developed based on literature on the subject and previous investigations. The instrument was used by consultants responsible for PGME in clinical departments (CREs). Apart from CREs' self-ratings, MSF responses were collected from heads of departments, consultants and young doctors-intraining. The MSF process included individual feedback as well as guidance on drafting developmental plans for both the department and the CREs. Themes emerging in the developmental plans were analysed and compared with the areas in need of improvement identified by the MSF process.

Results: The MSF instrument was found to be feasible, valid and reliable (Cronbach's $\alpha=0.98$ ). The study included 52 CREs from various specialties and 498 MSF respondents. The response rate was $84 \%$. Low ratings and negative gaps between others' ratings and self-ratings were identified for both management and leadership performance areas. The developmental plans mainly focused on management initiatives, whereas plans for the development of leadership performance were few.

Areas rated low by all respondents were scarcely represented in CREs' developmental plans.

Conclusion: An MSF process might in itself lead to development in administrative areas. However, MSF carried through as a single stand-alone procedure was not sufficient to foster plans for development of leadership performance. 


\section{Introduction}

Leadership and management in postgraduate medical education (PGME) are regarded necessary to improve quality of clinical training (1-9). Leadership has been described by Yukl (10) as 'the process of influencing others to understand and agree about what needs to be done and how to do it, and facilitating individual and collective efforts to accomplish shared objectives', whereas management includes administration, organisation and monitoring. Both leadership and management are necessary ingredients of good managerial performance $(10,11)$.

Postgraduate medical education programmes are often complex compositions involving several training sites and including many clinical departments and hospitals. Although the overall responsibility for PGME is placed differently in various countries (with universities, scientific societies, medical associations, national health boards) the head of each clinical department $(\mathrm{HoD})$ is the person most responsible for managing PGME in the clinical department. These responsibilities are often delegated to a local site director, as seen in USA, or to a consultant responsible for education (CRE), as in Denmark $(1,8,12)$. In a study of the CRE's role in the clinical department, various stakeholders called for CREs to develop more as leaders than as managers as they perceived them to already be good managers (13).

Leadership can be learned through formal training, through experience and through personal development $(6,12,14,15)$. Personal development can be guided by multi-source feedback (MSF) (16-18). In an MSF process, personal performance ratings are compared with ratings from superiors, peers and subordinates (16). Multi-source feedback processes are intended to make ratees aware of their strengths and weaknesses, to initiate reflections on how to improve performance, and to form the basis of developmental plans (16). Areas in need of improvement are identified through low ratings or gaps between ratings, such as differences between self- and others' ratings $(11,16)$.

Multi-source feedback processes are well suited for evaluating managerial performance $(10,18)$. The taxonomy of good managerial performance has been studied for many years and by many authors $(10,19)$. One theoretical approach to good managerial performance was introduced in the four-factor model by Scullen et al. (20), which consists of these categories: technical skills (knowledge and skills of leaders); administrative skills; human skills, and citizenship behaviour (leadership performance beyond what is expected of interpersonal and organisational behaviour). The categories 'technical skills', 'human skills' and 'citizenship behaviour' relate to the concept of 'leadership' whereas 'administrative skills' refers to the concept of 'management'.

According to Lockyer et al. (21) the MSF approach used in medical settings is valid, reliable and feasible and provide doctors with quality improvement data 
about competencies like medical expertise, communication skills, collegiality, and psychosocial and administrative skills.

However, the effect of MSF on performance improvement has been disputed $(16,20-24)$. Multi-source feedback has shown measurable effects on both individual and organisational level when used by managers in professional organisations (22), and $30 \%$ of general practitioners made changes in performance as a result of MSF (23). By contrast, Lockyer et al. (21) found that surgeons were unlikely to make changes following an MSF process (21). The extent of performance improvement following MSF is determined by various personal factors, like readiness to receive feedback, initial reactions to feedback $(16,23)$ and ability to formulate goals, which might be improved by personal feedback or coaching following the MSF process (24).

The purpose of this study was to identify areas of leadership in need of improvement through an MSF procedure, and to explore the effect of an MSF process on the content and quality of developmental plans made by PGME leaders in clinical departments. Because MSF instruments already developed $(17,18)$ do not include all responsibilities and tasks of a PGME leader, as described in a previous study (13) a new instrument was developed for this purpose.

We sought to answer the research question: to which extent are the areas in need of improvement (low ratings or gaps) identified by MSF responses from young doctors-in-training, consultants, HoDs and CREs used in the development plans of PGME leaders in clinical departments?

\section{Methods}

\section{The participants}

A single-group study was carried out using a pre-existing group of CREs from all clinical departments in the Northern Educational Region in Denmark, representing a multitude of specialities. It is mandatory for all departments participating in PGME in Denmark to appoint a consultant responsible for PGME (CRE).

A total of 154 clinical departments were identified in the Region. Inclusion criteria for this study required departments to have more than three trainees and more than three consultants besides the HoD; these criteria were fulfilled by 129 of the 154 departments in the Region. As formal leadership training might influence personal development, forty-two CREs who had previously participated in leadership training for CREs were excluded. Consultants responsible for PGME and respondents who participated in the development of the instrument (focus-groups and pilottests) were not included. Potential participants (87 CREs) were contacted and informed about the study and $52(60 \%)$ agreed to participate. 
Confidentiality was guaranteed and participants were assured that it would be impossible to trace results to individual participants, clinical departments or hospitals.

\section{Development of the MSF instrument}

An initial pool of items was created by a panel (two experts on development and use of MSF for leaders in healthcare and one experienced educationalist). The items were inspired by various descriptions of leadership behaviour $(2,4,6,10,11,14,20$, 25- 29), the MSF instrument used in the UK for leaders in healthcare (18), job description for CREs (8) and results from a previous study on the expected role of a CRE (13). Each item referred to one of the four categories described in the fourfactor model by Scullen et al. (20).

\section{Content validity and feasibility}

The first list of items was commented on by two experienced educationalists. Two focus group interviews with CREs, consultants and trainees from various clinical departments were conducted to discuss the content, relevance and phrasing of the items. Suggestions from the experts and the focus groups were included in a pilot test version of the instrument comprising 69 items. Five CREs and 48 respondents participated in the pilot test. The instrument was distributed by e-mail. The response rate was $94 \%$ (50/53). Participants in the pilot test found the instrument convenient and feasible.

\section{The final instrument}

Based on comments from the pilot-test, 16 items were rephrased, mostly to resolve confusion about terms like 'supervisor' and 'clinical teacher'. Two new items emerged (regarding power to penetrate and support from other consultants) and two items were removed because they were considered to repeat previous item content.

The final instrument consisted of 69 items arranged according to the four-factor model described by Scullen et al. (21). These included technical skills (14 items), human skills (seven items), citizenship behaviour (17 items) and administrative skills (31 items). Items were scored on a 7-point Likert scale where $1=$ not at all true and $7=$ very true. The option 'not able to answer' was included. The instrument is provided in Appendix S1. 


\section{The MSF procedure}

The CREs were requested to select and obtain consent from respondents (i.e. the HoDs, consultants and young doctors-in-training). It was preferable to include at least five consultants and five trainees. The CRE mailed the list of respondents to the study co-ordinator. If a list of respondents was not received three reminders were mailed to the CRE, the last of which was supplemented with a telephone call.

The MSF instrument with clear instructions was mailed to the CRE and the other respondents. The CREs and respondents answered the items electronically. Nonresponders were reminded twice by mail. The last reminder was supplemented with a telephone call to the CRE requesting him or her to remind all respondents.

All CREs received a report showing their own ratings compared with mean ratings obtained from each respondent group (identifying gaps), both for the individual items and in summary form for the four categories. The five items with the highest ratings and the five items with the lowest ratings were included, together with a scheme to be used for the developmental plan. Individual ratings were anonymised to the CRE except those from the HoD.

An experienced human resources consultant met with the CRE to provide individual feedback by presenting and explaining the results in the MSF report, initiating self-reflection and guiding the CRE in drafting the developmental plan.

The human resource consultants wrote down the initiatives mentioned by each CRE in pre-designed forms for analysis.

\section{Statistical analysis}

Internal reliability was expressed by calculating Cronbach's $\alpha$. Confirmatory factor analysis was performed to check if the individual items were placed in the best possible categories according to the four-factor model by Scullen et al. (20). In the factor analysis the answer 'not able to answer' was considered as a missing answer. Only respondents who answered all items within a category were included in the factor analysis. All respondents were included in the following calculations. Differences between the CRE's mean self-ratings and the mean ratings by other respondent groups for each dimension in the factor analysis were investigated by using a mixed model of variances. Using Bonferroni's correction, $\mathrm{P}<0.017$ corresponded to a $95 \%$ significance level. Mean ratings of $<5$ on a 7-point Likert scale were considered as low ratings.

The developmental initiatives mentioned by the CREs were analysed by the first author using deductive analysis (30). All initiatives were interpreted and distributed into categories using the four-factor model of Scullen et al. (20) as thematic framework. 


\section{Results}

\section{The participants}

The 52 included participants (CREs) represented 24 different specialties and 10 hospitals. Their mean length of time in post as a CRE was $2.7(0.5-21)$ years. Table 1 shows the number and distribution of respondents and response rate for all respondent groups.

Table 1. Participants in the multi-source feedback process according to respondent group and response rate. $\mathrm{MSF}$ = multi-source feedback; $\mathrm{RR}$ = response rate; $C R E s$ = consultants responsible for education at departmental level.

\begin{tabular}{lccccccc}
\hline & Included & Withdrew & No answer & $\begin{array}{c}\text { Completed MSF process } \\
\text { (RR*) }\end{array}$ \\
\hline CRE & 52 & $7.7 \%$ & $(4 / 52)$ & $11.5 \%$ & $(6 / 52)$ & $80.8 \%$ & $(42 / 52)$ \\
Respondents & 498 & $3.4 \%$ & $(17 / 498)$ & $12.3 \%$ & $(61 / 498)$ & $84.3 \%$ & $(420 / 498)$ \\
Head of Departments & 39 & & & & & & \\
Clinical Teachers & 224 & & & & & & \\
Trainees & 235 & & & & & & \\
Total & 550 & $3.8 \%$ & $(21 / 550)$ & $12.2 \%$ & $(67 / 550)$ & $84.0 \%$ & $(462+/ 550)$ \\
\hline
\end{tabular}

* Response rates (RR) are shown as percentages

+ Includes the number of participants who withdrew from the study and the number who never responded

\section{The MSF instrument}

Cronbach's $\alpha$ for the MSF instrument was 0.98. The factor analysis confirmed the four-factor model of Scullen et al. and reduced the 69 items to 14 dimensions (Table 2). The percentage of variance accounted for by choosing these dimensions varied between 68.2 and 75.6. One item ('points out a supervisor for all trainees') showed low correlation with all other items and was removed from further analysis. Mean rating for all respondent groups on this item was $>6.5$.

Table 2 shows CRE ratings (mean [SD]). The CRE ratings varied between 5 and 6 except for the dimension 'supervises the supervisors' (3.75), 'role-model and mediator' (4.71) and 'resource allocator' (6.06). 
Table 2. The 14 dimensions (D) from the confirmatory factor analysis arranged according to the fourfactor model of Scullen et al. (20). Leaders' own ratings (CRE ratings) are shown as means with SD. Dimensions where CRE ratings differ from others' ratings - positive or negative gaps are provided, together with P-values. Areas with overall low ratings (scores $<5$ on a 7-point Likert scale) are shown. CRE = consultant responsible for postgraduate medical education in a clinical department; $\mathrm{C}=$ Consultant; $\mathrm{T}=$ Trainee (registrar and residents); HoD = Head of department; NS = not significant.

\begin{tabular}{|c|c|c|c|c|c|c|}
\hline $\begin{array}{l}\text { Factors } \\
\text { Dimensions }\end{array}$ & $\mathrm{D}$ & $\begin{array}{l}\text { CRE rating } \\
\mathrm{N}=42 \\
\text { Mean (SD) }\end{array}$ & $\begin{array}{l}\text { Low } \\
\text { rating }\end{array}$ & $\begin{array}{l}\text { Negative } \\
\text { gap }\end{array}$ & $\begin{array}{c}\text { Positive } \\
\text { gap }\end{array}$ & $\mathrm{p}$-value \\
\hline \multicolumn{7}{|l|}{ Technical skills } \\
\hline Trainee counsellor & 1 & $5.95(0.91)$ & & $\mathrm{CRE}>\mathrm{T}$ & & NS \\
\hline Performs expected tasks & 2 & $5.13(1.15)$ & & & & \\
\hline Ensures support from stakeholders & 3 & $5.31(1.12)$ & & & & \\
\hline Resource allocator & 4 & $6.06(0.96)$ & & $\begin{array}{l}\mathrm{CRE}>\mathrm{T} \\
\mathrm{CRE}>\mathrm{C}\end{array}$ & & $\mathrm{P}<0.02$ \\
\hline \multicolumn{7}{|l|}{ Human skills } \\
\hline Empathic and open-minded & 10 & $5.87(0.72)$ & & $\mathrm{CRE}>\mathrm{C}$ & & NS \\
\hline Shows authority & 11 & $5.32(1.04)$ & & & $\mathrm{CRE}<\mathrm{T}$ & $P=0.08$ \\
\hline \multicolumn{7}{|l|}{ Citizenship behaviour } \\
\hline Commitment & 12 & $5.57(0.98)$ & & & & \\
\hline Engages colleagues & 13 & $5.35(0.97)$ & & $\begin{array}{l}C R E>T \\
C R E>C\end{array}$ & & NS \\
\hline Role-model and mediator & 14 & $4.71(0.95)$ & $x$ & & & \\
\hline \multicolumn{7}{|l|}{ Administrative skills } \\
\hline Implementer & 5 & $5.24(0.81)$ & & & & \\
\hline Frames learning possibilities & 6 & $5.36(0.92)$ & & & & \\
\hline Updates educational programmes & 7 & $5.63(0.82)$ & & $\mathrm{CRE}>\mathrm{T}$ & & $P=0.08$ \\
\hline \multirow[t]{3}{*}{ Supervises the supervisors } & 8 & $3.75(1.23)$ & $x$ & & $\mathrm{CRE}<\mathrm{T}$ & $P<0.01$ \\
\hline & & & & & $\mathrm{CRE}<\mathrm{C}$ & $P<0.01$ \\
\hline & & & & & $\mathrm{CRE}<\mathrm{HoD}$ & $\mathrm{P}<0.01$ \\
\hline Quality assurance & 9 & $5.20(0.96)$ & & & & \\
\hline
\end{tabular}

After Bonferroni correction $\mathrm{P}<0.017$ corresponds to a $95 \%$ significance level. Scores from all other respondents are shown in Appendix S2.

In dimension four 'resource allocator', trainees rated significantly lower than CREs $(p<0.02)$. By contrast the CREs rated significantly lower than all other respondents in the dimension 'supervises the supervisors' $(p<0.01)$. No significant difference was found between ratings of CREs and others in all other dimensions. Mean ratings by respondents are provided in Appendix S2.

Negative gaps between ratings of CREs and trainees were seen in the dimensions $1,4,7$ and 13 , and between ratings by CREs and consultants in dimensions 4 , 10 and 13.

Heads of clinical departments rated higher than CREs in all dimensions, as did consultants in $79 \%(11 / 14)$ of dimensions and trainees in $64 \%(9 / 14)$. 


\section{The developmental plans}

A total of 141 initiatives for performance improvement were mentioned in the developmental plans. The initiatives related to the 14 dimensions and to the two main areas of leadership and management are shown in Table 3. Management accounted for $75 \%$ of goals, human skills for $5 \%$, and technical skills and citizenship behaviour for $10 \%$ each.

The majority of plans were made for management skills although the only significant negative gap was found in the leadership area. Plans for improvement of leadership were vaguely expressed in superficial terminology whereas plans for improvement in management skills were clear and concrete.

Table 3. The 14 dimensions (D) from the confirmatory factor analyses arranged according to the fourfactor model by Scullen et al. (20) and divided into the main areas of leadership and management. The various initiatives from the CRE personal developmental plans made after a multi-source feedback process are shown for each dimension. Percentages represent the percentage of initiatives mentioned for each factor. $\mathrm{CRE}=$ consultant responsible for postgraduate medical education at clinical department level; MSF = multi-source feedback; PGME = postgraduate medical education.

\begin{tabular}{|c|c|c|}
\hline LEADERSHIP & $\mathrm{D}$ & Initiatives in CRE developmental plans \\
\hline \multicolumn{3}{|l|}{ Technical skills (10 \%) } \\
\hline Trainee counsellor & 1 & No plans made \\
\hline Performs expected tasks & 2 & No plans made \\
\hline Ensures support from stakeholders & 3 & Improve co-operation with other stakeholders \\
\hline \multirow[t]{2}{*}{ Resource allocator } & 4 & Delegate tasks \\
\hline & & Negotiate protected time for own function \\
\hline \multicolumn{3}{|l|}{ Human skills (5 \%) } \\
\hline Empathic and open-minded & 10 & $\begin{array}{l}\text { Clarify expectations of CRE function } \\
\text { Spot resources in others }\end{array}$ \\
\hline Shows authority & 11 & $\begin{array}{l}\text { Meet with respondents to discuss the MSF report (one) } \\
\text { Seek education in coaching (one) }\end{array}$ \\
\hline \multicolumn{3}{|l|}{ Citizenship behaviour (10 \%) } \\
\hline Commitment & 12 & $\begin{array}{l}\text { Create a deeper understanding for the need to improve } \\
\text { PGME } \\
\text { Initiate a new educational quality project in the depart- } \\
\text { ment (one) }\end{array}$ \\
\hline Engages colleagues & 13 & $\begin{array}{l}\text { Motivate and engage colleagues to focus on the educa- } \\
\text { tional environment } \\
\text { Put education on the agenda } \\
\text { Make education a multi-professional business (one) }\end{array}$ \\
\hline Role-model and mediator & 14 & Improve own performance as role-model \\
\hline
\end{tabular}


Table 3 continued. The 14 dimensions (D) from the confirmatory factor analyses arranged according to the four-factor model by Scullen et al. (20) and divided into the main areas of leadership and management. The various initiatives from the CRE personal developmental plans made after a multi-source feedback process are shown for each dimension. Percentages represent the percentage of initiatives mentioned for each factor. $\mathrm{CRE}=$ consultant responsible for postgraduate medical education at clinical department level; MSF = multi-source feedback; PGME = postgraduate medical education.

\begin{tabular}{|c|c|c|}
\hline MANAGEMENT & $\mathrm{D}$ & Initiatives in CRE developmental plans \\
\hline \multicolumn{3}{|l|}{ Administrative skills (75 \%) } \\
\hline Implementer & 5 & $\begin{array}{l}\text { Explain and translate blueprints, rules and regulations } \\
\text { Inform and motivate the consultants to take part in PGME } \\
\text { Introduce new discussion forums and meetings } \\
\text { Implement new training methods and in-training assess- } \\
\text { ment }\end{array}$ \\
\hline Frames learning possibilities & 6 & $\begin{array}{l}\text { Outline all educational courses and make rotation plans for } \\
\text { trainees } \\
\text { Make working schedule fit in with trainees' individual } \\
\text { educational needs } \\
\text { Secure more homogenous training and guidance }\end{array}$ \\
\hline $\begin{array}{l}\text { Updates educational } \\
\text { programmes }\end{array}$ & 7 & $\begin{array}{l}\text { Make realistic plans for each individual trainee's education } \\
\text { Take steps to improve educational programmes } \\
\text { Improve and take part in the introduction of new trainees } \\
\text { Work out various forms of checklists about the supervisor } \\
\text { function }\end{array}$ \\
\hline Supervises the supervisors & 8 & $\begin{array}{l}\text { Start a dialogue on how to supervise the supervisors and } \\
\text { consultants }\end{array}$ \\
\hline Quality assurance & 9 & $\begin{array}{l}\text { Send the consultants and supervisors on a train-the- } \\
\text { trainers course } \\
\text { Cary out quality assurance procedures } \\
\text { Participate in consultants' appraisal meetings with trainees } \\
\text { (one) } \\
\text { Make sure that the stakeholders know about best training } \\
\text { practice }\end{array}$ \\
\hline
\end{tabular}

\section{Discussion}

\section{The MSF instrument and study population}

The MSF instrument developed for this study was reliable (Cronbach's $\alpha=0.98$ ). Content validity was secured through thorough development of the instrument. The MSF process followed recommendations by Bracken et al. (16). The pilot-test participants found the electronic system convenient. The instrument was regarded as usable, judged by the high response rate (84\%) in a large study population (550 participants). The ratings in our study followed the general pattern: HoDs rated highest, consultants (peers) intermediate and trainees (subordinates) lowest. This indicated that the instrument was usable for leaders of PGME in clinical departments (16). 
Overall mean ratings on all dimensions was high, at 5-6 on a 7-point Likert scale. The instrument was able to point out areas in need of improvement, defined as dimensions where all respondents including self rated low and dimensions where selfratings were higher than ratings of others $(11,16)$.

The overall high ratings and the few negative gaps indicated that the CREs were actually doing a good job. The inclusion of only $60 \%$ of potential participants shows the difficulties of engaging busy clinicians in studies like this. The high scores therefore might be explained by selection, as the CREs included might represent the positive and engaged CREs. The fact that ten CREs (19.2\%) either withdrew or did not respond might have further contributed to the positive results.

The first author alone performed the deductive analysis of the interviews on developmental plans. We might have expected that the developmental plans would be interpreted in such a way as to make the plans fit the areas in need of improvement found in the MSF procedure. However, as the reverse result was found, bias was probably not pronounced.

\section{Relationship between MSF and developmental plans}

In our study the dimension 'supervise the supervisors' was rated low by all respondent groups. This result might have inspired the CREs to improve the supervision of the consultants' teaching and guidance of trainees, which is a very important part of the CRE's job according to the job description. However plans to do so were scarce. This might have been caused by the 'positive' gap, which appeared to indicate that this dimension represented a strength of the CRE. A previous study shows that although the CREs are given formal authority to lead PGME in clinical departments, consultants do not regard CREs as authorities. In the context of a culture where consultants see it as their job to give, not receive, feedback, this makes the task of leadership very difficult (13).

Another poorly rated dimension was 'role-model and mediator'. Only one CRE planned to improve as a role-model. Although the issue was not investigated in this study, the choice not to make plans for changes in the dimensions 'role-model and mediator' might be explained by distress created by negative feedback, Feedback that is perceived as negative and not useful has been described by other authors to have no or negative results $(23,24)$. However, it might also reflect lack of insight on how to improve in this dimension.

The highest negative gaps in our study were found in the dimensions 'resource allocator', 'engages colleagues' and 'updates educational programmes'. Only the latter was reflected in the developmental plans by clear and concrete plans to explain and teach new methods and to translate initiatives from authorities into practice. Plans to 'engage colleagues' were vague and plans made in the area 'resource allocator' mainly included plans for the CREs' management of their own time. The 
lack of plans in the dimension 'resource allocator' may reflect an absence of the CRE-perceived need to change in this area, where self-ratings were high.

\section{Developmental plans: leader or manager?}

Many authors have described how leaders should be able to master both leadership and management $(6,10,11,25,27)$. Only $25 \%$ of initiatives planned concerned leadership, whereas $75 \%$ of initiatives concerned management. This is by contrast with the more even distribution of items in the MSF instrument, where $55 \%(38 / 69)$ of the items concerned leadership and $45 \%$ (31/69) were related to management. The results of this study confirmed the findings of Smither et al (24) that goals for improvement are often set in areas in which the subject is already considered by himself and others to perform well because reaching these goals is seen as feasible.

Goals set for leadership were vaguely expressed (e.g. improve cooperation, put education on the agenda), whereas most goals set for management were clear and specific (e.g. devise a new introduction program, send consultants on courses). Why this difference occurred was not covered within the scope of this investigation, but it may be connected to various factors such as readiness to receive feedback, feedback orientation and ability to set goals, all of which are factors described by others as important $(23,24)$. Running the MSF process only once might have influenced the CREs' ability to set goals as it has been reported that MSF processes should be iterative to be effective (16).

The CREs investigated in this study were relatively inexperienced as leaders, having been in position for a mean of $<3$ years. This might have contributed to their reluctance to make plans to improve their leadership skills and hence personal development because maturation is one factor that contributes to the growth of leaders $(11,15)$. Consultants responsible for education might be located at middle management level, where, according to Yukl (13), management is a relatively more important part of the function.

A previous investigation, however, called for more leadership from CREs (13). In order to improve leadership in PGME in clinical departments, it is necessary to inspire leaders to develop. As self-reflection and self-insight are valuable means to improve leadership $(1,10,11,14,15,26,27)$, the initiation of an MSF process as in this study, mentoring and coaching might reinforce formal leadership training and personal development.

\section{Conclusion}

The MSF instrument used for developmental purposes by leaders of PGME in clinical departments showed content validity and was reliable and usable. Following the 
MSF process the CREs described very concrete and specific plans for performance improvement concerning the 'easy to set and measure' goals pertaining to management, whereas plans for the development of leadership skills and hence personal development were less concrete and were expressed in superficial terminology. The plans did not necessarily reflect the areas of improvement identified by low ratings and gaps between self-ratings and ratings by others in the MSF process. The difficulties of setting goals for personal development can be interpreted as indicative of a need for further leadership development. 


\section{References}

1. Beauchamp RD. The changing roles of a surgical department chair. Adapting to a changing environment. Arch Surg, 2005; 140: 258-63.

2. Benor DE. Faculty Development, teacher training and teacher accreditation in medical education: Twenty years from now. Med Teach, 2000; 22: 503-12.

3. Cohen JJ. Leadership for medicine's promising future. Acad Med. 1998; 73: 132-37

4. Hill F \& Stephens C. Building leadership capacity in medical education: developing the potential of course coordinators. Med Teach, 2005; 27: 145-49.

5. Klinge B. Leadership in academic institutions: raising the value of teaching. Med Educ, 2000; 34: 201-02.

6. McKimm J. Developing tomorrow's leaders in health care and social education. Special report No 5. Case Studies in leadership in medical and health care education. FDTL4 Leadership development programme. The Higher Education Academy, Newcastle upon Tyne, UK; 2004.

7. Steinert $Y$. Faculty development in the new millennium: key challenges and future directions. Med Teach, 2000; 22: 44-50.

8. The Danish National Board of Health. Guidance and evaluation in the training of specialists in Denmark. DNBH Publications 1998. In Danish.

9. World Federation for Medical Education. Postgraduate Medical Education. WFME Global Standards for Quality Improvement. University of Copenhagen, Denmark: WFME Office; 2003.

10. Kotter JP. What leaders really do. Boston: Harvard Business School Press; 1999.

11. Yukl G. Leadership in organizations. 6th ed. Upper Saddle River, New Jersey: Pearson Education Inc.; 2006.

12. Accreditation council for Graduate Medical Education. Program directors and coordinators. www.acgme.org [Accessed 10 June 2008]

13. Malling B, Scherpbier AJJA \& Ringsted C. What is the role of the consultant responsible for postgraduate education in the clinical department? Med Teach, 2007; 29: 471-78.

14. Lobas JG. Leadership in Academic Medicine: Capabilities and conditions for Organizational success. Am J Med, 2006; 119: 617-21.

15. Rooke D \& Torbert WR. The seven transformations of leadership. Harvard Business Rev, 2005; April: 67-76.

16. Bracken DW, Timmreck CW \& Church AH. Eds. The handbook of multisource feedback. The comprehensive resource for designing and implementing MSF processes. San Francisco: Jossey-Bass Inc.; 2001.

17. College of physicians and surgeons of Alberta - Physician Achievement Review Program. http/ www.par-program.org [Accessed 31 January 2008]

18. National Health Service. NHS Leadership Qualities Framework. http:/ www.nhsleadershipqualities.nhs.uk . [Accessed 31 January 2008]

19. Borman WC \& Brush DH. More progress toward a taxonomy of managerial performance requirements. Hum Perform, 1993; 6: 1-21.

20. Scullen SE, Mount MK \& Judge TA. Evidence of the construct validity of developmental ratings of managerial performance. J Appl Psych, 2003; 88: 50-66.

21. Lockyer J, Violato $C$ \& Fidler $\mathrm{H}$. Likelihood of change: a study assessing surgeon use of multisource feedback data. Teach Learn Med, 2003; 15: 168-74.

22. Van Rensburg T \& Prideaux G. Turning professionals into managers using multisource feedback. J Manag Dev, 2006; 25: 561-71.

23. Sargeant J, Mann K, Sinclair D, Van der Vleuten CPM \& Metsemakers J. Challenges in multisource feedback: intended and unintended outcomes. Med Educ, 2007; 41: 583-91.

24. Smither JW, London M \& Reilly RR. Does performance improve following multisource feedback? A theoretical model, meta-analysis, and review of empirical findings. Pers Psych, 2005; 58: 33-66. 
25. McKimm J \& Swanwick T. Educational Leadership. Understanding Medical Education Series. Edinburgh (UK): Association for the Study of Medical Education; 2007

26. Souba WW. New ways of understanding and accomplishing leadership in academic medicine. J Surg Res, 2004; 117: 177-86.

27. Naylor CD. Leadership in academic medicine: reflections from administrative exile. Clin Med, 2006; 6: 488-492.

28. Steinert Y, Nasmith L, McLeod PJ \& Conochie L. A Teaching Scholars Program to Develop Leaders in Medical Education. Acad Med, 2003; 78: 142-49.

29. Wong JG, Fagan M \& Pinsker J. Expectations of and for the medical director of the resident's ambulatory clinic. Am J Med, 2001; 111: 84-7.

30. Pope C, Ziebland S \&nd Mays N. Qualitative research in health care: Analysing qualitative data. BMJ, 2000; 320, 114-116. 



\section{CHAPTER 5}

Combining a leadership course and multisource feedback has no effect on leadership skills of leaders in postgraduate medical education. An intervention study with a control group 


\begin{abstract}
Background: Leadership courses and multi-source feedback are widely used developmental tools for leaders in health care. On this background we aimed to study the additional effect of a leadership course following a multi-source feedback procedure compared to multi-source feedback alone especially regarding development of leadership skills over time.
\end{abstract}

Methods: Study participants were consultants responsible for postgraduate medical education at clinical departments. Study design: pre-post measures with an intervention and control group. The intervention was participation in a seven-day leadership course. Scores of multi-source feedback from the consultants responsible for education and respondents (heads of department, consultants and doctors in specialist training) were collected before and one year after the intervention and analysed using Mann-Whitney's U-test and Multivariate analysis of variances.

Results: There were no differences in multi-source feedback scores at one year follow up compared to baseline measurements, either in the intervention or in the control group $(p=0.149)$.

Conclusions: The study indicates that a leadership course following a MSF procedure compared to MSF alone does not improve leadership skills of consultants responsible for education in clinical departments. Developing leadership skills takes time and the time frame of one year might have been too short to show improvement in leadership skills of consultants responsible for education. Further studies are needed to investigate if other combination of initiatives to develop leadership might have more impact in the clinical setting. 


\section{Background}

Postgraduate medical education (PGME) usually takes place at many clinical departments in both university and non-university hospitals (1-3). The increasing demands to PGME in the clinical departments at hospitals have made it necessary to appoint leaders of PGME at every training site $(1,3)$.

The expectations of the leader of PGME in the clinical departments are high and they vary across stakeholders according to their position in the department (3). Although the various stakeholders have only limited knowledge of the role of leaders in PGME, they suggest formal leadership education to meet the expectations (3).

Although it has recently been questioned it is still the general opinion that education of leaders results in improvement of leaders' performance (4-7), especially if the content of the leadership courses relates to the organisation the leader works in (5-8). Many authors have suggested the use of a combination of methods to develop leadership skills (4- 9). McKimm used a combination of a leadership course and mentoring in a program for leaders in health and social care education (4). Mintzberg advocated for a combination of personal development, leadership courses and experience by linking the leadership courses to practice in real or simulated situations (8). In other organisations than health care it has been suggested to combine leadership courses with multi-source feedback (MSF) or other initiatives supposed to initiate personal development in coherence with development of the organisation $(7,9)$.

We have previously demonstrated that MSF used by consultants responsible for PGME at clinical hospital departments resulted in clear and concrete plans for improvement of management skills, while plans for development of leadership skills and hence personal development were scarce and less concrete. These difficulties in formulating goals and plans for personal development were interpreted by stakeholders as a need for further initiatives to support leadership development (10).

On this background we aimed to study the effect of a leadership course following a MSF procedure compared to MSF alone especially regarding development of leadership skills over time.

\section{Methods}

\section{Context of the study}

Postgraduate medical education in Denmark is governed by the Danish National Board of Health. In clinical departments participating in PGME it is mandatory to appoint a consultant responsible for education (CRE). A number of different PGME 
programmes run in each clinical department and the CRE is thus responsible for a highly diverse group of young doctors in specialist training (trainees).

\section{Study design}

The study was a non-randomised intervention study with a control group. The intervention was participation in a leadership course designed for CREs in clinical departments. Both participants in the intervention group (I-group) and the control group (C-group) went through a MSF procedure including personal feedback at baseline (MSF-I). Only the I-group participated in the leadership course following the baseline MSF procedure. One year after the intervention MSF procedure was repeated (MSF-II) in both the I-group and the C-group.

Effect was measured by change in MSF scores from CREs and from the following respondents: The head of department, the clinical consultants, and the trainees in the department. The CRE chose at least three consultants and three trainees to secure anonymity.

The study was presented to the ethical committee for Viborg and Aalborg County. In our jurisdiction studies of this kind do not need approval.

\section{Measuring instrument}

The MSF instrument was developed for CREs in clinical departments and the validation has been described in a previous study (10). The MSF instrument comprised 69 statements divided into four categories: 1) Technical skills, referring to the CRE's proficiency in specific methods, processes and techniques; 2) Human skills, including the ability to work with and through people to meet goals; 3) Citizenship behaviour, professionalism regarding interpersonal, organisational and job/task performance; 4) Administrative skills, involving knowledge of the organisation, planning, organising and coordinating the tasks of a CRE. Statements in technical skills, human skills and citizenship behavior comprise leadership while administrative skills refer to management. Each statement was scored on a seven-point Likert scale (One = "not at all" and seven = "always"). The option "not able to answer" was provided. An email based electronic system (Enalyzer ${ }^{\circledR}$ ) was used. The MSF instrument is provided in appendix 1.

A report on the CRE's self-ratings compared to respondents' rating was provided together with individual personal feedback by an experienced human resource consultant. The CRE was expected to make a plan for development of PGME in the department as well as for personal development of leadership skills based on the report and the feedback session. 


\section{Participants}

The investigations took place in the Northern Educational Region in Denmark, where a leadership course designed for CREs was offered to all CREs in the region. The Northern Educational Region comprise one third of the country. There are both university and non-university hospitals in the region and all medical specialties are represented. A convenience sample of CREs, who were included in two consecutive leadership courses constituted the I-group. CREs would have to come from clinical departments with more than three consultants in addition to the head of the department and more than three trainees to fulfill the inclusion criteria. The C-group consisted of 28 CREs from matched departments regarding size and specialty. None of the CREs in the C-group participated in the leadership course during the study period. All participants were contacted by phone and informed about the study and the MSF procedure. Confidentiality was guaranteed and participants were assured that it would be impossible to trace findings to individual participants, clinical departments or hospitals. After one year we excluded the CREs who had not completed either MSF-I or the leadership course as well as those who no longer held a position as a CRE.

\section{The course}

The themes in the leadership course emerged from results of a needs assessment study (3), the general job description for CREs made by the Danish National Board of Health, and a literature study on leadership. The themes are shown in Table 1 . The leadership course was divided into three modules: two three-day residential modules and a follow-up day.

The course was held over a period of six months. Included in the course were two mandatory assignments: the first assignment was a general plan for one of the PGME programs in the department, the second was a five-year overall developmental plan for all PGME programs including possibilities in the department and possible barriers to implementation. The assignments were supposed to initiate reflection on own practice and hence combine the leadership course with real life experience.

The course was evaluated by the participants in four areas: 1 ) if the course met participants expectations, 2 ) if the content was relevant for the daily work as a CRE, 3) perceived benefits from attending the course and 4) perceived learning outcome. The four areas were scored on a four-point scale ranging from one = "not at all" to four = "to a high degree". 
Table 1. Themes in the leadership course designed for consultants responsible for education at departmental level (CRE).

\begin{tabular}{|c|c|}
\hline \multirow[t]{4}{*}{ Pedagogical knowledge } & Principles of teaching and learning in clinical setting \\
\hline & How to teach teachers and supervisors \\
\hline & Various teaching methods \\
\hline & Group dynamics \\
\hline \multirow[t]{3}{*}{ Organization of specialist training } & Laws, rules and regulations \\
\hline & Tasks and responsibilities of the CRE \\
\hline & Handling problem-trainees \\
\hline \multirow[t]{2}{*}{ Educational culture } & Factors influencing the educational culture \\
\hline & How to influence the educational culture \\
\hline \multirow[t]{2}{*}{ Evaluation and quality assurance } & In-training assessment \\
\hline & Internal and external evaluation \\
\hline \multirow[t]{3}{*}{ Planning specialist training in the department } & Effective teaching methods \\
\hline & Integrating education and the working schedule \\
\hline & Administrative tasks of a CRE \\
\hline \multirow[t]{4}{*}{ Supervision of supervisors } & Consultation skills \\
\hline & How to supervise peers \\
\hline & Power relations in the department \\
\hline & Appreciative inquiry and other methods \\
\hline \multirow[t]{4}{*}{ Implementation strategies } & Change management \\
\hline & Project management \\
\hline & Implementation of new initiatives \\
\hline & Strategic communication \\
\hline Personal development & Personal development plan \\
\hline \multirow[t]{3}{*}{ Leadership in specialist training } & Motivating and enabling \\
\hline & Role modeling \\
\hline & Conflict resolution \\
\hline \multirow[t]{2}{*}{ Research in medical education } & Best evidence medical education \\
\hline & Knowing the literature \\
\hline
\end{tabular}

\section{Statistics}

Mean of scores from CREs and MSF respondents were calculated. If a score was missing it was replaced by a mean of all other scores in the same category from the same respondent. A multivariate analysis was used to compare effect of a combination of MSF and a leadership course to the use of MSF alone. Covariant factors investigated were 1) respondent type (CRE or MSF respondents), 2) level of baseline MSF scores and 3) change in scores from baseline to one year after. MannWhitney's U-test was used to compare baseline scores in I-group and C-group and to compare completers and dropouts in the C-group. A p-value $<0.05$ was considered significant. 


\section{Results}

Figure 1 show the total number of CREs included in the study, the response rate and the number of CREs who dropped out or were excluded before MSF-II. Participants represented 16 of the 37 specialties in Denmark. Participants' evaluated the leadership course highly regarding relevance and perceived learning, see Table 2 .

Table 2. Evaluation of a leadership course rated by $40 / 42$ consultants responsible for education at clinical departments. Evaluations are expressed as mean (SD) within four areas, and are rated by participants on a four-point scale ranging from 1 = "not at all" to 4 = "to a high degree".

\begin{tabular}{ll}
\hline & Mean (SD) \\
\hline The course met my expectations & $3.4(0.2)$ \\
Course content relevant for my daily work as a CRE & $3.4(0.2)$ \\
I benefited from attendance & $3.3(0.2)$ \\
I learned from participation & $3.2(0.2)$ \\
\hline
\end{tabular}

Table 3 shows the MSF mean scores with SD of CREs and respondents from I-group and C-group respectively. Scores are shown for baseline and one year after the intervention. At baseline there were no differences in MSF scores between the Igroup and the C-group in the scores from the CREs and respondents respectively.

Table 3. Number of consultants responsible for education at clinical departments (CRE) and respondents in a multi-source feedback procedure (MSF) at baseline (MSF-I) and one year after the intervention group completed a leadership course (MSF-II). Mean MSF score (SD) for CREs and respondents are shown for the intervention and control groups (scale $1-7)$.

\begin{tabular}{lllll}
\hline & \multicolumn{2}{l}{ Intervention group } & \multicolumn{2}{l}{ Control group } \\
\hline & CREs & Respondents & CREs & Respondents \\
Completed MSF-I (N) & 27 & 288 & 15 & 131 \\
Completed MSF-II (N) & 20 & 217 & 9 & 72 \\
& Mean (SD) & Mean (SD) & Mean (SD) & Mean (SD) \\
MSF score & & & & \\
Baseline & $5.5(0.7)$ & $5.6(0.5)$ & $5.4(0.5)$ & $5.5(0.5)$ \\
One year after & $5.8(0.6)$ & $5.6(0.5)$ & $5.5(0.5)$ & $5.7(0.5)$ \\
\hline
\end{tabular}

There was no difference in MSF scores for completers and dropouts in the C-group at baseline. The covariance analysis showed no statistical difference between Igroup and C-group considering measurements at baseline and one year after $(\mathrm{p}=$ 0.149) when respondent type, level of baseline score and change in C-group from baseline to one year after was taken into account. 


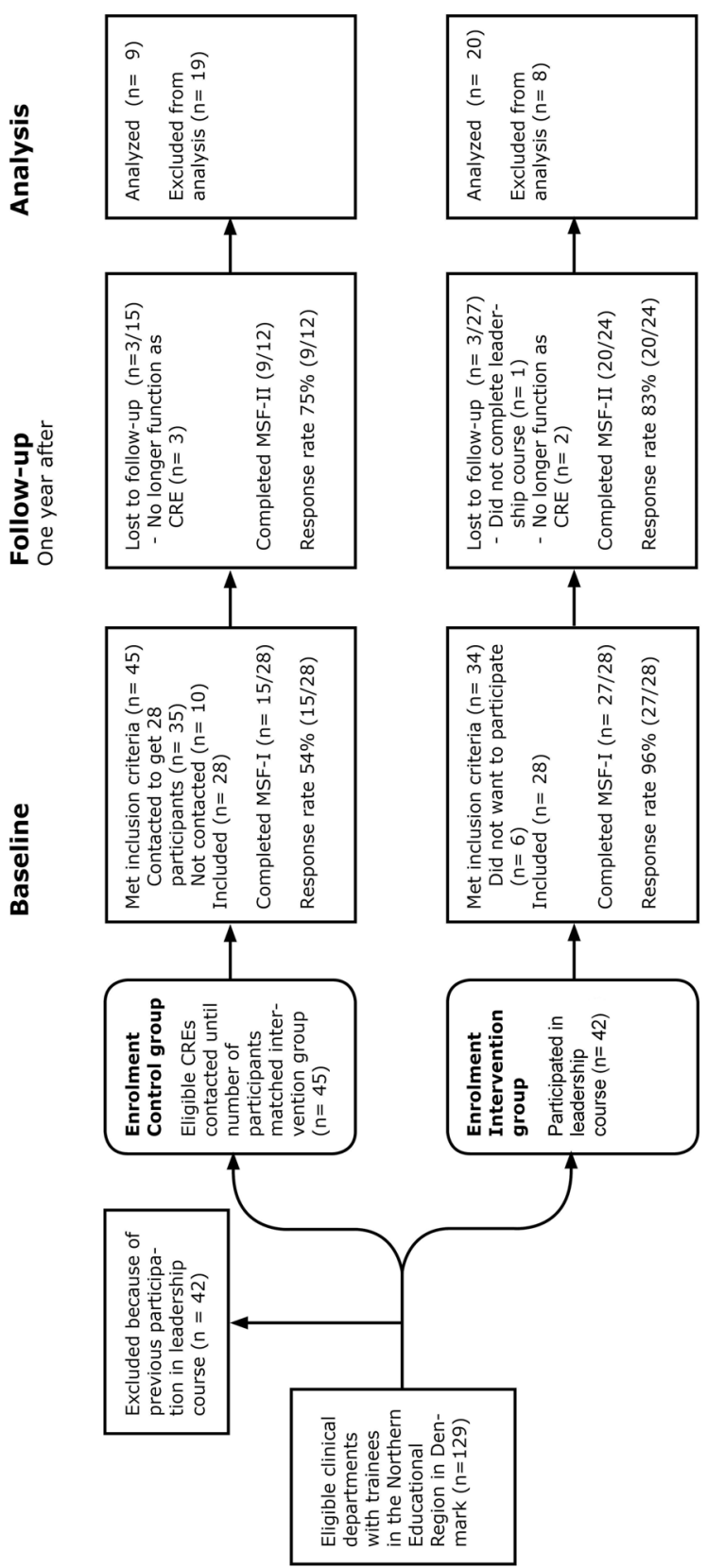

Figure 1. Flowchart of the study. The number of consultants responsible for postgraduate medical education in clinical departments (CRE) included in the intervention and the control group. Intervention was a seven-day leadership course combined with a multisource feedback procedure before (MSF-I) and one year after (MSF-II) participation in the course. The control group went through both MSF-I and MSF-II. Response rate for CREs in both MSF-I and MSF-II is provided. 


\section{Discussion}

In this study the effect of a leadership course for consultants responsible for education in clinical departments following a MSF procedure was compared to MSF alone especially regarding development of leadership skills over time. Surprisingly, the study did not show the expected effect of a combination of a leadership course and MSF compared to MSF alone. In the following we first discuss various validity threats to our results including selection biases, problems of study design and instrumentation. Next we discuss various explanations of the un-expected results.

The use of a convenience sample of course participants may be a limitation in this study. The leadership course was offered to all CREs in the Northern Educational Region. Thus although all CREs in the region had the opportunity to participate in the course we cannot exclude a selection-bias in our sample, who represented those CREs who voluntarily signed up for the course. However, no difference in MSF scores was found between the I-group and C-group at baseline indicating that the groups were comparable.

The high drop-out rate especially in the C-group reflects the difficulties in recruiting busy clinicians to studies of this kind which included a time consuming MSF procedure. Another explanation to the high drop-out rate in the C-group might be that participants in this group were not supported in the same way as participants in the l-group who all passed through a course where they got help to solve various problems in their daily leadership of PGME in the departments. Therefore the motivation to complete the MSF-II procedure might have been much higher in the Igroup than in the C-group who only got a phone call asking them to complete the MSF once more. Hence the C-group who completed the second MSF procedure might be the most enthusiastic CREs; they might be the CREs who actively seeks personal development. A selection-bias of this kind could have reduced the differences between the I-group and the C-group. However, at baseline, the MSF scores of participants from the C-group who completed both MSF procedures and scores of dropouts did not differ indicating that the influence of the high dropout might be small.

MSF in itself is an intervention intended to improve leaders' performance and hence the use of MSF as a measuring instrument might have been problematic. However, the results of the C-group do not indicate a major influence of the MSF procedure in itself. This is in accordance with our previous study where the development plans for CREs were not representative for areas needing improvement (10). At baseline, both the scores of CREs and respondents are quite high and a ceiling effect cannot be ruled out.

Pooling the scores from respondents (the head of the department, the other consultants and the trainees in the department) into one score might have blurred the results, since it is well known that there are different perspectives on leaders' 
performance according to the position you hold in the organization (chief, peer, subordinate), and since the perception of the concept "good leader" varies among stakeholders $(6,11)$. According to a previous study, stakeholders' knowledge of the job as CRE is scarce and the expectations to the CRE as leader of the medical education in the department differs according to stakeholders' position in the department (3). However, it has been shown that these different expectations did not result in differences in the various stakeholders' scoring in a MSF process (10). We therefore feel confident in pooling the results from various stakeholders into one score of respondents for each CRE.

The second MSF was performed one year after the CREs participated in the leadership course. It is generally agreed that repeated MSF processes would eventually improve leaders' performance (11-14). However, some describe that a timespan of one year is too short to detect any improvement in MSF scores $(12,13)$. It might therefore have been interesting to see if improvement in leadership skills of the CRE could be detected if the MSF procedure was repeated after 2-3 years, since developing as a leader is a time-consuming process and initiating changes in a highly bureaucratic organization is a slow process (6). However, expanding the study period to more than one year might also have been problematic and might have resulted in even higher drop-out rates than was actually found.

The participants in our study came from both university and non-university hospitals and represented a variety of specialties. This supports the generalisability of the results within the domain of medical education. However, as both the instrument and the leadership course were tailored to CREs it is questionable whether results can be translated into health care leaders in general or to other domains of organisations.

Despite the limitations of the study we feel confident in concluding that the impact of leadership courses on performance in actual practice must be disputed. Previous studies have mainly described a positive effect of courses on leaders' knowledge and performance based on self-reported data $(15,16)$. The well-known gap between knowing and doing might be reflected in our study where the stakeholders' ratings do not indicate any improvement in leader performance, while at the same time participants in the study reported to have learned from the course. Some of the factors influencing this knowing-doing gap include physician barriers (peer influence and inertia), organizational barriers, and support / resource barriers $(17,18)$. In a previous study it was described how the CRE is considered to be in a weak position regarding influence and power, and how difficult it is for the CRE to take on a leadership role due to various environmental factors like peer influence, his place in the hierarchy and the general inertia existing for developmental initiatives in hospitals. (3). When evaluating course effects factors such as support and follow-up from superiors, openness to change and new knowledge in the organization, stability and resources in the organization, and the possibility to practice what 
has been learned should be considered $(15,18,19)$. In addition when studying the effect of MSF procedures environmental factors like feedback orientation, organisational cynicism, how MSF fits into other developmental initiatives and stability in the organisation must be considered $(11,13)$.

Further investigations are needed to explore the degree to which the clinical department supports the leaders of PGME and to investigate the relations between the culture in the department and the opportunity for CREs to display leadership skills.

\section{Conclusions}

In this study the effect of a leadership course following a MSF procedure compared to MSF alone regarding development of leadership skills of consultants responsible for education at clinical department was investigated. Although participants reported to have learned from the leadership course no improvement was found. Various explanations like lack of organisational support and the culture in the departments might be speculated. Further studies are needed to investigate the role of environmental and other factors on leadership development in CREs. 


\section{References}

1. Beauchamp RD. The changing roles of a surgical department chair. Adapting to a changing environment. Arch Surg, 2005; 140: 258-63.

2. Cooke M, Irby DM, Sullivan W \& Ludmerer KM. American medical education 100 years after the Flexner report. N Engl J Med, 2006; 355: 1339-44.

3. Malling B, Scherpbier AJJA \& Ringsted C. What is the role of the consultant responsible for postgraduate education in the clinical department? Med Teach, 2007; 29: 471-77.

4. McKimm J. Developing tomorrow's leaders in health and social care education. Special report No 5. Case Studies in leadership in medical and health care education. FDTL4 Leadership development programme. The Higher Education Academy, Newcastle upon Tyne, UK; 2004.

5. Lobas JG. Leadership in academic medicine: Capabilities and conditions for organizational success. Am J Med. 2006; 119: 617-21.

6. Yukl G. Leadership in organizations. 6th ed. Upper Saddle River, New Jersey: Pearson Education Inc.; 2006.

7. Quatro SA, Waldman DA \& Galvin BM. Developing holistic leaders: Four domains for leadership development and practice. Hum Res Manag Rev, 2007; 17: 427-41.

8. Mintzberg H. The manager's job: Folklore and facts. Harvard Business Rev, 1990: 163-76.

9. Day DV \& Harrison MM. A multilevel, identity-based approach to leadership development. Hum Res Manag Rev, 2007; 17: 360-73.

10. Malling B, Bonderup T, Mortensen L, Ringsted C \& Scherpbier AJJA. Effect of multi-source feedback on developmental plans for leaders of postgraduate medical education. Med Educ, 2009; 43: 159167.

11. Bracken DW, Timmreck CW \& Church AH. Eds. The handbook of multisource feedback. The comprehensive resource for designing and implementing MSF processes. San Francisco: Jossey-Bass Inc.; 2001.

12. Atwater LE, Brett JF \& Charles AC. Multisource feedback: Lessons learned and implications for practice. Hum Res Manag, 2007; 46: 285-307.

13. Walker AG \& Smither JW. A five-year study of upward feedback: What managers do with their results matters. Pers Psych, 1999; 52: 393-423.

14. Lockyer JM, Violato C \& Fidler HM. What multisource feedback factors influence physician selfassessments? A five-year longitudinal study. Acad Med, 2007; 82: S77-S80.

15. Saleh SS, Williams D \& Balougan M. Evaluating the effectiveness of public health leadership training: The NEPHLI experience. Am J Pub Health, 2004; 94: 1245-49.

16. Steinert Y, Nasmith L, McLeod PJ \& Conochie L. A teaching scholars program to develop leaders in medical education. Acad Med, 2003; 78: 142-49.

17. Cochrane L, Olson CA, Murray S, Dupuis M, Tooman T \& Hayes S. Gaps between knowing and doing: Understanding and assessing the barriers to optimal health care. J Contin Educ Health Prof, 2007; 27: 94-102.

18. Brinkerhoff RO \& Apking AM. High Impact Learning. Strategies for leveraging business results from training. New perspectives in organizational learning, performance and change. New York: Basic books; 2001.

19. Tannenbaum SI \& Yukl G. Training and development in work organizations. Annu Rev Psychol, 1992; 43: 399-441. 


\section{CHAPTER 6}

\section{Issues of governance in postgraduate medical education. A curriculum analysis}




\begin{abstract}
Postgraduate medical education (PGME) and clinical service are inseparable and interdependent. The purpose of this study was to explore the impact of governance issues on clinical work-based PGME. The study was an instrumental case-based study of the Danish PGME curriculum using Posner's model for curriculum analysis as a guiding framework. Results were put into perspective with international PGME curricula.

The governance of PGME is characterised by being complex, holding many traditions, and being comprised of many stakeholders with heterogeneous interests. A skewed power balance in favour of administration compared to pedagogic influence seems to have developed. Furthermore work-based PGME inside the clinical departments appears to be managed by outside bodies.

There are discrepancies between the curriculum on paper describing the competent physician in separable roles or competencies, and the curriculum in use, which takes clinical situations embracing all roles as the point of reference. While the structural changes according to PGME reforms are well implemented, cultural changes and especially in-training assessment are lagging behind. There is a lack of instructional programmes and strategies to support the complex learning in workbased education.

Discrepancies between the curriculum on paper and the curriculum in use might in part be explained by the complex governance of PGME on both micro- and macro-level.
\end{abstract}




\section{Introduction}

Worldwide educators and clinicians in postgraduate medical education (PGME) are challenged with the introduction of outcome-based education (OBE) and in-training assessment (ITA) (1). In OBE core competencies are defined by describing the competent (good) physician and what he should be able to do (2 - 6). Although the frameworks for describing the core competencies are slightly different the content is quite similar (Table 1 ).

However, there seem to be problems internationally with the implementation of OBE. (7 - 15). There is a wide acceptance of the roles or core competencies (7 - 9, 16), but still some uncertainty about how to implement these roles in educational programmes $(7,11,13,17)$. The implementation of ITA is especially troublesome $(8$, $9,14)$, although some cases of successful implementation have been reported (18, 19). Implementation problems have been ascribed to poor staff development (12, $14)$, common resistance to changes (20) and a culture not ready for change $(10,15)$. However there might be some crucial issues regarding the complexity of the workbased nature of PGME and its governance that contribute to implementation difficulties.

The aim of the study was to explore the influence of governance issues on clinical work-based PGME. The research questions were:

1. What characterises the governance of PGME?

2. What underlying assumptions and epistemologies are reflected in the content and organisation of OBE curricula on paper?

3. What characterises the curricula in use, enabling factors and barriers? 
Table 1. Content of the curriculum developed in United States of America (US), United Kingdom (UK) and Canada (CAN). The table describes the authorities behind the curriculum and the core competencies that the curriculum is built upon.

\begin{tabular}{|c|c|c|}
\hline US & UK & CAN \\
\hline $\begin{array}{l}\text { ACGME } \\
\text { ABMS }\end{array}$ & $\begin{array}{l}\text { MMC } \\
\text { PMETB }\end{array}$ & RCPSC \\
\hline $\begin{array}{l}\text { Six core competencies } \\
\text { - Patient care } \\
\text { - Medical knowledge } \\
\text { - Practice-based learning and } \\
\text { improvement } \\
\text { - Interpersonal and communi- } \\
\text { cation skills } \\
\text { - Professionalism } \\
\text { - Systems-based practice }\end{array}$ & $\begin{array}{l}\text { Good medical practice } \\
\text { - Technical skills (medical expert) } \\
\text { - Non-technical skills } \\
\text { - Professionalism } \\
\text { - Communication } \\
\text { - Leadership and management and } \\
\text { teamwork } \\
\text { - Patient safety } \\
\text { - Research } \\
\text { - Education and teaching } \\
\text { - Integration of a balance of techni- } \\
\text { cal and non-technical skills }\end{array}$ & $\begin{array}{l}\text { CanMEDS } 7 \text { roles } \\
\text { - Medical expert } \\
\text { - Communicator } \\
\text { - Collaborator } \\
\text { - Manager } \\
\text { - Health Advocator } \\
\text { - Scholar } \\
\text { - Professional } \\
\text { CanMEDS roles revised in } 2005 \\
\text { to increase integration be- } \\
\text { tween roles and to accentuate } \\
\text { the ethical perspective }\end{array}$ \\
\hline
\end{tabular}

ACGME: Accreditation Council for Graduate Medical Education; ABMS: American Board of Medical Specialties; MMC: Modernising Medical Careers; PMETB: Postgraduate Medical Education and Training Board; RCPSC: Royal College of Physicians and Surgeons of Canada; CanMEDS: Canadian Medical Education Directions for Specialists.

\section{Methods}

An instrumental case-based study of the PGME curriculum in Denmark was performed using Posner's four-step model for curriculum analysis (21) as a guiding framework. The analysis was entirely based on documents. Results were put into the perspective of international curricula.

The first step was an analysis of 'Curriculum origins' including reasons for development of the curriculum and the resulting rules and regulations. The second step was 'The curriculum on paper' in which the assumptions and epistemologies of the purpose, content, and organisation of the curriculum was explored. In the third step, 'The curriculum in use', the implementation and evaluation of the curriculum were investigated. Finally, in the fourth step 'Summary' a synthesis of the findings in steps one to three was performed and a model of power-relations in the governance of PGME described. 


\section{Results}

The documents used in the analysis are listed in table 2, categorised according to the steps in the analysis.

Table 2. List of documents used in analysis of Danish postgraduate medical curriculum.

\begin{tabular}{ll}
\hline $\begin{array}{l}\text { Curriculum } \\
\text { origins }\end{array}$ & The Danish Ministry of Health. (2006). Bekendtgørelse om de regionale råd for lægers \\
& videreuddannelse. Bekendtgørelse nr. 1706 af 20/12/2006. [Executive order on \\
& Regional Educational Councils in specialist training]. Retrieved 2. August, 2010 from \\
& www.sundhedsstyrelsen.dk. In Danish. \\
& The Danish Ministry of Health. (2006). Bekendtgørelse om opgaver og \\
& forretningsorden for det nationale råd for lægers videreuddannelse. Bekendtgørelse \\
& nr. 1707 af 20/12/2006. [Executive order on the Composition of the National Educa- \\
& tional Council in specialist training]. Retrieved 2. August, 2010 from \\
& www.sundhedsstyrelsen.dk. In Danish.
\end{tabular}

The Danish Ministry of Health. (2006). Bekendtgørelse om sammensætningen af det nationale råd for lægers videreuddannelse. Bekendtgørelse nr. 1726 af 21/12/2006. [Executive order on the Order of Business for the National Educational Council in specialist training]. Retrieved 2. August, 2010 from www.sundhedsstyrelsen.dk. In Danish.

The Danish Ministry of Health. (2000) Fremtidens speciallæge. Betænkning fra speciallægekommissionen. Betænkning nr. 1384 ["The future Specialist". Report and recommendation on specialist training. Report no. 1384]. (Copenhagen, Denmark, GS Grafik ApS). In Danish.

The Danish Ministry of Health. (2007). Bekendtgørelse om uddannelse af specialæger. Bekendtgørelse nr. 1257 af 25/10/2007. [Executive order on Specialist Training]. Retrieved 2. August, 2010 from www.sundhedsstyrelsen.dk. In Danish.

Curriculum on paper
Blue-prints from the specialties: Cardiology, Rheumatology, Infectious Medicine, Orthopedic surgery, Surgery, Thoracic surgery, Anaesthesiology, Radiology and Microbiology.

Davis, D. J., Ringsted, C. V. (2004). Akkreditering af lægelig videreuddannelse. En sammenligning af forskellige kvalitetssikringssystemer. [Accreditation of specialist training. Comparing various quality assurance systems] Ugeskrift for Læger, 166/21, 2044-2046. In Danish.

Davis, D.J., Ringsted, C., Bonde, M., Scherpbier, A. \& Van der Vleuten, C. (2009). Using participatory design to develop structured training in child and adolescent psychiatry. European Child Adolescence Psychiatry,18, 33-41.

Educational progammes from the specialties: Cardiology, Rheumatology, Infectious Medicine, Orthopedic surgery, Surgery, Thoracic surgery, Anaesthesiology, Radiology and Microbiology. 
Frank, J.R. (Eds.) (2005). The CanMEDS 2005 Physician Competency Framework. Better standards, Better physicians. Better care. Ottawa: The Royal College of Physicians and Surgeons in Canada. Retrieved 10 January 2010 from www.rcpsc.medical.org

Malling, B. (2003). CRE. The consultant responsible for education. Framing the function and mapping the educational needs. Masterthesis, Maastricht University.

Malling, B., Scherpbier, A. J. J.A. \& Ringsted, C. (2007a). What is the role of the consultant responsible for postgraduate education in the clinical department? Medical Teacher, 29, 471-477.

Qvesel, D. Beslutningsgrundlag for strukturændringer i sygehusvæsenet - med focus på akutberedskabet. [Decision making in health care - focus on the emergency alertness]. Masterthesis, Odense University. In Danish.

Ravn, L. I. (2004). Vejlederfunktionen i den nye speciallægeuddannelse. [The role of the educational supervisor in the new postgraduate medical curriculum]. Ugeskrift for læger, 166/21, 2020-2022. In Danish.

Regional PGME Council, Region North. (2009). Specifikke Uddannelsesporgrammer. [Specific Educational Programs for educational courses]. Retrieved 10. September 2009 from www.videreuddannelsen-nord.dk. In Danish.

Ringsted, C., Østergaard, D. \& Scherpbier, A. (2003). Embracing the new paradigm of assessment in residency training. An assessment programme for first-year residency training in anaesthesiology. Medical Teacher, 25, 54-62.

Ringsted, C., Skaarup, A. M., Henriksen, A. H. \& Davis, D. (2006). Person-task-context: a model for designing curriculum and in-trtaining assessment in postgraduate education. Medical Teacher, 28, 70-76.

Ringsted, C., Skjelsager, K., Bested, K., Malling, B. \& Østergaard H. T. Håndbog for uddannelsen i anæstesiologi. Om målbeskrivelser, portefølje,

uddannelsesprogrammer og -planer, kompetencevurdering og andet. [Handbook for PGME and ITA in Anaesthesiology]. www.dasaim.dk . In Danish.

Royal College of Physicians and Surgeons of Canada. (1996). Skills for the new millenium: report of the societal needs working group. Retrieved 10. September, 2009 from www.rcpsc.medical.org .

The Danish Ministry of Health. (2008). Vejledning om kompetencevurdering i den lægelige videreuddannelse. Vejledning nr. 9586 af 14/07/2008. [Guidance on intraining assessment in specialist training]. Retrieved 10. September, 2009 from www.sundhedsstyrelsen.dk. In Danish.

The Danish Ministry of Health. (2008). Vejledning om uddannelsesprogrammer i den lægelige videreuddannelse. Vejledning nr. 9587 af 27/08/2008. [Guidance on Educational Programmes in specialist training]. Retrieved 10. September, 2009 from www.sundhedsstyrelsen.dk. In Danish.

The Danish Ministry of Health. (2008). Vejledning om revision af målbeskrivelser i 
speciallægeuddannelsen. Vejledning nr. 9288 af 30/06/2008 [Guidance for revision of blueprints in specialist training]. Retrieved 10. September, 2009 from www.sst.dk. In Danish.

The Danish National Board of Health. (1998). Vejledning og evaluering i den lægelige videreuddannelse. Struktur, retningslinier og ansvarsfordeling. [Guidance and evaluation in the training of specialists in Denmark. Structure, instructions and disposition of responsibility]. (DNBH Publications). In Danish.

The Danish National Board of Health. (2001). Retningslinier for udarbejdelse af: Målbeskrivelser og logbøger [Guidelines for writing curricula and portfolios]. Retrieved 10. September, 2009 from www.sst.dk. In Danish.

The Danish National board of Health. (2004). Generelle kurser i den lægelige videreuddannelse. Sundhedsstyrelsens vejledning. [Guidance for establishing courses in postgraduate medical education]. Retrieved 10. September, 2009 from www.sst.dk. In Danish.

The Danish National board of Health. (2008). Vejledning om udarbejdelse af uddannelsesprogrammer i den lægelige videreuddannelse. Vejledning nr. 9587 af $14 / 07 / 2008$. [Guidelines for educational programmes in postgraduate medical education]. Retrieved 10. September, 2010 from www.sst.dk. In Danish.

The Danish National board of Health. (2004). Retningslinier for udfærdigelse af portefølje i speciallægeuddannelsen. [Guidelines for development of portfolios in specialist training]. Retrieved 10. September, 2006 from www.sst.dk. In Danish.

The Danish National board of Health. (2004). Specialespecifikke kurser i den lægelige videreuddannelse. [Guidance for specialty specific courses in postgraduate medical education]. Retrieved 10. September, 2009 from www.sst.dk. In Danish.

The Danish National board of Health. (2005). Sundhedsstyrelsens vejledning for den obligatoriske forskningstræning i speciallægeuddannelsen. [Guidance for mandatory research training in specialist training]. Retrieved 10. September, 2006 from www.sst.dk. In Danish.

The Danish National board of Health. (2009). Målbeskrivelser i speciallægeuddannelsen. [Blue-prints in specialist training]. Retrieved 10. September, 2009 from www.sst.dk. In Danish.

The Danish Society of Anaesthesiology and Intensive Medicine (2007). Portefølje for hoveduddannelsen i anæstesiologi. [Portfolio and ITA-program for Anaesthesiology]. Retrieved 10. September, 2009 from www.dasaim.dk. In Danish. 
Curriculum in use Bayer, M. (2007). Speciallægeuddannelse i Danmark-en empirisk undersøgelse af tendenser inden for speciallægeuddannelsen efter implementeringen af den nye speciallægeuddannelse. [Specialist training in Denmark - an empirical analysis of tendencies in specialist training after implementation of the new reform]. København, Danmarks Pædagogiske Universitets forlag. In Danish.

Davis, D. J., Skaarup, A. M. \& Ringsted, C. (2005). A pilot study of junior doctors' confidence in tasks related to broad aspects of competence. Medical Teacher,27, 548552.

Dehn, P., Nielsen, C. H., Larsen, K. \& Bayer, M. (2009). Implementering af speciallægereformens syv roller. [Implementing the seven roles of the specialist training reform]. Ugeskrift for Læger, 171/19: 1580-1584. In Danish.

Eriksen, G. (2009). Reformen af den lægelige videreuddannelse i Danmark - et udviklingsprojekt med muligheder for forbedringer - men hvad skal der til? [The reform of specialist training in Denmark - a development project with possibilities of improvement - but what is needed?]. Masterthesis. Master of Public Management, Odense, Denmark. In Danish.

Lillevang, G., Bugge, L., Beck, H., Joost-Rethans, J. \& Ringsted, C. (2009). Evaluation of a national process of reforming curricula in postgraduate medical education. Medical Teacher, 31, e260-e266.

Malling, B., Bested, K. M., Skjelsager, K., Østergaard, H. T. \& Ringsted, C. (2007). Longterm effect of a course on in-training assessment in postgraduate specialist education. Medical teacher, 29, $966-971$.

Mortensen, L., Malling, B., Ringsted, C. \& Rubak, S. (2010). What is the impact of a national postgraduate medical specialist education reform on the daily clinical training 3.5 years after implementation? A questionnaire survey. BMC Medical Education, 10: 46 .

Ravn, L. I. \& Lund, C. M. (2004). Flyvefærdighedsplanen - en struktureret, accelereret introduktion. [A clinical skills training program - a structured, accelerated introduction]. Ugeskrift for læger, 166/21, 2014-2017. In Danish.

Ringsted, C. (2004) In-training assessment in a work-based postgraduate medical education context. PhD thesis from University of Maastricht, Maastricht, The Netherlands.

Ringsted, C., Hansen, T. L., Davis, D. \& Scherpbier, A. (2006). Are some of the challenging aspects of the CanMEDS roles valid outside Canada? Medical Education, 40, 80715

Ringsted, C., Henriksen, A. H., Skaarup, A. M. \& Van der Vleuten, C. P. M. (2004). Educational impact of in-training assessment (ITA) in postgraduate education: a qualitative study of an ITA programme in actual practice. Medical Education, 38, 767777.

Ringsted, C., Østergaard, D. \& Van der Vleuten, C. P. M. (2003). Implementation of a 
formal in-training assessment programme in anaesthesiology and preliminary results

of acceptability. Acta Anaesthesiologica Scandinavica, 47, 1196-1203.

Rubak, S., Mortensen, L., Ringsted, C. \& Malling, B. (2008). A controlled study of the short- and long-term effects of a train the trainers course. Medical Education, 42, 693

-702 .

Skjelsager, K. (2003). Believes and opinions of specialists in anaesthesiology about assessment of postgraduate physicians. Masterthesis, Maastricht University.

Skjelsager, K., Malling, B., Bested, K. M., Østergaard, H. T., Ravn, L., Østergaard, D. \& Ringsted, C. (2008). Implementering af et nationalt kompetenceprogram. [The implementation of a national in-training assessment program]. Ugeskrift for Læger, 170/44, 3557-3561. In Danish.

The Danish National board of Health. (2007). Evaluering af inspektorordningen [Evaluation of the peer review inspection]. Retrieved 10. January, 2010 from www.sst.dk. In danish.

The Danish National board of Health. (2007). Vejledning for inspektorordningen. [Guidance for peer review inspection]. Retrieved 10. September, 2010 from www.sst.dk. In Danish.

\section{Curriculum origins}

A committee under the National Board of Health (NBH) was set up in 1998 to outline a reform in PGME. The members in the committee, who are listed in table 3, represented the contracting authority, the hospitals, the doctors' union, the specialty societies and the universities.

The background for the committee's work was a concern about deteriorating quality in specialist training, upcoming structural changes in the hospital service and a need for greater flexibility in PGME. The mandate of the committee was primarily analysis and recommendations on 1) specialist structure and number of specialties, 2) higher efficiency in specialist training, and 3) decentralisation in the governance of PGME, including management of PGME in clinical departments.

\section{Outcome}

The number of specialties was decreased and all subspecialties erased. Decisions on number of specialties were made by the NBH. A National PGME council was established as an advisory board for the NBH and the Ministry of Health in matters of PGME. The council consists of 18 members. The composition is shown in table 3.

The NBH issues rules and regulations for PGME, grants authority, manages external peer inspection of quality, and decides the number and distribution of train- 
ing sites across specialties and across the three regions in the country. Furthermore they advise the Ministry of Health regarding educational issues (see table 4). The distribution of training sites across hospitals, however, was decentralised and handed over to the Regional PGME councils, which were established in each of the three educational regions. The Regional PGME councils approve training sites and educational programmes. They are advisory boards for the National PGME council and for the hospital owners. The chairman of a Regional PGME council is appointed by the hospital owners, and there must be representation from various clinical departments and general practitioners, the trainees, and the university. At least three of the doctors in the council must be appointed by the doctor's union. The hospital owners established secretariats for administrative support to each council.

Table 3. Composition of the reform committee (year 1998) and the National Postgraduate Medical Educational Council (year 2010). Number of members representing various stakeholders. Others marked by * are the chairmen from the three Regional PGME Councils. PGME: Postgraduate medical education.

\begin{tabular}{lcc}
\hline & $\begin{array}{c}\text { Reform committee } \\
\text { Number of representatives }\end{array}$ & $\begin{array}{c}\text { National PGME Council } \\
\text { Number of representatives }\end{array}$ \\
\hline The contracting authority & 4 & 1 \\
Ministry of Health & 1 & 1 \\
Ministry of Research & 1 & 2 \\
Ministry of Education & 3 & 3 \\
National board of Health & 5 & 2 \\
Hospitals & & 2 \\
Doctors Union & 3 & 3 \\
Specialists & 1 & 1 \\
Trainees & 1 & $3 *$ \\
Specialist societies & 0 & 14 \\
Universities & & 4 \\
Others & 14 & 2 \\
Doctors & 6 & 2 \\
Officials & & 2 \\
\hline
\end{tabular}

To create a link between the Regional PGME councils and the universities a Pedagogical Development Function was established. Professors and associate professors in PGME were nominated. The main duties of the professor are research and development of PGME, in addition to advising the Regional PGME council. The job of an associate professor includes development and research in PGME and administrative assistance in the development of educational programmes and plans for rotations in PGME. Furthermore, the associate professors advise clinical departments on issues regarding $P G M E$. 
At the departmental level one consultant is responsible for PGME in the department (CRE). A supervisor is appointed for each trainee and all doctors in the department function as clinical teachers.

The structure of specialist training after one foundation year includes an introductory year in the specialty followed by residency of four to five years depending on the specialty. Residency training includes various rotations between departments and hospitals, described in the educational programmes. Trainees are employed as doctors during training. Employment law prevents information regarding a trainee from being relayed to supervisors in the next rotation, since they are regarded as separate employments. Hence a kind of mentorship was needed to provide oversight of the whole training period and to support the trainee along the way.

Finally OBE and ITA were introduced. Specialist examinations were rejected in favour of ITA. An external peer inspection system evaluates the quality of training in each clinical department. The system is managed by the $\mathrm{NBH}$, but developed as a

joint venture between the hospital owners and the $\mathrm{NBH}$, and members appointed by the specialty society carry out the peer inspection of sites.

\section{Analysis}

The organisational chart of PGME indicates linkage from the Regional PGME councils, through the National PGME council to the NBH. However, this does not represent line responsibility, the educational councils are predominantly advisory. Decisions on PGME are made by the NBH. The Regional PGME councils have executive power regarding distribution of trainees across hospitals.

The Chief of Hospital is ultimately responsible for PGME in his hospital and the CRE is responsible for managing PGME in the clinical department. Thus inside the hospitals and clinical departments responsibility for PGME is well described. However, residency training is characterised by rotations across clinical departments and there is no formal institution overseeing the longitudinal perspective.

The peer inspection system ensures the quality of PGME in the clinical departments. However, there is no accreditation body taking care of the more overreaching aspects of PGME. 
Table 4. The stakeholders in the organisation of Postgraduate Medical Education (PGME) and their duties.

\begin{tabular}{|c|c|}
\hline Ministry of Health & - Issues laws \\
\hline $\begin{array}{l}\text { National Board of } \\
\text { Health }\end{array}$ & $\begin{array}{l}\text { - Set rules and regulations } \\
\text { - Approves blue-prints } \\
\text { - Issues guidelines } \\
\text { - Issues specialist authority } \\
\text { - Decides the distribution of training sites across specialties and across regions } \\
\text { - Advices Ministry of Health regarding PGME } \\
\text { - Manages the external peer inspection of the quality in PGME in clinical depart- } \\
\text { ments }\end{array}$ \\
\hline Specialist Societies & $\begin{array}{l}\text { - Define the content of PGME according to the seven CanMEDs roles } \\
\text { - Set goals and objectives for specialist training } \\
\text { - Make blueprints } \\
\text { - Indicate teaching and assessment strategies } \\
\text { - Make specialty-specific courses (financed by the National board of Health) } \\
\text { - Advice the National Board of Health regarding PGME }\end{array}$ \\
\hline Hospital owners & $\begin{array}{l}\text { - Financial responsibility for hospitals } \\
\text { - Responsible for specialist training and for educational culture in hospitals } \\
\text { - Runs the secretariats for the Regional PGME councils }\end{array}$ \\
\hline $\begin{array}{l}\text { National PGME } \\
\text { Council }\end{array}$ & - Advices the National Board of Health \\
\hline Regional PGME & - Decide distribution of training sites across hospitals \\
\hline Councils & $\begin{array}{l}\text { - Approve training positions } \\
\text { - Approve educational rotations } \\
\text { - Approve educational programmes made by associate professors of PGME } \\
\text { - Manage PGME locally } \\
\text { - Advice the National PGME council } \\
\text { - }\end{array}$ \\
\hline $\begin{array}{l}\text { Professor of post- } \\
\text { graduate medical } \\
\text { education }\end{array}$ & $\begin{array}{l}\text { - Research in and development of PGME } \\
\text { - Advices Regional PGME council }\end{array}$ \\
\hline $\begin{array}{l}\text { Associate professors } \\
\text { in postgraduate } \\
\text { medical education }\end{array}$ & $\begin{array}{l}\text { - Development and research in PGME } \\
\text { - Make out educational programmes in cooperation with the clinical departments } \\
\text { - Define educational rotations } \\
\text { - Plan which goals should be obtained where } \\
\text { - Advice clinical departments on issues regarding PGME } \\
\text { - Advice Regional PGME councils }\end{array}$ \\
\hline Hospitals & $\begin{array}{l}\text { - Make financial decisions } \\
\text { - Ensure labour } \\
\text { - Ultimate responsible for PGME at the hospital }\end{array}$ \\
\hline $\begin{array}{l}\text { Consultant responsi- } \\
\text { ble for PGME in } \\
\text { clinical department } \\
\text { (CRE) }\end{array}$ & $\begin{array}{l}\text { - Responsible for PGME in department } \\
\text { - Manages PGME on departmental level }\end{array}$ \\
\hline
\end{tabular}




\section{The curriculum on paper}

The curriculum took reference in the CanMEDS framework (table 1). The specialty societies worked out blueprints with support from guidelines, rules and regulations issued by the NBH. The blueprints provided the clinicians and the trainees with a list of learning goals, to which learning and teaching strategies and ITA methods were connected, and set up in a mandatory matrix. The educational programmes developed from the blueprints were mainly based on clinical training supplemented by specified mandatory courses on learning and teaching, leadership and management, communication skills and research training, which were developed alongside specialty-specific courses.

The blue-prints and the educational programmes were developed in 2004 and revisions made for all specialties in the period 2007-2010.

\section{Educational programmes}

The educational programmes described the rotations between departments and the distribution of learning goals across rotations. The learning goals were arranged around the seven CanMEDs' roles. In the matrix the roles were separated with little or no overlap. An example is presented in table 5 (year 2004).

Most specialties used this approach in the development of both blueprints and educational programmes. However, in anaesthesiology the learning goals were arranged according to clinical situations, for example 'Emergency induction of general anaesthesia' or 'Admission to intensive care unit'. In the revisions several specialties pursued this 'up-side-down' approach. In table 6 an example is provided (year 2008). The difference from the version in 2004 is striking.

Participation in clinical work, apprenticeship learning, supervised practice, bedside teaching and learning, or self-study were suggested as learning strategies for the medical expert goals (table 4), while attending courses was the predominant learning strategy for the non medical expert roles. The predominant assessment strategies were structured clinical observation, discussion with supervisor, and multi-source feedback. 


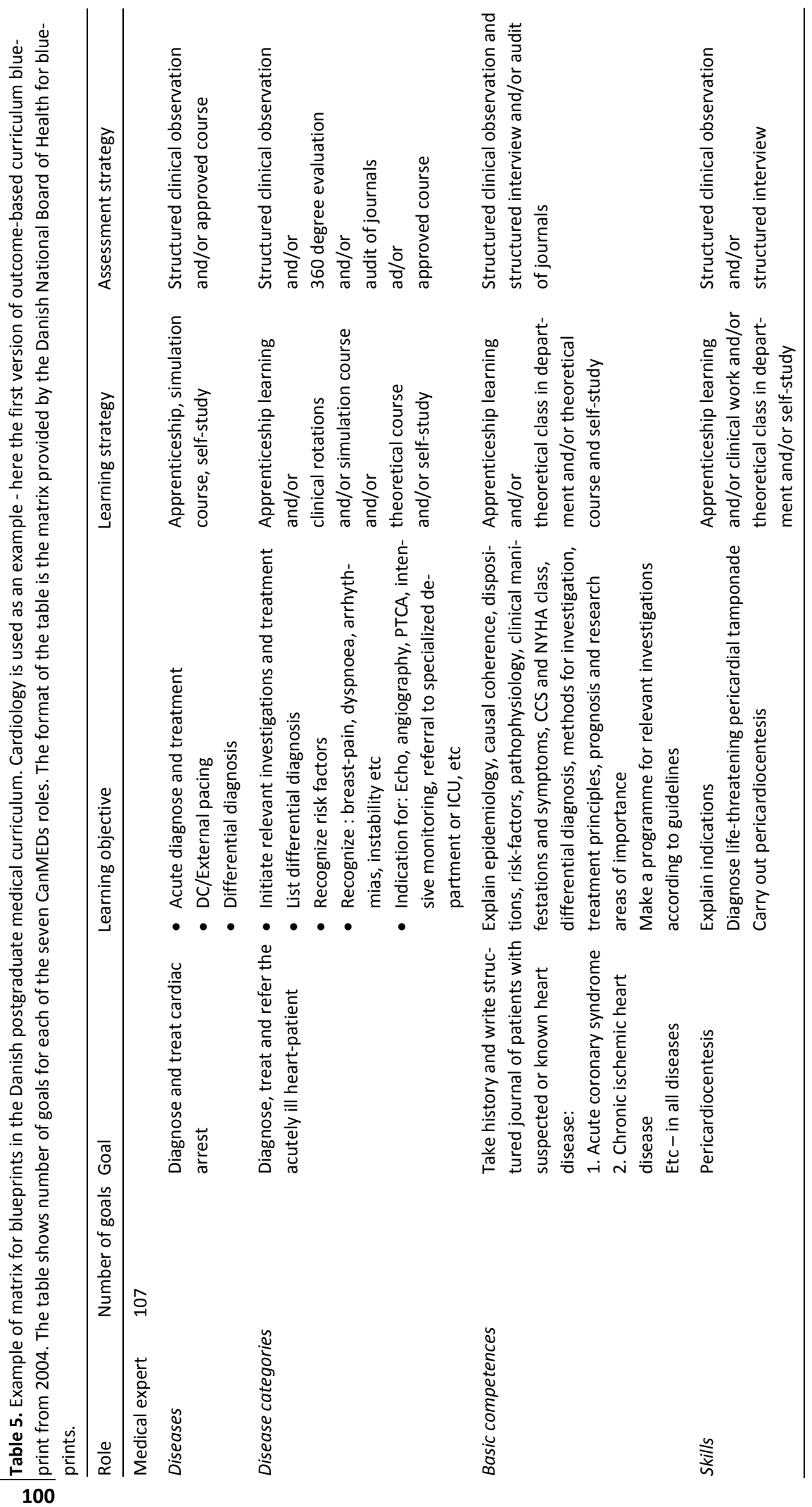




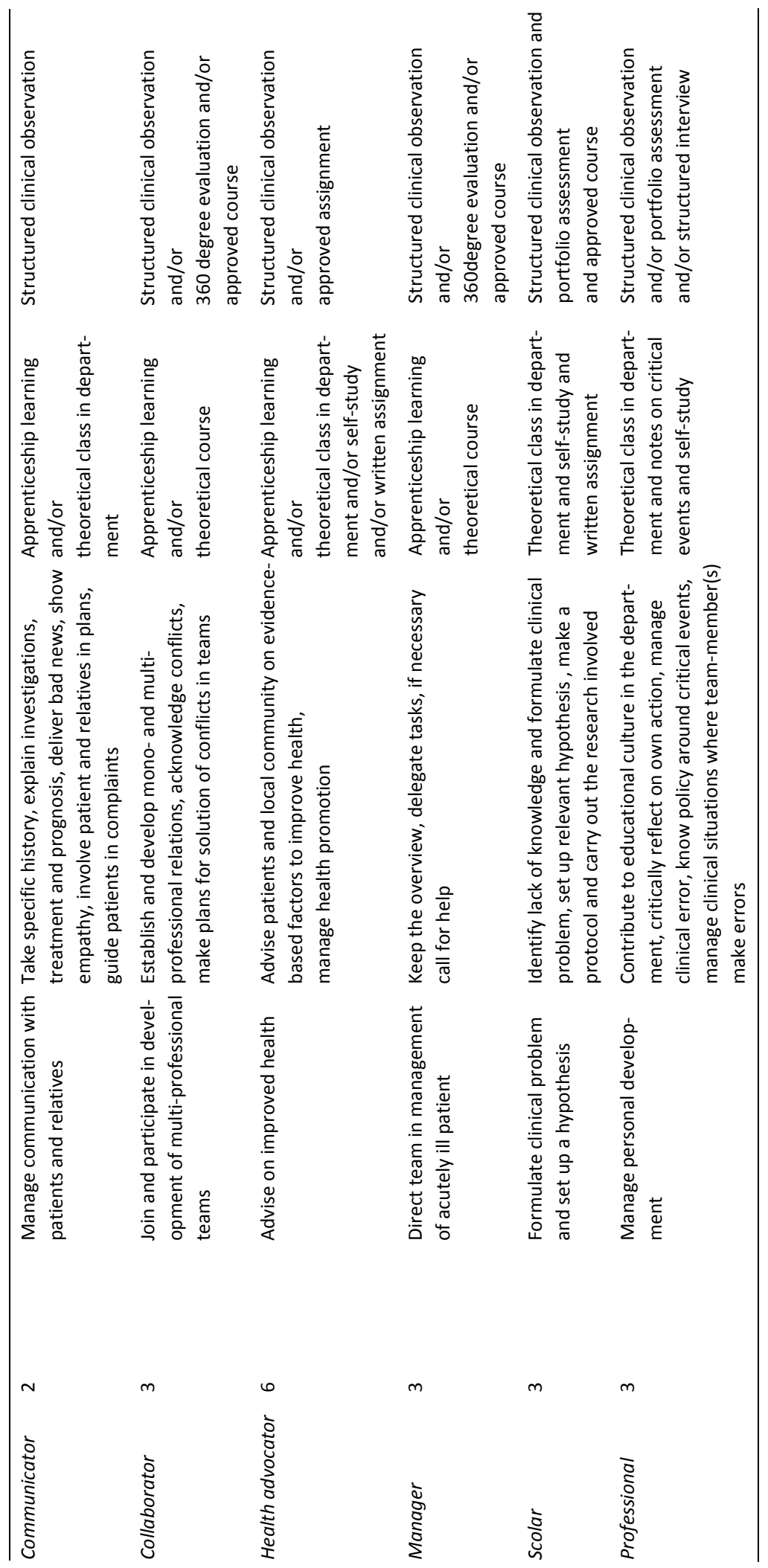




\section{Analysis}

In accordance with the work-based nature of PGME, most of the learning goals were expressed in the active voice. All goals were expressed as end-goals, no milestones were provided. The goals were distributed across rotations. The role of medical expert had a higher number of goals and learning objectives than the other roles. Each clinical department decided which of the proposed learning and assessment strategies they would choose, and how to use them.

Table 6. Example of learning goals from the Danish postgraduate medical curriculum in Cardiology, year 2008. The table shows number of goals within general and specialty-specific competencies and the roles embedded in the goals.

\begin{tabular}{|c|c|c|c|}
\hline Competencies & $\begin{array}{l}\text { Number } \\
\text { of goals }\end{array}$ & Goal (example) & $\begin{array}{l}\text { Assessment } \\
\text { strategy }\end{array}$ \\
\hline \multicolumn{4}{|l|}{ General competencies } \\
\hline Ward round & 12 & $\begin{array}{l}\text { Chair team-conference includ- Manager, Collabo- } \\
\text { ing guidance and supervision of rator } \\
\text { younger trainees }\end{array}$ & $\begin{array}{l}360 \text { degree } \\
\text { evaluation and } \\
\text { approved } \\
\text { course on } \\
\text { leadership and } \\
\text { management }\end{array}$ \\
\hline Out-patient care & 2 & 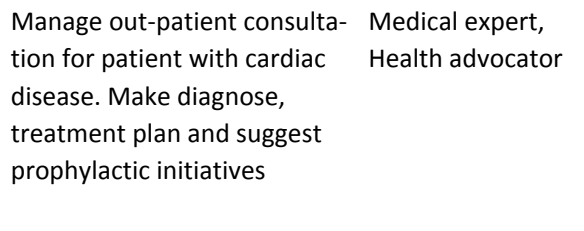 & $\begin{array}{l}360 \text { degree } \\
\text { evaluation and } \\
\text { approved } \\
\text { course on } \\
\text { leadership and } \\
\text { management }\end{array}$ \\
\hline On-duty competences & 7 & $\begin{array}{l}\text { Take responsibility for the Manager } \\
\text { department during duty-time. } \\
\text { Prioritise and delegate tasks, } \\
\text { manage whole team. }\end{array}$ & \\
\hline Cardiology & & & $\begin{array}{l}\text { Structured } \\
\text { interview and } \\
\text { structured } \\
\text { clinical observa- } \\
\text { tion }\end{array}$ \\
\hline Symptoms & 9 & $\begin{array}{l}\text { Manage diagnostics, treatment Medical expert } \\
\text { and prophylactic initiatives of } \\
\text { patients presenting with heart } \\
\text { murmur }\end{array}$ & $\begin{array}{l}\text { Structured } \\
\text { interview }\end{array}$ \\
\hline Heart diseases & 8 & $\begin{array}{l}\text { Theoretical knowledge (patho- Medical expert } \\
\text { physiology, diagnose, treat- } \\
\text { ment and prophylactic initia- } \\
\text { tives) of ischemic heart disease }\end{array}$ & $\begin{array}{l}\text { Structured } \\
\text { observation }\end{array}$ \\
\hline Skills & 19 & $\begin{array}{l}\text { Carry out transesophagial } \\
\text { echocardiography }\end{array}$ & \\
\hline
\end{tabular}


The psychological claim of a curriculum built up by competencies and mastery of these is behavioural. In this perspective the teacher is responsible for learning. However, at the same time the trainees are placed in a very active role taking responsibility for learning in almost all of the educational programs, indicating a more constructivist approach, where the teachers are placed in a more facilitating role.

\section{The curriculum in use}

To facilitate the implementation of the OBE curriculum in 2004, courses for CRES and "Train-the-trainer"- courses were established. Furthermore 21 doctors from various specialties participated in masters' programme in health professions education abroad. The evaluation report from the NBH concluded that the changes implemented were mainly structural, the outcome-based approach was not easily comprehended, and apparently ITA had not yet been established. However, PGME had become an increasingly prominent issue in the departments.

\section{Summary}

The governance and power-relations in the governance of PGME can be outlined using Bordieus' field analysis (22) as a framework. According to Bordieu the field is a social space, habitus is the members' ways of acting, feeling, thinking, and being, while capital can be understood by the position we have in the field through our culture, education and employment, and through the organisation we represent. Social practice is dependent on the relation between the field, the habitus and the capital members bring into the field (22). The strategies of each member in a field are to maximise their position (capital). 


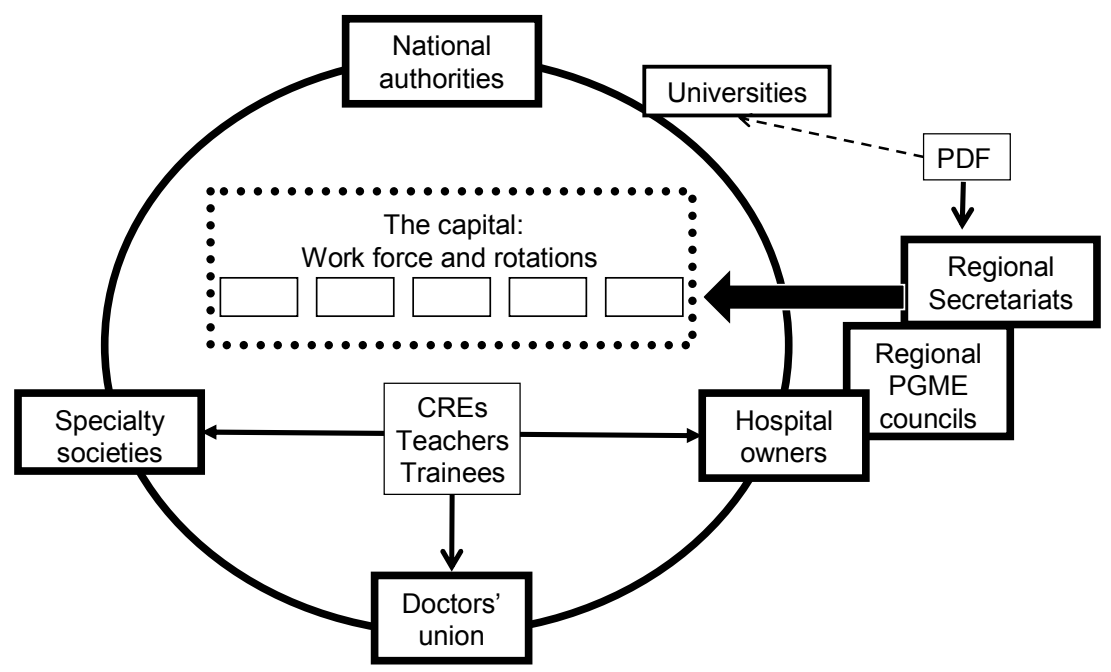

Figure 1. Model for governance of postgraduate medical education (PGME). The figure shows the stakeholders and their interests in PGME. PDF: Pedagogical Development Function. CRE: Consultant responsible for PGME in clinical department.

Figure 1 is an illustration of the social field of PGME using Bordieu's framework. Placed on the solid circle are the key stakeholders: The national authorities, the universities, the hospital owners, the doctors' union, and the specialty societies. The rectangle in the middle indicates the capital, which is work force and training positions, the rotations. That is the subject of the power-play among stakeholders. Placing the stakeholders on a cycle rather than a hierarchy is a result of the advisory status of PGME institutions and councils: The specialty societies advise the NBH on curricular goals and content, the NBH advises the Ministry of Health, the National PGME council advises the NBH, the Regional PGME councils advise the hospital owners. The stakeholders bring their capital and habitus to the field and by striving to maximise their own capital they keep each other at bay in the councils. However, this also has the effect that decisions are difficult to make due to the large number of members and the complex relations between them. Outside the cycle, but closely linked to the hospital owners, are the Regional PGME councils and their administrative support functions, the regional secretariats. As the Regional PGME councils are constituted similarly to the National PGME council with a lot of members keeping each other at bay, the real power eventually goes to the officials in the secretariats. Also outside the cycle is the Pedagogical Development Function, the PGME professors, and associate professors. Although they have a dual reference to the universities and the regional secretariats, the latter connection becomes the strongest as the universities' position and interest in PGME is minor. The weak position is evident in the allocation of only one representative in the National PGME council from 
the three universities with medical schools. Finally, within the cycle are placed some key players in PGME: the CREs, the clinical teachers/supervisors, and the trainees. The following is a description of the habitus and capital of individual players in the field of PGME, the relations and conflicts between them, and how these influence PGME.

The capital of the specialty societies is medical expertise and hence the content matter of PGME. Specialty societies are concerned with claiming territorial ownership of managing certain categories of patients or procedures, which in some instances leads to a conflict between specialties. In addition they have an interest in controlling the admittance of members of the society 23, 24). Education is one way to solidify the territorial claim, which is expressed in PGME curricula goals. Another way of control is having high demands regarding goals for competencies and running specialist exams. In countries having end-of-training exams these are usually run by the specialist boards or societies who set the standards. However, in Denmark the reform committee recommended ITA instead of exams. Although there are several good reasons for introducing ITA avoiding exams is one way of weakening the societies' power. In our case NBH control the level of goals as the societies are only advisory regarding the curricula that have to be approved by the NBH. Yet, the national authorities are depending on the collaboration with the specialty societies as they possess the expertise and hence the content knowledge of PGME. This collaboration thus becomes delicate. Interestingly the societies deliver the work for the proposed curricula free of charge. Although developing curricula is the ticket to power, this situation is in contrast to Bordieu's statement that finances are crucial in power relations (22).

Over time there has been a tendency to evolve sub-specialties due to the increasing complexity of health care. Sub-specialisation has been particularly prevalent within internal medicine and surgical specialties. With increasing specialisation there has been a tendency to centralise a main part of residency training in tertiary health care sectors. However, sub-specialisation is in conflict with the interest of the national authorities and the hospital owners. Training for sub-specialisation on top of basic training makes PGME inadvertently long and inefficient. The subspecialisation is problematic and expensive for the hospitals when staffing the clinical departments and ensuring service in general hospitals. Moreover subspecialisation makes it complicated to plan appropriate trainee rotations including a risk that rotations become too short, too many, and centralised in tertiary centres (25). Hence national authorities and hospital owners have an interest in keeping the number of specialities and sub-specialities as low as possible for several reasons: avoiding long specialist educations, maximising the possibility of distributing trainees and thereby workforce to smaller hospitals, and finally, especially for the hospital owners, optimising the supply of generalists to take care of the majority of patients with common conditions. Moreover, hospitals and the doctors' union have an 
interest in long rotations - the hospitals in order to gain return of the investment in the training and the unions for the sake of optimal working conditions. In Denmark no rotations are allowed to be shorter than six months. That is contrary to other countries where rotations might be limited to few weeks (25).

In the Danish context there is a strong tradition of trade unions and more than $90 \%$ of the physicians are members of the Danish association of doctors. Without doubt the union has had a strong impact on the PGME format and on optimising the learning environment, i.e. the working conditions for junior doctors. However, the interest of the union is in some ways opposed to the specialty societies. The union might not be keen on having high demands regarding competencies and summative exams as they strive to protect the interest of all their members. Having too high demands will lead to some doctors not getting certified as specialists and that has implications for their salaries. Therefore expressing goals in the curricula as minimum goals is in their interests. This interest is shared by the hospitals and the national authorities, who want to ensure sufficient number of certified doctors distributed across the country.

The capital of the hospitals is holding the learning environment of PGME. PGME is work-based and hence availability of positions as junior doctors within the health care service is crucial. The interests of the hospitals in PGME is primarily ensuring present and future work force.

In each clinical department, there is a CRE and a number of clinical teachers representing one rotation. However, CREs and teachers are sort of floating in the power field of PGME stakeholders and interests. As specialists they relate to the societies and as doctors employed in clinical departments they follow the standard line of reference to the chief of department, the hospital director and eventually to the hospital owners. The same goes for the trainees who are employed as junior doctors. However, whereas the union takes care of the working conditions for junior as well senior doctors, there is no formal organisation fighting for the interests and conditions of CREs and clinical teachers. Although they might be represented in the Regional PGME councils they are somewhat isolated within individual clinical departments. Yet, CREs are responsible for managing PGME at the departmental level and complying with rules and guidelines issued by National authorities.

According to the behaviourist perspective reflected in the OBE curricula, CRES and teachers are responsible for trainees' learning. However, the PGME curricula on paper also indicate that learning relates to constructivist and social learning perspectives. The role of the teachers in those perspectives is facilitating learning and coaching trainees' progressive professional development. However, neither CREs nor teachers have a longitudinal role across rotations, indicated in Figure 2 by the detachment of rotational blocks. The Regional Secretariats are those who in practice coordinate the rotations, endorse instructional programs of the individual rotations, and eventually approve the trainees by completion of the entire education. Also, 
the secretariats are responsible for managing problem trainees. Hence in practice the secretariats have a very strong position, whereas the CREs are in a very weak position.

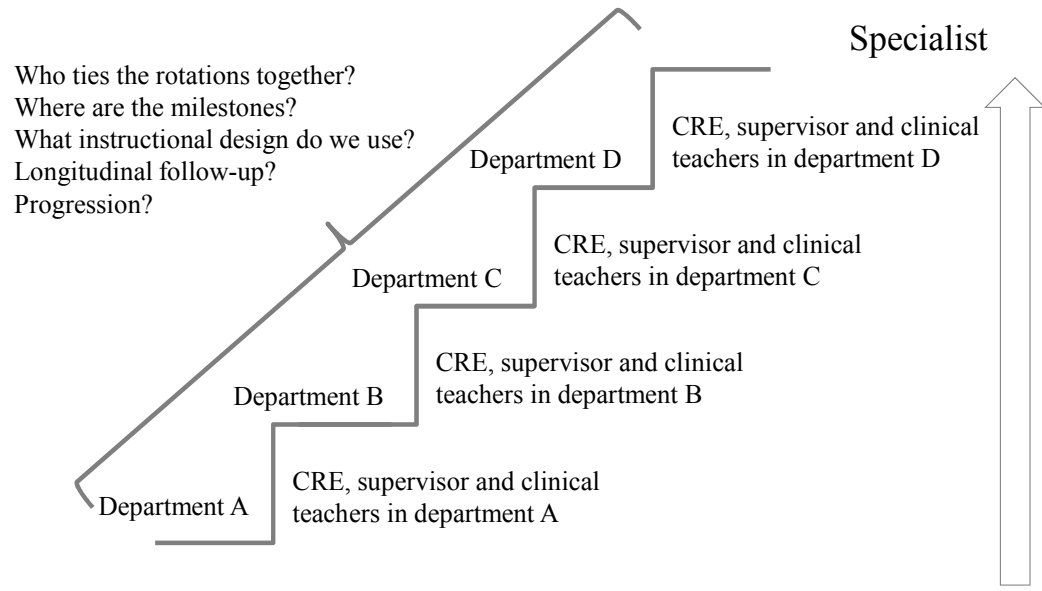

New trainee

Figure 2. The journey from novice to specialist in the outcome based curriculum for postgraduate medical education (PGME). CRE: Consultant responsible for PGME in clinical department.

Interestingly the Pedagogical Development Function is unusually placed on the schema. The PGME professors and associate professors are not represented in the PGME councils. Furthermore, their weak connection to the universities leads to a strong connection to the secretariats. The role and responsibilities of the secretariats are mainly administrative, not pedagogical, and hence the secretariats tend to use the PGME professors and associate professors for administrative purposes rather than pedagogical development. However, the Pedagogical Development Function has a challenging task as pedagogical issues related to work-based PGME are scarcely described in the literature, an issue further elaborated on in the discussion.

\section{Discussion}

The curriculum analysis and the resulting model of governance give rise to some general considerations around the governance of work-based PGME. In the following discussion some of these considerations will be addressed under the headings: 'The governance of PGME' (macro-level) and 'Work-based education' (micro-level). 


\section{The governance of PGME}

The model of governance of PGME developed from this curriculum analysis might not fit perfectly into the governance seen in other countries since history and national values play an important role in the development of governance $(26,27)$. In some countries the universities play a prominent role (28 - 30), in other countries the union (31). However, the stakeholders and the power-play described in our model are common for most governance models.

A psychological perception of disconnection between university and thus pedagogic knowledge and clinical departments has previously been described (32) perhaps because education and clinical work run in seemingly split lines of management $(33,34)$. This split and unclear line of reference contribute to a lack of transparency in the governance of PGME (35). As a result the leaders of PGME (deans, programme directors, and others), might not know who they are leading (the clinical teachers), since the clinical teachers are employed in the hospital or in some countries are self-employed but simply granted privileges at the hospital and thus refer to the administrative line. To cope with the split line of reference, various forms of partnership between the two lines have developed to create alignment ( 35 - 37). However, as Bourdieu points out, the economic and financial field is by far the most powerful (22). Thus it might be a challenge for leaders in PGME to influence working condition and work-based learning in the clinical departments, which are run by the hospital administrations. Combining this with the tendency to choose leaders in professional organisations due to their individual achievements (research, clinical skills) - rather than their leadership skills (24, 38 - 40), might contribute to the challenges of leadership in PGME.

In most countries specialist training comprises foundation year(s) followed by residency. In Denmark we have placed an introductory year between foundation and residency where the trainee can try out a specialty before starting in residency. This is well accepted by both trainees and trainers and contributes to the decision on the trainees' future specialty choice, and thus working life. Working hours in Denmark are lower than in most other countries, probably due to the strong influence from the doctors' union. Yet it has been possible to keep working hours low despite the introduction of a reform in PGME. In other countries with less strong traditions of doctor's union lowering working hours has been very difficult and has given rise to major concern regarding trainees' education. Although this concern is also expressed in our country, there is only one comparative study on this issue (41). Every system has both strengths and weaknesses. And it will probably not be possible to recommend one system over another due to cultural discrepancies across countries. There might, however, be some issues in the micro-level governance in PGME that contribute to the difficulties seen in many countries around the implementation of OBE and ITA, which will be addressed in the next section. 


\section{Work-based education}

It has been questioned if the behavioural approach to transform complex competencies or roles into assessable learning objectives in the curricula can be applied to the broad visionary concept of competence $(42,43)$, without taking into consideration the context in which these competencies are to be applied $(25,44,45)$. Some fear that OBE leads to fragmentation of PGME by dividing medical expertise and professionalism into competencies and further into learning objectives (43 - 45). Others fear that it will result in mediocre physicians since the structured approach may constrain physicians' freedom to learn (46), and since the goals for competence are expressed as "minimal acceptable goals.

Postgraduate medical education relies on 'opportunistic learning situations' (34). Thus it might be difficult for clinical teachers and trainees to stick to the often very structured OBE curricula (47). Furthermore pursuing a behavioural approach, placing the responsibility of learning on the teacher, might be difficult in work-based education with ever-changing teachers due to working schedules and the multiple rotations, which is in contrast to the "one teacher-one trainee" principle behind traditional apprenticeship learning. The lack of milestones in the OBE curricula might be one way to acknowledge the unpredictability in clinical work, but at the same time makes it difficult to evaluate if the trainees are on the right track and pace in the overall professional development (48).

The importance of incorporating adult learning theories with self-directed learning and learner-centered teaching into PGME has been stressed $(49,50)$. Thus a more constructivist approach has been suggested. According to Coles learning should take experience (practical clinical work) as point of reference in PGME (49, 51). This approach might be appealing to clinicians since it attaches importance to daily clinical work, which is regarded crucial by both clinicians and educators $(49,52$, 53). It also places the trainee as an active participant in the learning process and the trainer in a more facilitating role, which is more like the way clinical work is carried out. However, taking a pure constructivist approach is difficult in a culture with no tradition of reflection in and on action and underdeveloped supervisor skills in this area $(54,55)$. Thus a more socio-cultural approach to PGME has been suggested $(45$, $47,56)$. However, the social-cultural perspective also leaves us with no guidance on how to train juniors effectively.

The educational goals described in many curricula are conceptualised on individualistic learning theories $(45,57)$, which may not be sufficient to create the kind of learning organizations and systemic thinking needed to meet societal demands for high quality and safe treatment (58-60). Provision of health care is team-based and highly dependent on systems issues (48). The introduction of the core competencies 'systems-based practice' and 'practice based learning' in the US model might be a first step towards incorporating systems based thinking into PGME $(4,61)$. Recently it has been suggested to introduce a $7^{\text {th }}$ core competency in US curriculum 
- 'Recognition and disclosure of error' (62). This is in line with Irby et al., (48) who point out the necessity to take patient safety and quality issues into more consideration in PGME. However, in the power-play between PGME stakeholders this aspect is poorly addressed and issues of how quality of care relates to trainees' competence seems to be a minor point compared to securing workforce. Perhaps the trend of accreditation of hospitals will be the lever to ensure trainees' competence rather than ITA.

There seems to be no single learning theory that completely covers the complex learning situations in the workplace $(63,64)$. Recently Teunissen et al. has provided a model on how residents learn from work-related activities (53). Their model embraces various learning theories like experiential learning, situated learning, sociocultural learning and informal learning. Thus a mixed model stressing the importance of interaction between trainee and clinical teachers has emerged. This model provides a framework for further investigation into work-based learning in PGME.

\section{Limitations of the study}

The first author who performed the curriculum analysis might be prejudiced since she is a director of PGME and thus knows the internal organisation around PGME in Denmark. However, a proper curriculum analysis requires familiarity with PGME concepts.

\section{Conclusion}

The governance of PGME is characterised by many stakeholders with contrasting interests, which they strive to maximise. In the power-struggle stakeholders seem to keep each other at bay, and the resulting power-balance might make leaders in PGME unable to make decisions or to exert leadership. In theory the outcomebased curricula are ideal to secure high quality and safe patient treatment. However, there seems to be discrepancies between the curriculum on paper describing the competent physician in separable roles or competencies, and the curriculum in use, which takes clinical situations embracing all roles as point of reference. Combining this with a lack of sufficient teaching, learning, and assessment strategies makes governance of PGME complex and management of PGME in hospitals and thus clinical departments an unclear task. 


\section{References}

1. Harden RM. (Ed.). Trends and the future of postgraduate medical education. EMJ, 2006; 23, 798802.

2. Royal College of Physicians and Surgeons of Canada. Skills for the new millenium: report of the societal needs working group. 1996. Retrieved September 2009 from www.rcpsc.medical.org .

3. The Danish Ministry of Health. Fremtidens speciallæge. Betænkning fra speciallægekommissionen. Betænkning nr. 1384; 2000. ["The future Specialist". Report and recommendation on specialist training. Report no. 1384]. (Copenhagen:GS Grafik ApS). In Danish.

4. Leach DC. A model for GME: shifting from process to outcomes. A progress report from the Accreditation Council for Graduate Medical Education. Med Educ, 2004; 38, 12-14.

5. Frank JR. The CanMEDS 2005 Physician Competency Framework. Better standards, Better physicians. Better care. 2005. Ottawa: The Royal College of Physicians and Surgeons of Canada. Retrieved 10 January 2010 from www.rcpsc.medical.org

6. Postgraduate Medical Education and Training Board (PMETB). Educating tomorrow's doctors Future models of medical training; medical workforce shape and trainee expectations. 2008. Retrieved August 8, 2009 from www.pmetb.org.uk .

7. Davis DJ, Skaarup AM \& Ringsted C. A pilot survey of junior doctor's confidence in tasks related to broad aspects of competence. Med Teach, 2005; 6, 548-552.

8. Swing SR. The ACGME outcome project: retrospective and prospective. Med Teach, 2007; 29, 648 654.

9. Bayer, M. Speciallægeuddannelse i Danmark - en empirisk undersøgelse af tendenser inden for speciallægeuddannelsen efter implementeringen af den nye speciallægeuddannelse. 2007. [Specialist training in Denmark - an empirical analysis of tendencies in specialist training after implementation of the new reform]. København, Danmarks Pædagogiske Universitets forlag. In Danish.

10. Agius SJ, Willis SC, McArdle PJ \& O’Neill PA. Managing change in postgraduate medical education: still unfreezing? Med Teach, 2008; 30, e87-e94.

11. Tsouroufli M \& Payne H. Consultant medical trainers, modernising medical careers (MMC) and the European time directive (EWTD): tensions and challenges in a changing medical education context. BMC Med Educ, 2008; 8, 31.

12. Dehn $\mathrm{P}$, Nielsen $\mathrm{CH}$, Larsen $\mathrm{K}$ \& Bayer M. Implementering af speciallægereformens syv roller. [Implementing the seven roles of the specialist training reform]. UfL, 2009; 171/19, 1580-1584. In Danish.

13. Didwania A, McGaghie WC, Cohen E \& Wayne DB. Internal medicine residency graduates' perception of the systems-based practice and practice-based learning and improvement competencies. Teach Learn Med, 2010; 22, 33-36.

14. Green ML \& Holmboe E. The ACGME Toolbox: Half empty or half full? Acad Med, 2010; 85, 787 790.

15. Mortensen L, Malling B, Ringsted C \& Rubak S. What is the impact of a national postgraduate medical specialist education reform on the daily clinical training 3.5 years after implementation? A questionnaire survey. BMC Med Educ, 2010; 10: 46.

16. Ringsted C, Hansen TL, Davis D \& Scherpbier A. Are some of the challenging aspects of the CanMEDS roles valid outside Canada? Med Educ, 2006; 40, 807-15.

17. Chou S, Cole G, McLaughlin K \& Lockyer J. CanMEDS evaluation in Canadadian postgraduate training programmes: tools used and programme director satisfaction. Med Educ, 2008; 42, 879-886.

18. Ringsted C, Østergaard D \& Van der Vleuten CPM. Implementation of a formal in-training assessment programme in anaesthesiology and preliminary results of acceptability. Acta Anaesth Scand, 2003; 47, 1196-1203.

19. Skjelsager K, Malling B, Bested KM., Østergaard HT, Ravn L, Østergaard D \& Ringsted C. Implementering af et nationalt kompetenceprogram i anæstesiologi. [The implementation of a national in-training assessment program]. UfL, 2008; 170/44, 3557-3561. In Danish. 
20. Frank JR \& Danoff D. The CanMEDS initiative: implementing an outcomes-based framework of physician competences. Med Teach, 2007; 29, 642-647.

21. Posner GJ. Analyzing the curriculum. $2^{\text {nd }}$ Ed. New York: McGraw-Hill, Inc.; 1995.

22. Grenfell M. Ed. Pierre Bordieu - Key concepts. Durham: Acumen Publishing Limited; 2008.

23. Lave J \& Wenger E. Situated Learning. Legitimate peripheral participation. Cambridge: Cambridge University Press; 1991.

24. Mintzberg H. The structuring of organizations. Upper Saddle River, NJ: Prentice-Hall, Inc.; 1979.

25. CookeM, Irby DM \& O'Brien BC. Educating physicians. A call for reform of medical school and residency. San Francisco: Jossey-Bass; 2010.

26. Seguin C \& Hodges B. Educating physicians in France and Canada: are the differences based on evidence or history? Med Educ, 2005; 39, 1205-1212.

27. Hofstede G \& Hofstede GJ. Cultures and organizations: software of the mind. New York: McGrawHill; 2005.

28. Royal college of Physicians and Surgeons of Canada. General standards applicable to the university and affiliated sites. 2007. Retrieved January 6, 2010 from www.rcpsc.medical.org

29. Accreditation Council of Graduate Medical Education. Common Programme Requirement (July 2007). Retrieved January 2010 from www.acgme.org.

30. Postgraduate Medical Education and Training Board (PMETB). Generic standards for specialty training including GP training. 2010. Retrieved January 6, 2011 www.gmc-uk.org.

31. Legeforeningen. Generelle bestemmelser for specialist utdanningen. [Specialist training for physicians in Norway]. 2005. Retrieved from the Web august 2006. http:// www.legeforeningen.no

32. Steinert $Y$, McLeod PJ, Boillat M, Meterissian S, Elizov M \& Macdonald ME. Faculty development: a "Field of dreams"? Med Educ, 2009; 43, 42-49.

33. Schwartzstein RM, Huang GC \& Coughlin CM. Development and implementation of a comprehensive strategic plan for medical education at an academic medical center. Acad Med, 2008; 83, 550559.

34. Egan T \& Jaye C. Communities of clinical practice: the social organization of clinical learning. Health, 2009; 13, 107-125.

35. Chervenak FA \& McCullogh LB. Responsibly managing the medical school - teaching hospital power relationship. Acad Med, 2005; 80, 690-693.

36. Culbertson RA, GoodeLD \& Dickler RM. Organizational models of medical school relationships to the clinical enterprise. Acad Med, 1996; 71, 1257-1274.

37. Weiner BJ, Culbertson R, Jones RF \& Dickler R. Organizational models for medical school - clinical enterprise relationships. Acad Med, 2001; 76, 113-124.

38. McKimm J. Developing tomorrow's leaders in health care education. FDTL4 Leadership development programme. Special report No 5. Case studies in leadership in medical and health care education. 2004. ISBN 0-7017-0174-9.

39. Malling. B, Scherpbier AJJA \& Ringsted C. What is the role of the consultant responsible for postgraduate education in the clinical department? Med Teach, 2007; 29, 471-477.

40. Margo K, Gazewood J, Jerpbak C, Burge S \& Usatine R. Clerkship directors' characteristics, scholarship, and support: A summary of published surveys from seven medical specialties. Teach Learn Med, 2009; 21, 94-99.

41. Schijven MP, Reznick RK, ten Cate OTJ, Grantcharov TP, Regehr G, Satterthwaite L, Thijssen AS \& MacRae HM. Transatlantic comparison of the competence of surgeons at the start of their professional career. Br J Surg, 2010; 97, 443-449.

42. Talbot M. Monkey see, monkey do: a critique of the competency model in graduate medical education. Med Educ, 2004; 38, 587-592.

43. Huddle TS \& Heudebert GR. Taking apart the art: The risk of anatomizing clinical competence. Acad Med, 2007; 82, 536-541.

44. Ten Cate $\mathrm{O} \&$ Scheele F. Competency-based postgraduate training: Can we bridge the gap between theory and clinical practice. Acad Med, 2007; 82, 542-547. 
45. Lingard L. What we see and don't see when we look at "competence": notes on a god term. Adv Health Sci Educ, 2009; 14, 625-628.

46. Mennin S. Self-organisation, integration and curriculum in the complex world of medical education. Med Educ, 2010; 44, 20-30.

47. Swanwick T. Informal learning in postgraduate medical education: from cognitivism to "culturism". Med Educ, 2005; 39, 859-865.

48. Irby DM, Cooke M \& O'Brien BC. Calls for reform of medical education by the Carnegie Foundation for advancement of teaching: 1910 and 2010. Acad Med, 2010; 85, 220-227.

49. Coles C. How students learn: the process of learning. In: Jolly B \& Rees L Eds. Medical education in the millenium (pp 63-84). Oxford: Oxford Medical Publications, 1998.

50. Harden RM \& Crosby J. AMEE Guide No 20: The good teacher is more than a lecturer - the twelve roles of the teacher. Med Teach, 2000; 22, 334-347.

51. Parsell G \& Bligh J. Recent perspectives on clinical teaching. Med Educ, 2001; 35, 409-414.

52. Kaufman DM. Applying educational theory inpractice. BMJ, 2003; 326, 213-216.

53. Teunissen PW, Scheele F, Scherpbier AJJA, van der Vleuten CPM, Boor K, Van Luijk SF \& Van Diemen-Steenvoorde JAAM. How residents learn: qualitative evidence for the pivotal role of clinical activities. Med Educ, 2007; 41, 763-770.

54. Kilminster S, Cottrell D, Grant J \& Jolly B. AMEE Guide No 27: Effective educational and clinical supervision. Med Teach, 2007; 29, 2-19.

55. Mann K, Gordon J \& McLeod A. Reflection and reflective practice in health professions education: a systematic review. Adv Health Sci Educ, 2009; 14, 595-621.

56. Bleakley A. Pre-registration house officers and ward-based learning: "new apprenticeship" model. Med Educ, 2002; 36, 9-15.

57. Bleakley A. Broadening conceptions of learning in medical education: the message from teamworking. Med Educ, 2006; 40, 150-157.

58. Carroll JS \& Edmondson AC. Leading organisational change in health care. Qual Safe Health Care, 2002; 11, 51-56.

59. Trochim WM, Cabrera DA, Milstein B, Gallagher RS \& Leischow SJ. Practical challenges of systems thinking and modeling in public health. Am J Pub Health, 2006; 96, 538-546.

60. Souba WW. The leadership dilemma. J Surg Res, 2007; 138, 1-9.

61. Leach DC. Changing education to improve patient care. Qual Health Care, 2001; 10, ii54-ii58.

62. Christmas C \& Ziegelstein RC. The seventh competency. Teach Learn Med, 2009; 21, 159-162.

63. Cheetham $G$ \& Chivers $G$. How professionals learn in practice: an investigation of informal learning amongst people working in professions. J Eur Indust Train, 2001; 25, 248-292.

64. Mann KV. Theoretical perspectives in medical education: past experience and future possibilities. Med Educ, 2011; 45, 60-68. 

CHAPTER 7

Discussion 
This chapter is a reflection on the findings in the five studies included in this thesis. The studies aimed to answer the overall research question: "How is work-based postgraduate medical education managed in clinical departments?" The first section in this chapter is a review of the main findings in the five studies. The second section provides a discussion on methodological aspects. The third section covers reflections, perspectives and implications for future research. Finally, future research questions are suggested.

\section{Main findings}

This is a summary of the findings according to the five research questions generated from the overall research question: How is work-based postgraduate medical education managed in clinical departments?

Research question 1: What is the role and position of the consultant responsible for postgraduate medical education and what is expected from him concerning tasks and responsibilities, qualifications, influence and prestige?

The consultants responsible for education (CRE) regarded their job as a leadership position, but they also found that there were many time-consuming administrative duties connected to the job. Key stakeholders' knowledge on what a CRE actually does was scarce and they found the position unclear. The CRE was, however, perceived as a leader of postgraduate medical education (PGME) in the department, although the leadership role was considered to be weak. The CREs' job was considered important, but not prestigious. There was an overall expectation of the CRE to exert more leadership and to influence the educational climate while still addressing the administrative duties.

Research question 2: What is the relation between the educational climate in the clinical department and the leadership skills of the consultant responsible for education?

The CREs were considered fairly good leaders and managers according to respondents' scores in a multi-source feedback (MSF) process. Surprisingly no correlation was found between the CREs' leadership skills and the educational climate. Similarly, there was no correlation between the CREs' administrative skills and the organisation of work in the departments. This might indicate that the influence of CREs in the department is minor.

Research question 3: To which extent are the areas in need of improvement (low ratings or gaps) identified by MSF responses from young doctors-in-training, con- 
sultants, heads of departments and CREs used in the development plans of PGME leaders in clinical departments?

The development plans worked out by CREs in connection with a MSF process mainly included plans to develop administrative skills, while plans for development of leadership skills were lagging behind. The plans for performance improvement concerning the "easy to set and measure" goals regarding management were very concrete and specific while plans for development of leadership skills and hence personal development were less concrete and expressed in superficial terminology.

Research question 4: What is the effect of a leadership course following a MSF procedure compared to MSF alone especially regarding development of leadership skills over time?

Neither MSF alone nor the participation in a leadership course combined with MSF seems to improve managerial skills of CREs.

Research question 5: What characterises the governance of PGME? What underlying assumptions and epistemologies are reflected in the content and organisation of outcome-based education curricula on paper? What characterises the curricula in use, enabling factors and barriers?

The governance of PGME is characterised by many stakeholders with contrasting interests, which they strive to maximise. Thus a power-struggle keeping each other in check might have developed. A slightly skewed power-balance in favour of the labour market parties seem to have emerged. This might make leaders in PGME incapable of making decisions and make it difficult to exert leadership. Furthermore it seems as if the organisation of clinical service and PGME runs in two separate lines making initiatives around PGME come from outside bodies and thus bypassing the ordinary line of command in the hospitals.

The curriculum on paper appears to be far from the curriculum in practice. The outcome-based postgraduate curriculum which takes physician roles as a starting point is somehow upside-down compared to the clinicians' perception of the clinical situation as the starting point for education and assessment. The tight structure of outcome-based education is not easy to live up to in the clinical departments where you have to rely on "opportunistic learning situations". Besides, the primarily behaviouristic approach of the written curriculum is in contrast to the more constructivist and socio-cultural approach to education in the clinical departments. Combining this with a lack of instructional design in the curricula makes leadership of PGME in clinical departments complex and unclear. 


\section{Conclusion}

In summary the educational leaders in clinical departments are perceived as having good management and leadership skills, but at the same time are considered to be in a weak, non-influential and unclear position. Their leadership skills seem rather resistant to traditional leadership development initiatives such as MSF, supported development plans, and courses. However, this might be due to the context in which the leadership is exerted, characterised by being inherently unclear regarding tasks, responsibilities, and line of reference. The governance of PGME includes many stakeholders with contrasting interests. However, there seems to be a slightly skewed power-balance among stakeholders in favour of the hospitals and the labour market parties, which emphasise the work-based nature of PGME. A prominent task for an educational leader is to manage outcome-based education with intraining assessment. It might be problematic to manage a basically behavioural curriculum in the clinical department where more constructivist and socio-cultural learning strategies are prevalent. Thus the curriculum on paper is far from the curriculum in practice. Furthermore it seems as if the instructional design lacks in the curricula.

In conclusion, the tasks and the context for leaders of PGME in clinical departments are complex and often conflicting, and take place in professional organisations, inherently reluctant to change. Even leaders with the best qualifications and competence might find it difficult to exert leadership under these conditions.

\section{Methodological aspects}

Research in management of PGME includes research in a complex working place due to the tight connection between clinical departments and PGME and the workbased nature of PGME. Clinical departments differ from each other in culture (1-3), organisation of daily work, and ways of conducting PGME $(4,5)$. This complexity and variation between departments might pose a threat to the validity of the results. Furthermore, the nature of the investigations in our study made it necessary to rely on convenience sampling. However, the departments included in our studies represented the distribution of departments in a whole Danish region in terms of specialty and there was an appropriate distribution between university and regional hospitals. The number of departments and participants was high and the drop-out rate acceptable considering the nature of the investigations. The response rate to MSF procedures was high and thus contributes to validity of the results. We did not replicate the studies, however, finding the same scores on the MSF in various groups at different times might represent a proxy for replication.

There are many definitions of leadership in the literature (6 - 10), and the taxonomy around leadership is still disputed $(10,11-15)$. For the purpose of the stud- 
ies, one of many definitions of leadership (6) and one of several taxonomies around leadership (13) was chosen. This might have narrowed the perspective on leadership, but nonetheless several aspects have been dealt with in the studies involved.

In our studies CREs seemed to be resistant to the investigated developmental initiatives, even though it is widely accepted that leadership can be learned $(6,7$, 16-26). This might be caused by a too short timeframe of the studies (one year), since leadership development includes experience and a maturation process, which is time-consuming $(9,17,23,24,27)$. However, extending the investigation over a longer time might have lead to higher drop-out rate. Furthermore, over time the external influences on leadership skills would probably contribute to make inferences in our results even more difficult.

The complex governance and the seemingly split organisation of PGME and clinical service contributes considerably to the complexity of investigating leadership in PGME. The narrowing of our investigations to comprise only the service line and the stakeholders here might be a limitation of our studies. However, PGME takes place in the clinical departments and thus the leadership role inside the departments is a very important factor in PGME acknowledging that there are other aspects of managing PGME.

In the design of the studies both qualitative and quantitative methods were included, and thus ensuring a triangulation. The results of the five studies involved all pointed in the same direction increasing the validity of the results.

\section{Generalisability}

Despite the above mentioned limitations, the results in the studies included in this thesis ought to be transferable to other contexts than the Danish organisation of PGME. As described in Chapter 6 there are many similarities in the complex governance in PGME around the world, even if the culture in which PGME is embedded differs between countries (28). Educators and clinicians are challenged with reforms in PGME comprising outcome-based education and introducing new training methods and in-training assessment to guarantee the societal demands for high quality and safe health care (29). In chapter 6 the similar trajectory of the development of the outcome-based curricula in various countries from core competencies to assessable learning goals is described (30-33).

In some countries the university plays a major role, in others national boards of health and still in others the unions are involved (34-38). However, one feature is common - there are two seemingly separate lines of reference $(39,40)$, which must be united at the departmental level to make the work-based PGME function in practice.

Finally, PGME takes place in professional organisations since this is the most natural way for professionals like physicians to organise (10). In summary, every- 
where the medical profession is challenged by the same aspects of PGME: the complex governance, the split line of reference, the professional organisation and the implementation of outcome-based education and in-training assessment where the curriculum on paper is far from the curriculum in practice (Chapter 6).

\section{Reflections, perspectives and implications for future research}

\section{Reflections}

The thesis builds on three perspectives in management of PGME in clinical departments: the task (Chapter $2 \& 3$ ), the leader (Chapter 4 \& 5) and the context (Chapter 6). I used a windmill in the introduction as a figure of speech. The windmill converts strong, windy impulses into new forms of energy, while the blades all move in the same direction. The windmill was drawn with three blades - representing the three perspectives on management of PGME in clinical departments. This drawing might be too simplistic. The results in the five studies reveal a host of perspectives, which all contribute to the complexity of the clinical department as a work-place, and contribute to the unclear image of what managing PGME in the clinical department is all about. However, all these perspectives still relate to one of the three major perspectives used in this thesis - that is, if a certain overlap between the blades is allowed, and if it is kept in mind that none of the three major perspectives can stand alone, and none of them can be removed.

The figure below is an elaboration of the three major perspectives: the task, the leader and the context relating to the results of this thesis. The list is not exclusive other perspectives might be speculated. Thus, all the perspectives coming from the educational line are omitted from the figure, they come from outside bodies. In the windmill metaphor they might represent one of the winds contributing to making the blades move. The figure also illustrates the importance of the context and governance of PGME. The complexity in the governance of PGME contributes to making it difficult to exert leadership even though the leaders are regarded as good leaders. 


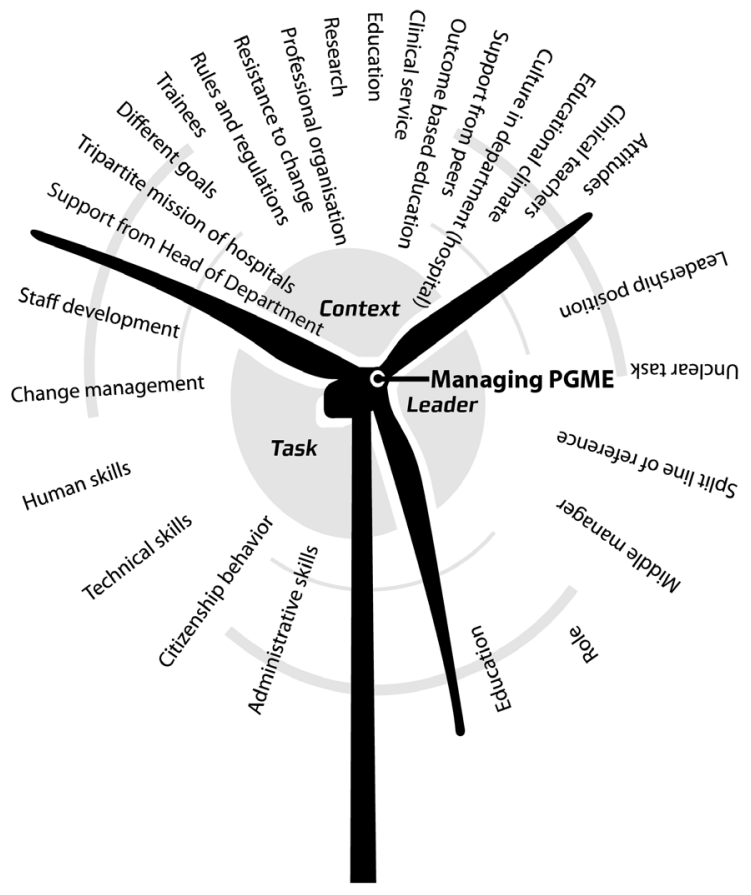

From an organisational theoretical point of view it is beneficial to appoint one person responsible for the management of PGME, even in professional organisations (10). This contributes to getting things done. Furthermore, the importance of PGME is clearly enunciated by making it a leadership position. However, making one person responsible might seduce others to disclaim responsibility (Chapter 2). Combining this with the reluctance of the mid-level managers (CREs) to delegate tasks to colleagues, whom they regard as being busy in clinical service (41), might contribute to the scanty knowledge key stakeholders in a clinical department have about the duties and tasks of the educational leaders, as outlined in Chapter 2. Whether the educational leaders are capable of delegating tasks to colleagues to get them involved, or not, they still need proper support from the head of department, peer consultants, trainees, and all other staff in order to do the job, as it involves everybody in the department. In Chapters 2-4 it is described how key stakeholders believe that CREs do a great job and how they regard the CREs as good leaders, and thus believing that the responsibility for PGME is well placed inside the department.

It might, however, be challenging for the educational leader to exert true leadership in the department as long as key stakeholders, as described in Chapters 1 and 2, perceive the CRE as a weak leader without influence. It is well known that scarce and unclear knowledge of what leaders really do can be an impediment to leadership (42). Combining this with the complex governance of PGME described in Chapter 6 makes management of PGME a delicate matter. The results in Chapter 5 show 
that neither education nor personal development nor a combination of the two appears to be the sole solution to these challenges.

In PGME trainees rotate between clinical departments and hospitals. It thus becomes a major concern to manage trainees' longitudinal development across rotations. This aspect of management in PGME has not been solved by introducing a CRE in each clinical department, since he is only responsible for the trainee during his/her stay at this particular department (Chapter 1). Programme Directors, as seen in other countries, are responsible for tracking trainees across rotations $(36,37)$. However, they might not have legitimate access to change conditions inside particular departments to the same extent as CREs, even though the Programme Directors can make decisions on whether or not to send trainees to the department. Thus both organisational models have strengths and weaknesses.

The five studies in this thesis support the impression that managing PGME is important $(22,37,43-46)$ and that the workload in the management of PGME is increasing (47). One of the major responsibilities of an educational leader in clinical departments is the introduction of outcome-based education (OBE) and in-training assessment (ITA). The curriculum in practice is still far from the written curriculum (48-55). As described in Chapter 6, the slow implementation might be rooted in the difficult power position of educational leaders hold, but it might also be rooted in the complex governance of PGME where educational initiatives seem to bypass the administrative line in hospitals where PGME takes place. However, there may be inherent difficulties in the concept of OBE in connection with work-based teaching and learning in clinical departments. Although OBE theoretically is the best way of designing PGME, the reference to OBE in its present form stems from the undergraduate curriculum and thus might not have been "translated" into the complex clinical world in which PGME takes place (56). This translation currently is placed in the hands of the educational leaders in the clinical departments, since the curricula provide clear instruction on how to use OBE in clinical work-based educations. In Chapter 6 it is described how the basic assumption of clinical teachers - that education is based on clinical situations, and is not artificially divided into roles or competencies - has been incorporated in the "second generation" of OBE curricula in PGME. However, clinical teachers and trainees have still not been provided with clear instructional strategies to be applied to the work-based education in PGME. The next generation of curricula might benefit from taking in systems-based thinking instead of relying on individualistic learning theories (57-60). Teunissen et al. (61) made a model of work-based learning that might stimulate more research into the way trainees learn in clinical context, while working with patients. 


\section{Perspectives}

The way PGME is structured in two seemingly separate lines raises the question of whether a similar distance has evolved in the relationship between educators and clinicians as is seen between managers and clinicians. The discussion in the manager-physician relationship often comes to the conclusion that physicians should be encouraged to become more involved in decision making, that hospital managers should commit to greater transparency in decision making, and that communication between the two parties could be improved by creating a common (management) language $(45,62-64)$. In the physician-manager relationship discussion it has been suggested that managers should try to understand the world of the physicians in order to improve their relationship $(65,66)$. Further, it has been described that when there is a higher degree of cooperation and understanding between managers and physicians the clinical service benefits (62-66).

This precedent in relationship between physicians and managers has parallels to the relation between clinical teachers and PGME authorities, cf. Chapter 6 . It is tempting to make the inference that PGME authorities could benefit from understanding the clinical context on a wider scale and that collaboration between key stakeholders in education and clinical service would lead to improvements in PGME. Collaborative governance and congruency in expectations of the strategic apex of clinical service and of PGME authorities, respectively, is a critical factor for success $(25,67)$. Maybe reaching a common understanding between clinicians and PGME authorities and working towards common goals will lead to better outcome regarding medical education (59). This collaboration and understanding might be accomplished by combining the considerable knowledge of teaching and learning principles and practice that professional educators have, with clinicians' considerable experience with work-based learning, and the knowledge and experience managers have in both management and leadership of health care organisations.

\section{Implications for future research}

The research behind this thesis has made valuable contributions to the understanding of the educational leaders' role and position in the clinical department, and to the understanding of the governance of PGME. The thesis has focused on the leader, the task and the context of leadership in PGME. The findings in our studies all point at the complexity of PGME and the environment in which PGME takes place as important factors. The empirical data show that there is a need for more research in this area. Given the complexity of PGME approaches and methods developed to investigate complex problems such as the realist review, success-case method or empowerment evaluations should be considered (68-72). The use of these more socio-cultural approaches might change focus to embrace the whole complexity of the environment where PGME takes place instead of using a more 
fragmented approach as seen hitherto. Such future studies might help us in understanding what works for whom, in which circumstances, in which respects and how. Some relevant questions could be:

- What is the connection between the educational climate and the organisational culture in a clinical department?

- How do we support management and leadership of PGME?

- What characterises the leadership role of PGME leaders - in the educational line?

- What characterises successful clinical departments?

- What kind of implementation strategies work in PGME? 


\section{References}

1. Schein EH. Organizational culture and leadership, $3^{\text {rd }}$ Ed. San Francisco, California: Jossey-Bass; 2004.

2. Cross V, Hicks C, Parle J \& Field S. Perceptions of the learning environment in higher specialist training of doctors: implications for recruitment and retention. Med Educ, 2006; 40: 121-128.

3. Genn JM. AMEE Medical Education Guide No. 23 (Part 2): Curriculum, environment, climate, quality and change in medical education - a unifying perspective. Med Teach, 2001; 23: 445-454.

4. Guest CB, Regehr G \& Tiberius RG. The lifelong challenge of expertise. Med Educ, 2001; 35: 78-81.

5. Ringsted C, Skaarup AM, Henriksen AH \& Davis D. Person-task-context: a model for designing curriculum and in-training assessment in postgraduate education. Med Teach, 2006; 28: 70-76.

6. Yukl G. Leadership in organizations, $6^{\text {th }}$ Ed. Upper saddle River, New Jersey: Pearson Education Inc.; 2006.

7. McKimm J \& Swanwick T. Educational Leadership. Understanding Medical Education Series. ASME; 2007

8. Kotter JP. On What leaders really do. Boston, Massachusetts: Harvard Business School press; 1999.

9. Fullan M. Leading in a culture of change. San Fransisco, California: Jossey-Bass; 2001.

10. Mintzberg H. The structuring of organizations. Upper Saddle River, New Jersey: Prentice Hall Inc.; 1979.

11. Borman WC \& Brush DH. More progress toward a taxonomy of managerial performance requirements. Hum Perform, 1993; 6: 1-21.

12. Motowidlo SJ, Borman WC \& Schmit MJ. A theory of individual differences in task and contextual performance. Hum Perform, 1997; 10: 71-83

13. Scullen SE, Mount MK \& Judge TA. Evidence of the construct validity of developmental ratings of managerial performance. J Appl Psychol, 2003; 88: 50-66.

14. Coleman VI \& Borman WC. Investigating the underlying structure of the citizenship performance domain. Hum Resour Manage R, 2000; 10: 25-44.

15. Conway JM. Distinguishing contextual performance from task performance for managerial jobs. J Appl Psychol, 1999; 84: 3-13.

16. Day DV \& Harrison MM. A multilevel, identity-based approach to leadership development. Hum Resour Manage R, 2007; 17: 360-373.

17. Simpson J \& Calman K. Making and preparing leaders. Med Educ, 2000; 34: 211-15.

18. Mintzberg H. The manager's job: Folklore and facts. Harvard Bus Rev, 1990: 163-76.

19. Golemann D. Leadership that gets results. Harvard Bus Rev, 2000; 78: 78-90.

20. Day DV. Leadership development: A review in context. Leadership Quart, 2001; 11: 581-613.

21. Hill F \& Stephens C. Building leadership capacity in medical education: developing the potential of course coordinators. Med Teach, 2005; 27: 145-49.

22. McKimm J. Developing tomorrow's leaders in health and social care education. FDTL4 Leadership development programme. Special report No 5. Case studies in leadership in medical and health care education. 2004.

23. Hollenbeck GP \& Hall DT. Self-confidence and leader performance. Organ Dyn, 2004; 33: 254-69

24. Rooke D \& Torbert WR. The seven transformations of leadership. Harvard Bus Rev, 2005: 67-76.

25. Lobas JG. Leadership in Academic Medicine: Capabilities and conditions for organizational success. Am J Med, 2006; 119: 617-21.

26. Quatro SA, Waldman DA \& Galvin BM. Developing holistic leaders: Four domains for leadership development and practice. Hum Res Manag R, 2007; 17: 427-41.

27. Souba WW. The new leader: new demands in a changing, turbulent environment. J Am Coll Surg, 2003; 197: 79-87.

28. Seguin C \& Hodges B. Educating doctors in France and Canada: are the differences based on evidence or history? Med Educ, 2005; 39: 1205-1212.

29. Harden RM. Trends and the future of postgraduate medical education. EMJ, 2006: 23: 798-802. 
30. Frank JR. The CanMEDS 2005 Physician Competency Framework. Better standards, Better physicians. Better care. Ottawa: The Royal College of Physicians and Surgeons of Canada. 2005. Retrieved 10 January 2010 from www.rcpsc.medical.org

31. Postgraduate Medical Education and Training Board (PMETB). Educating tomorrow's doctors Future models of medical training; medical workforce shape and trainee expectations. 2008. Retrieved August 8, 2009 from www.pmetb.org.uk .

32. Royal College of Physicians and Surgeons of Canada. Skills for the new millenium: report of the societal needs working group. 1996. www.rcpsc.medical.org . Retrieved September 2009.

33. Leach DC. A model for GME: shifting from process to outcomes. A progress report from the Accreditation Council for Graduate Medical Education. Med Educ, 2004; 38: 12-14.

34. The Danish Ministry of Health. Fremtidens speciallæge. Betænkning fra speciallægekommissionen. Betænkning nr. 1384 [The future Specialist. Report and recommendation on specialist training. Report no. 1384]. 2000. www.sum.dk. In Danish.

35. Postgraduate Medical Education and Training Board (PMETB). Postgraduate Medical Education and Training Board. Strategy document: 2006-2010. 2006. Retrieved from the Web August 2006. http:// www.pmetb.org.uk

36. Accreditation Council for Graduate Medical Education, ACGME. Program director guide to the common programme requirements. 2009. Retrieved from the Web January 2011. www.acgme.org

37. Royal college of Physicians and Surgeons of Canada. General standards applicable to the university and affiliated sites. 2007. Retrieved January 6, 2010 from www.rcpsc.medical.org.

38. Legeforeningen. Specialist training for physicians in Norway. 2005. Retrieved from the Web august 2006. http:// www.legeforeningen.no

39. Schwartzstein RM, Huang GC \& Coughlin CM. Development and implementation of a comprehensive strategic plan for medical education at an academic medical center. Acad Med, 2008; 83: 550559.

40. Weiner BJ, Culbertson R, Jones RF \& Dickler R. Organizational models for medical school - clinical enterprise relationships. Acad Med, 2001; 76: 113-124.

41. Gleeson D \& Shain F. Managing ambiguity: between markets and managerialism - a case study of "middle" managers in further education. Sociol Rev, 1999; 47: 461-490.

42. Longnecker DE, Patton M \& Dickler RM. Roles and responsibilities of chief medical officers in member organisations of the Association of American Medical Colleges. Acad Med, 2007; 82: 258-263.

43. Klinge B. Leadership in academic institutions: raising the value of teaching. Med Educ, 2000; 34: 201-02.

44. Parsell G \& Bligh J. Encouraging educational leadership. Med Educ, 2000; 34: 199-200.

45. Davis MH \& Harden RM. Leadership in education and the strategy of the dolphin. Med Teach, 2002; 24: 581-582.

46. World Federation for Medical Education. Postgraduate Medical Education. WFME Global Standards for Quality Improvement. WFME Office, University of Copenhagen, Denmark. 2003.

47. Beauchamp RD. The changing roles of a surgical department chair. Adapting to a changing environment. Arch Surg, 2005; 140: 258-263.

48. Bayer M. Speciallægeuddannelse i Danmark - en empirisk unders $\varnothing$ gelse af tendenser inden for speciallægeuddannelsen efter implementeringen af den nye speciallægeuddannelse. [Specialist training in Denmark - an empirical analysis of tendencies in specialist training after implementation of the new reform]. København, Danmarks Pædagogiske Universitets forlag. 2007. In Danish.

49. Dehn P, Nielsen CH, Larsen K \& Bayer M. Implementering af speciallægereformens syv roller. [Implementing the seven roles of the specialist training reform]. UfL, 2009; 171/19: 1580-1584. In Danish.

50. Swing SR. The ACGME outcome project: retrospective and prospective. Med Teach, 2007; 29: 648 654.

51. Agius SJ, Willis SC, McArdle PJ \& O'Neill PA. Managing change in postgraduate medical education: still unfreezing? Med Teach, 2008; 30: e87-e94. 
52. Didwania A, McGaghie WC, Cohen E \& Wayne DB. Internal medicine residency graduates' perception of the systems-based practice and practice-based learning and improvement competencies. Teach Learn Med, 2010; 22: 33-36.

53. Davis DJ, Skaarup AM \& Ringsted C. A pilot survey of junior doctors' confidence in tasks related to broad aspects of competence. Med Teach, 2005; 27: 548-552.

54. Harden RM. Outcome-based education - the ostrich, the peacock and the beaver. Med Teach, 2007; 29: 666-671.

55. Tsouroufli $M$ \& Payne $H$. Consultant medical trainers, modernising medical careers (MMC) and the European time directive (EWTD): tensions and challenges in a changing medical education context. BMC Med Educ, 2008; 8: 31.

56. Ten Cate $\mathrm{O} \&$ Scheele F. Competency-based postgraduate training: Can we bridge the gap between theory and clinical practice. Acad Med, 2007; 82: 542-547.

57. Bleakley, A. Broadening conceptions of learning in medical education: the message from teamworking. Med Educ, 2006; 40: 150-157.

58. Lingard, L. What we see and don't see when we look at "competence": notes on a god term. Adv in Health Sci Educ, 2009; 14: 625-628.

59. Irby DM, Cooke M \& O'Brien BC. Calls for reform of medical education by the Carnegie Foundation for the advancement of teaching: 1910 and 2010. Acad Med, 2010; 85: 220-227.

60. Mann KV. Theoretical perspectives in medical education: past experience and future possibilities. Med Educ, 2011; 45: 60-68.

61. Teunissen PW, Scheele F, Scherpbier AJJA, van der Vleuten CPM, Boor K, Van Luijk SF \& Van Diemen-Steenvoorde JAAM. How residents learn: qualitative evidence for the pivotal role of clinical activities. Med Educ, 2007; 41: 763-770.

62. Carroll JS \& Edmondson AC. Leading organisational change in helath care. Qual Saf Health Care, 2002; 11: 51-56.

63. Rundall TG, Kaiser HJ, Davies HTO \& Hodges CL. Doctor-manager relationships in the United States and the United Kingdom. J Healthc Manage, 2004; 49: 251-270.

64. Souba WW. The leadership dilemma. J Surg Res, 2007; 138: 1-9.

65. Chervenak FA \& McCullogh LB. Responsibly managing the medical school - teaching hospital power relationship. Acad Med, 2005; 80: 690-693.

66. Edwards N. Doctors and managers: building a new relationship. Clin Med, 2005; 5: 577-579.

67. Curry RH, Burgener AJ, Dooley SL \&Christopher RP. Collaborative governance of multiinstitutional graduate medical education: Lessons from the McGraw Medical Centre of Northwestern University. Acad Med, 2008; 83: 568-573.

68. Pawson R, Greenhalgh T, Harvey G \& Walshe K. Realist review - a new method of systematic review designed for complex policy interventions. J Health Serv Res Policy, 2005; 10: 1-21.

69. Modell S. In defence of triangulation: A critical realist approach to mixed methods research in management accounting. Manage Account Res, 2009; 20: 208-221.

70. Brinkerhoff RO. The success case method. San Francisco, California: Berrett-Koehler Publishers Inc. 2003.

71. Fetterman DM. Empowerment evaluation. AJE, 1994; 15: 1-15.

72. Dahler-Larsen $P$ \& Krogstrup HK, Eds. Tendenser i evaluering. [Tendencies in evaluation]. Odense, Denmark: Syddansk Universitetsforlag. 2001. In Danish. 

CHAPTER 8

\section{Summary}


The central theme in this thesis is the management of postgraduate medical education (PGME) in clinical departments with focus on the characteristics of the leadership role of the educational leaders in the clinical departments (CRE). Postgraduate medical education is a work-based education that predominantly takes place in specialised clinical departments. With the appointment of a CRE, the responsibility for managing PGME is clear, which from an organisational theoretical point of view seems optimal. The CRE's job resembles the job of a site director or a programme director known in other countries. The introduction of out-come based education (OBE) and in-training assessment is a major challenge for the CRE and for the clinical departments. At the same time society, health care services and clinical departments constantly undergo changes. The importance of managing PGME in clinical departments in times of change is well recognised.

The overall research question in this thesis is: What characterises leadership and management of PGME in clinical departments?

The thesis consists of five independent studies conducted around leadership of PGME in clinical departments. In the first study we explored the role and position of the clinical consultant responsible for education in the clinical departments (CRE). The second study focused on the influence of a CRE on the educational culture in the clinical departments. In the third and fourth study we investigated the effect of formal leadership training and personal development on the leadership skills of CREs. Finally the fifth study dealt with the wider context of the management of PGME.

Chapter 1 contain the introduction to this thesis. The theme in the thesis will be addressed from three perspectives of the management of PGME in clinical departments: the task, the leader and the context. The introduction provides the theoretical background for these perspectives.

The task perspective refers to the management of PGME in the clinical department. It focuses on what the CREs are actually doing and how key stakeholders perceive his leadership and position in the clinical department. The CRE's primary duty as a mid-level manager is interpretation and implementation of policies and programs. However he also plays a major role in facilitating educational changes in the department. Chapters two and three deal with the task perspective.

The leader perspective comprises the CRE's leadership skills and the effect of developmental initiatives. As professionals, physicians are more aligned with their profession than with the organisation they practice in. Thus physicians in leadership- 
positions are often novices regarding leadership and in need of developing a more systemic view and fundamental organisational understanding.

To develop leadership skills it is therefore recommended to combine experience as a leader with formal leadership education and personal development. Multisource feedback (MSF) is a popular and widely used method to initiate personal development. Chapters four and five focus on the effect of MSF as well as the impact of a formal leadership course on CRE's leadership skills.

The context perspective deals with PGME as a work-based education and thus inseparable from the work in clinical hospital departments. Hospital departments are complex workplaces where it is difficult to make an exact plan for educating young physicians prior to full licensure (trainees). The very structured OBE with in-training assessment thus may be in conflict with actual practice in the clinical departments (the micro-level context). The many stakeholders in the governance of PGME (macro-level) contribute to the complexity in the leadership of PGME in clinical departments. Chapter six presents the context from both the micro-level and the macro-level perspective.

Chapter 2 answers a basic question in this thesis: What is a CRE actually doing? The role and position of a CRE was investigated through focus-group discussions (6 focus groups) and semi-structured interviews (3 interviews). Participants were medical chiefs of hospitals (1), heads of departments (2), consultants (9), CREs (6) and trainees (18). Key stakeholders' knowledge of what a CRE is doing was generally scarce. Both the CREs and key-stakeholders acknowledged his leader-position. However, stakeholders found that the duties of a CRE were mainly administrative like taking care of the organisation and the paperwork involved in PGME, while the CREs perceived their function as comprising both administrative and leadership tasks. The CRE was not perceived as influential, and the job was not considered prestigious. However, it was generally agreed that the CRE could get the power and prestige he wanted by doing a good job, and that this eventually would lead to more influence. The CREs were in a position to take on more leadership and it was an overall expectation of the CRE to exert more leadership while still taking care of the administrative duties. Leadership development was suggested.

Chapter 3 deals with influence of the CRE on the educational climate in the clinical department. Participants were 56 CREs and their departments. We used MSF to measure leadership skills of CREs. The educational climate was evaluated using a questionnaire among all physicians in the department. Surprisingly no correlation was found between the leadership skills of CREs and the educational climate. Likewise, there was no correlation between the administrative skills of CREs and the 
organisation of work in the departments. This indicates that the CRE has minor influence on the educational climate and the daily work.

Chapter 4 describes the development, validation and use of a MSF instrument for CREs. The MSF instrument comprised 69 questions of which 38 (55\%) concerned leadership while 31 (45\%) dealt with administration. In the study, 52 CREs went through a MSF procedure. The CREs chose respondents among the other consultants and the trainees in the department as well as the head of the department. Based on the scores a report pointed out low/ high scores and positive and negative gaps were worked out. Besides this report the CRE received personal feedback from an experienced human resource consultant that guided the CRE in drafting a personal development plan.

The response rate of the MSF-procedure was above $80 \%$. The vast majority of initiatives in the developmental plans concerned administrative duties or management $(75 \%)$ while initiatives concerning development of leadership skills were lagging behind (25\%). This is in contrast to the more even distribution of the questions in the questionnaire. The plans for performance improvement concerning the "easy to set and measure" goals regarding management were concrete and specific while plans for development of leadership skills and hence personal development were less concrete and expressed by superficial terminology. The plans did not necessarily reflect the areas of improvement identified by low ratings or gaps between selfratings and the ratings of others in the MSF process.

Chapter 5 brings the effect of a combination of leadership developmental initiatives in focus. The study was conducted as an intervention study with a control group. The intervention was participation in a leadership course developed specifically for CREs. In the intervention group participation in the leadership course was combined with a MSF process before the course and one year after participation. The CREs in the control-group went through MSF twice with a one year interval. In all 56 CRES participated, 28 in the intervention and control group, respectively.

The CREs in the intervention group rated the course as highly important and reported to have learned from participation. However this was not reflected in the MSF scores that were unchanged one year after compared to the scores of CREs in the control group. The study therefore indicates that a leadership course following a MSF procedure compared to MSF alone does not improve leadership skills of CRES in clinical departments.

Chapter 6 provides an analysis of the Danish PGME curriculum. The analysis revealed several challenges in the context of the managerial position of a CRE. The governance of PGME is characterised by many stakeholders with contrasting interests, which they strive to maximise. Thus a power-struggle keeping each other in 
check might have developed. A slightly skewed power-balance in favour of the labour market parties seems to have emerged. This might make leaders in PGME incapable to make decisions and make it difficult to exert leadership. Furthermore it seems as if the organisation of clinical service and PGME runs in two separate lines making initiatives around PGME come from outside bodies and thus bypassing the ordinary line of command in the hospitals.

The responsibility to establish coherence between the educational and the administrative line has been placed on the CRE, who is a mid-level manager in the administrative line. In educational matters the CRE refers to an outside body while in more administrative matters he refers to the head of department, and thus the administrative line. Even if he might refer to the administrative line in educational matters since the chief of the hospital is ultimately responsible for PGME in the hospital, there appears to be no natural connection between the chief of the hospital and the PGME authorities.

Postgraduate medical education is a work- based education and PGME is inseparable from clinical service. However, there seems to be a discrepancy between the curriculum on paper describing the competent physician in separable roles or competencies, and the curriculum in use, which takes clinical situations embracing all roles as point of reference. In theory, an outcome-based curriculum is ideal to secure high quality and safe patient treatment, and translating the OBE curriculum into clinical practice becomes a prominent part of the CREs' managerial duties. However, the tight structure of outcome-based education is not easy to live up to in the clinical departments where you have to rely on "opportunistic learning situations". Besides, the basically behaviouristic approach of the written curriculum is in contrast to the more constructivist and socio-cultural approach to education in the clinical departments. Combining this with a lack of instructional design in the curricula makes leadership of PGME in clinical departments a complex and unclear task.

\section{Conclusion}

The research behind this thesis has given valuable contributions to the understanding of management of work-based postgraduate medical education in clinical departments. The educational leaders in clinical departments are perceived as having good management and leadership skills, but at the same time are considered in a weak, non-influential and unclear position. Their leadership skills seem rather resistant to traditional leadership development initiatives such as MSF, supported developmental plans, and courses. However, this might be due to the context in which the leadership is exerted, which is characterised of being inherently unclear regarding tasks, responsibilities, and line of reference. The governance of PGME includes many stakeholders with contrasting interests. However, there seems to be a slightly 
skewed power-balance among stakeholders in favour of the hospital owners and the labour market parties, which might emphasise the work-based nature of PGME.

A prominent task for an educational leader is to manage outcome-based education with in-training assessment. It might be problematic to manage a basically behavioural curriculum in the clinical department where more constructivist and socio-cultural learning strategies are prevalent. Thus the curriculum on paper is far from the curriculum in practice. Furthermore it seems as if the instructional design is lacking in the curricula.

In conclusion the task and the context for leaders of PGME in clinical departments are complex and often conflicting, and take place in professional organisations, which are inherently reluctant to changes. The role of leaders of PGME in clinical departments is characterised by being unclear regarding tasks, responsibilities, and line of reference. Even leaders with the best qualifications and competences might find it difficult to exert leadership under these conditions. 
CHAPTER 9

Samenvatting (Summary in Dutch) 
Het centrale thema van dit proefschrift is het onderwijsmanagement van de specialistenopleiding op de klinische afdelingen, met nadruk op de kenmerken van de leiderschapsrol van de opleiders die binnen de klinische afdelingen verantwoordelijk zijn voor het onderwijs (CRE). De specialistenopleiding speelt zich voornamelijk af in de klinische werkplaats binnen de verschillende klinische afdelingen. Met het aanstellen van een opleidingscoördinator is de verantwoordelijkheid voor de specialistenopleiding duidelijk vastgelegd. Vanuit een theoretisch organisatiekundig oogpunt gezien is dit een optimale managementsituatie. De positie van de opleidingscoördinator in de specialistenopleiding is vergelijkbaar met de rol van een 'site director' of 'programme director' in andere landen. De invoering van uitkomstgericht onderwijs (OBE) en werkplektoetsing stelt zowel de opleidingscoördinator als de klinische afdeling voor een grote uitdaging. Tegelijkertijd zijn er voortdurend veranderingen in maatschappij, gezondheidszorg en ook binnen de afdelingen. De betekenis van onderwijsmanagement voor de specialistenopleiding in tijden van verandering wordt algemeen onderschreven.

De centrale onderzoeksvraag van dit proefschrift is: Wat zijn de kenmerken van leiderschap en onderwijsmanagement met betrekking tot de specialistenopleiding binnen de klinische afdelingen?

Dit proefschrift bestaat uit vijf afzonderlijke studies betreffende leiderschap op het gebied van het onderwijs in de specialistenopleidingen binnen de klinische afdelingen. Het eerste onderzoek betrof de rol en positie van de specialist die binnen een afdeling verantwoordelijk is voor de specialistenopleiding (CRE). Het tweede onderzoek betrof de invloed van deze opleidingscoördinator op de onderwijscultuur binnen de afdeling. In de derde en het vierde studie is onderzocht wat het effect is van formele managementtraining en persoonlijke ontwikkeling op de managementvaardigheden van opleidingscoördinatoren. Het vijfde en laatste onderzoek was gericht op de bredere context van het management van de specialistenopleiding.

Hoofdstuk 1 vormt de inleiding van dit proefschrift. Het centrale thema wordt belicht vanuit drie invalshoeken van waaruit onderwijsmanagement binnen klinische afdelingen kan worden bestudeerd: de taak, de leider en de context. De introductie beschrijft de theoretische achtergronden van deze invalshoeken.

Vanuit de taakgerichte invalshoek ligt de nadruk op het onderwijsmanagement van de specialistenopleiding binnen een klinische afdeling. Hierbij wordt vooral gekeken naar de activiteiten van de opleidingscoördinator en de opvattingen van de belangrijkste groepen binnen de afdeling ten aanzien van diens leiderschap en positie. Als functionaris op het niveau van middenmanagement heeft de opleidingscoördinator als belangrijkste taak het beleid en de programma's te interpreteren en uit te voe- 
ren. Hij speelt echter ook een belangrijke rol in het stimuleren van onderwijsvernieuwingen binnen de afdeling. Hoofdstuk 2 en 3 zijn gewijd aan dit taakgerichte perspectief.

Vanuit de leiderschapsinvalshoek wordt gekeken naar de managementvaardigheden van de opleidingscoördinator en het effect van initiatieven ten aanzien van het ontwikkelen daarvan. Artsen voelen zich als professionals meer betrokken bij hun beroepsgroep dan bij de organisatie waarbinnen zij werkzaam zijn. Dit betekent dat een leiderschapspositie vaak nieuw is voor de arts die deze rol bekleedt en dat de arts voor het functioneren in deze rol een systematische visie en fundamenteel inzicht met betrekking tot organisatorische aspecten moet ontwikkelen.

Voor het ontwikkelen van leiderschapsvaardigheden is het daarom aan te bevelen om ervaring in de leiderschapsrol te combineren met formeel onderwijs in leiderschap en persoonlijke ontwikkeling. 360-gradenfeedback is een bekende en vaak toegepaste methode om de persoonlijke ontwikkeling te stimuleren. Hoofdstuk 4 en 5 beschrijven onderzoeken naar de invloed van 360-gradenfeedback en een formele leiderschapscursus op de ontwikkeling van leiderschapsvaardigheden van opleidingscoördinatoren binnen de specialistenopleiding.

Vanuit de contextinvalshoek wordt naar de specialistenopleiding gekeken als een vorm van werkplekleren die een ondeelbaar geheel vormt met het werk op de klinische afdelingen. Ziekenhuisafdelingen zijn complexe werkomgevingen, die er niet op zijn ingericht om mogelijkheden te bieden voor het opstellen van een welomschreven onderwijsplan voor AIOS. Sterk gestructureerd uitkomstgericht onderwijs met werkplaatsgebonden toetsing kan daardoor strijdig zijn met de dagelijkse praktijk op klinische afdelingen (context op microniveau). De vele belanghebbenden bij het onderwijsmanagement van de specialistenopleiding (macroniveau) dragen bij tot de complexiteit van leiderschap voor de specialistenopleiding op klinische afdelingen. Hoofdstuk 6 geeft een beschouwing van deze context zowel op micro- als op macroniveau.

Hoofdstuk 2 probeert een antwoord te geven op een fundamentele vraag van dit proefschrift: Wat doet een opleidingscoördinator (CRE)? The rol en positie van de opleidingscoördinator zijn onderzocht met behulp van zes focusgroepen en drie semigestructureerde interviews, waaraan werd deelgenomen door één medisch directeur van een ziekenhuis, twee afdelingshoofden, negen specialisten, zes opleidingscoördinatoren en achttien AIOS. De belangrijkste belangengroepen hadden over het algemeen weinig inzicht in de werkzaamheden van de opleidingscoördinator. De opleidingscoördinatoren en de belangrijkste belangengroepen erkenden de leiderschapsrol van de opleidingscoördinator. De belanghebbenden waren echter van mening dat de opleidingscoördinator voornamelijk administratieve taken had, 
zoals organisatie en administratie van de specialistenopleiding, terwijl de opleidingscoördinatoren zelf van mening waren dat hun taken zowel administratieve als sturende aspecten behelsden. De opleidingscoördinator werd niet gezien als een functie met veel invloed en status. Men was het er echter over eens dat de opleidingscoördinator macht en status kon verwerven door zijn taken goed uit te voeren, waardoor hij uiteindelijk zijn invloed kon versterken. De opleidingscoördinatoren konden meer leiderschapstaken op zich nemen en de algemene verwachting was dat de opleidingscoördinator naast meer leiderschapstaken zijn administratieve taken kon blijven vervullen. Er werd voorgesteld om leiderschapsontwikkeling te bevorderen.

Hoofdstuk 3 beschrijft een onderzoek naar de invloed van opleidingscoördinatoren op het onderwijsklimaat binnen hun afdeling. Zesenvijftig opleidingscoördinatoren en hun afdelingen namen deel aan het onderzoek. Met behulp van 360gradenfeedback werden leiderschapsvaardigheden gemeten. Aan alle artsen op de afdeling werd gevraagd een enquête in te vullen over het onderwijsklimaat. Een verrassende uitkomst was dat er geen relatie werd gevonden tussen de leiderschapsvaardigheden van de opleidingscoördinator en de organisatie van het werk binnen de afdeling. Er werd ook geen verband gevonden tussen de administratieve vaardigheden van de opleidingscoördinator en de organisatie van het werk binnen de afdeling. Dit wijst erop dat de invloed van de opleidingscoördinator op het onderwijsklimaat en de dagelijkse gang van zaken slechts gering is.

In hoofdstuk 4 worden de ontwikkeling, validering en toepassing van een instrument voor 360-gradenfeedback voor opleidingscoördinatoren beschreven. Het instrument bestaat uit 69 vragen: 38 vragen (55\%) over leiderschap en 31 vragen (45\%) over administratie. Tweeënvijftig opleidingscoördinatoren namen deel aan een 360-gradenfeedbackprocedure. De opleidingscoördinatoren kozen als beoordelaars specialisten en AIOS van hun afdeling en het hoofd van de afdeling. Een rapport op basis van de scores gaf aan hoe lage/hoge scores and positieve en negatieve hiaten waren uitgewerkt. Naast dit rapport kreeg de opleidingscoördinator individuele feedback van een ervaren "humanresources"-medewerker, die de opleidingscoördinator begeleidde bij het opstellen van een persoonlijk ontwikkelingsplan.

De respons op de 360-gradenfeedbackprocedure was $80 \%$. Veruit de meeste ontwikkelingsplannen waren gericht op administratieve of managementtaken (75\%), terwijl er minder aandacht was voor initiatieven om leiderschapsvaardigheden te ontwikkelen (25\%). Dit is in tegenstelling tot de gelijkmatige verdeling van de vragen over deze onderwerpen in de enquête. Verbeterplannen voor het functioneren met betrekking tot gemakkelijk te omschrijven en goed meetbare managementdoelen waren concreet en specifiek, terwijl plannen voor het ontwikkelen van leiderschapsvaardigheden en daarmee ook de persoonlijke ontwikkeling minder 
concreet waren en oppervlakkiger beschreven werden. De plannen waren niet altijd een afspiegeling van de verbeterpunten die naar voren kwamen uit lage beoordelingen of verschillen tussen zelfbeoordelingen en de beoordelingen van andere deelnemers aan de 360-gradenbeoordeling.

Hoofdstuk $\mathbf{5}$ is gericht op het effect van een combinatie van initiatieven om leiderschapsvaardigheden te ontwikkelen. Het onderzoek bestond uit een interventiestudie met een controlegroep. De interventie bestond uit deelname aan een leiderschapscursus die speciaal ontwikkeld was voor opleidingscoördinatoren. Naast de cursus namen de opleidingscoördinatoren ook deel aan een 360-gradenfeedbackprocedure zowel voorafgaand aan de cursus als een jaar na deelname. De controlegroep nam alleen deel aan twee 360-gradenfeedbackprocedures met een tussenpoos van een jaar. Alle 56 opleidingscoördinatoren deden mee. Dit leverde een interventie- en een controlegroep van 28 deelnemers op.

De opleidingscoördinatoren in de interventiegroep waren van mening dat de cursus zeer belangrijk was en deelname eraan leerzaam. Dit werd echter niet teruggevonden in de scores op de 360-gradenfeedback na en voor deelname aan de cursus. De scores van de interventiegroep op de 360-gradenfeedbackprocedure een jaar na de eerste 360-gradenfeedback gaf geen verschil te zien met de scores van de controlegroep. Hieruit blijkt dat deelname aan een 360-gradenfeedbackprocedure gevolgd door een leiderschapscursus niet voldoende is om de leiderschapsvaardigheden van opleidingscoördinatoren te verbeteren.

Hoofdstuk 6 geeft een analyse van het curriculum van de Deense specialistenopleiding. De analyse bracht verschillende uitdagingen aan het licht ten aanzien van de positie van de opleidingscoördinator. Het managen van de specialistenopleiding wordt gekenmerkt door veel belanghebbenden die allen streven naar het verwezenlijken van hun tegenstrijdige belangen. Hierdoor kan een machtsstrijd ontstaan waarbij verschillende partijen elkaar in evenwicht houden. Het lijkt er echter op dat er een enigszins scheve verdeling is gegroeid ten gunste van belanghebbenden vanuit de arbeidsmarkt. Dit zou ertoe kunnen leiden dat leiders van de specialistenopleiding geen beslissingen kunnen nemen en moeite hebben hun leiderschap te doen gelden. Ook vormen de organisatie van de patiëntenzorg en de opleiding twee afzonderlijke lijnen waardoor initiatieven ten aanzien van de opleiding buiten het ziekenhuis ontwikkeld worden en daardoor buiten de normale managementstructuur van het ziekenhuis om gaan.

De taak om de onderwijslijn en de bestuurlijke lijn op elkaar aan te laten sluiten is in handen van de opleidingscoördinator die een middenkaderfunctie vervuld binnen de administratieve lijn. Voor onderwijszaken richt de opleidingscoördinator zich tot een externe organisatie terwijl hij zich voor administratieve zaken richt tot het hoofd van de afdeling. Hoewel hij zich voor onderwijszaken kan wenden tot de 
administratieve lijn, aangezien de directeur van het ziekenhuis eindverantwoordelijkheid heeft voor de specialistenopleiding in het ziekenhuis, lijkt er geen natuurlijke communicatielijn te bestaan tussen ziekenhuisdirectie en het bestuur van de specialistenopleiding.

De specialistenopleiding bestaat uit leren in de werkplaats en is daarom onverbrekelijk verbonden met de patiëntenzorg. Er lijkt echter een onderscheid te bestaan tussen het curriculum-op-papier, waarin de competente arts beschreven wordt in termen van onderscheiden rollen of competenties, en het curriculum-in-actie dat gebaseerd is op een klinische omgeving waarin combinaties van alle rollen aan de orde kunnen komen. In theorie is een uitkomstgestuurd curriculum een ideaal middel om hoge kwaliteit van zorg en patiëntveiligheid te garanderen. Het is een belangrijk onderdeel van de managementtaken van de opleidingscoördinator om het uitkomstgestuurde curriculum to vertalen naar de klinische praktijk. Het is echter niet gemakkelijk om in een klinische afdeling waar onderwijs vooral afhangt van toevallige leermomenten de strakke structuur van een uitkomstgericht curriculum te realiseren. Daarnaast bestaat er ook een tegenstelling tussen de fundamenteel behavioristische benadering van het curriculum-op-papier en de constructivistische, sociaal-culturele benadering van het onderwijs binnen de klinische afdelingen. Als daar ook nog een gebrekkige onderwijskundige structuur van het curriculum bijkomt, wordt het management van de specialistenopleiding binnen een klinische afdeling onvermijdelijk een complexe en onduidelijke taak.

\section{Conclusie}

Het in dit proefschrift beschreven onderzoek levert waardevolle bijdragen aan een beter inzicht in het managen van werkplaatsleren tijdens de specialistenopleiding binnen klinische afdelingen. De algemene opvatting is dat de opleidingscoördinatoren binnen de afdelingen beschikken over goede management- en leiderschapsvaardigheden, maar dat hun positie niettemin gezien wordt als zwak, onduidelijk en weinig invloedrijk. Daarnaast lijken hun leiderschapsvaardigheden niet erg gevoelig voor traditionele methoden om managementvaardigheden te ontwikkelen, zoals 360-gradenfeedback, begeleide persoonlijke ontwikkelplannen en cursussen. Dit zou echter kunnen samenhangen met het feit dat dit leiderschap uitgeoefend wordt binnen een context die gekenmerkt wordt door onduidelijkheid met betrekking tot taken, verantwoordelijkheden en organisatorische lijnen. Bij het managen van de specialistenopleiding zijn veel belanghebbenden betrokken met tegenstrijdige belangen. Het machtsevenwicht van de betrokkenen lijkt enigszins scheef verdeeld ten gunste van ziekenhuiseigenaren en partijen op de arbeidsmarkt, waardoor het werkgestuurde karakter van de opleiding benadrukt wordt.

Het is een belangrijke taak van de onderwijsleider om sturing te geven aan de combinatie van uitkomstgericht onderwijs en praktijkbeoordeling op de werkplaats. 
Het is geen eenvoudige taak om een primair behavioristisch curriculum tot uitvoering te brengen in een klinische afdeling waar constructivistische en sociaalculturele leerstrategieën de overhand hebben. Het curriculum-op-papier lijkt dan ook ver verwijderd van het curriculum-in-actie. Bovendien lijkt het erop dat de curricula niet gebaseerd zijn op een duidelijk onderwijskundig model.

Samenvattend, de taken van de opleidingscoördinatoren van de specialistenopleiding binnen klinische afdelingen en de context waarin zij die uitvoeren zijn complex en vaak tegenstrijdig. Ook werken de opleidingscoördinatoren binnen een professionele organisatie die van nature afwijzend staat ten opzichte van verandering. De rol van de opleidingscoördinatoren wordt gekenmerkt door onduidelijkheid met betrekking tot taken, verantwoordelijkheden en organisatorische structuur. Onder dergelijke omstandigheden is het niet verwonderlijk dat zelfs leiders met de beste kwalificaties en vaardigheden moeilijkheden ondervinden bij het effectief leidinggeven. 

CHAPTER 10

Acknowledgements 
I sincerely want to thank all the consultants responsible for education who participated in the multi-source feedback procedures for their courage and enthusiasm, especially for their effort in recruiting their respondents. I am grateful that all the physicians in the departments who served as respondents in both the multi-source feedback process and the measurement on the educational climate were willing to spend some of their precious time filling in the questionnaires.

I want to express my deepest gratitude to the Danish and Canadian co-authors Lene Mortensen, Thomas Bonderup and Deborah Davis for their great effort and contributions. Above all I wish to thank you, Lene for great and enjoyable collaboration on this and several other projects. I cannot express how highly I appreciate that.

With all my heart I wish to thank the "Master Ladies": Kirsten Bested, Helle Thy $\varnothing$ stergaard, Doris $\varnothing$ stergaard, Karen Skjelsager, and Charlotte Ringsted for many good discussions and help along the way. A special thank goes to Karen and Kirsten who willingly commented on my interview guides and the multi-source feedback instrument.

A special thank to Anne Mette Mørke, who taught me about focus-groups and analysis of qualitative data. I could not have come so far without the help from all of you. Thank You.

I wish to thank my former chief Ole $\varnothing$ sterballe for encouraging me to pursue a PhD and for helping me find the finances to getting it done. Ida Gøtke always believed in quality and thus quality in education. Thank you for many good discussions on this theme. A special thank to my present employers Anette Schmidt Laursen and Kristjar Skajaa for accepting the time I was on leave to finish this thesis.

A warm thanks to all the lovely people in my net-work groups, and especially to Berit Eika. You always believed in me and reached out to help me. Thank you.

The practical completion of the investigations could not have been undertaken without the invaluable help from you, Gudny Krossteig Mortensen - I sincerely thank you. A special thank to Arno Muitjiens for statistical help, to Marianne Bech Godt Hansen and Mereke Gorsira for excellent linguistic service, and to Gitte Skovgaard for help with figures, tables, posters and other graphical material.

The visionary allocation of financial support from the scientific foundation in Viborg County, together with resources from the Foundation to Improve Quality in clinical medical education (KUL foundation), Aarhus County and support from Aalborg County made it possible to carry through the research. In connection with financing of my study a special thank goes to Jan Greve and Jonna Hyldgaard. 
The international collaboration in this thesis has been most inspiring. I would not have been without this wide perspective. It has taught me so much. I wish to express my deepest respect for my supervisors: Charlotte Ringsted and Albert Scherpbier. They have encouraged and supported me all the way and they have carried me through a learning journey towards a higher competence level. Their criticism and feedback was prompt, relevant and even included an offer to shout out my frustrations over the phone when things did not go as smoothly as I wanted it to. You have been very patient. Thank you so much. You are the best. 

CHAPTER 11

Appendices 


\section{Appendix S1}

The multisource feedback instrument

\section{Leadership}

\section{Technical skills}

The CRE in your department

1. takes on the role as spokesman for trainees in educational matters

2. is a role-model in relation to education in the department

3. expresses his overall vision for education in the department

4. makes clear decisions

5. takes responsibility for education in the department

6. makes sure that the head of department supports the prioritization of education in the department

7. states that the quality of education in the department influences how attractive the trainees find the department

8. is goal-oriented

9. has managed to obtain influence on the organization of the work

10. announces if education is given too low priority

11. shows interest in each individual trainee

12. makes sure the consultants and other specialists in the department support educational matters

13. motivates the supervisors to maintain focus of the goals for education

14. is willing to guide and advice in educational matters

\section{Human skills}

The CRE in your department

15. shows interest in the trainees as human beings not only as trainees

16. is sensitive to ideas and suggestions

17. sees resources in other people

18. calls for the opinion of others

19. has power to penetrate

20. shows that he likes the job as CRE

21 . is ready to receive feedback himself

\section{Citizenship skills}

The CRE in your department

22. signals commitment in his function as CRE

23. puts education on the department's agenda with enthusiasm

24. constantly develops educational activities in the department 
25. motivates doctors in the department to use all training possibilities

26. introduces all new doctors in the department

27. establishes network around education in the department

28. establishes contacts to create networks around education outside the department

29. works for a good educational environment

30. is visible to the doctors in the department in his function as CRE

31. is visible as CRE to other staff members in the department

32. points out when educational projects succeed

33. constantly works to make education a common responsibility in the department

34. helps to use critical incidents as the basis for learning

35. is the first to use feedback as a natural part in daily work

36. makes sure that all doctors in the department teach

37. constantly spreads the use of supervision as a tool in specialist training

38. works towards making it attractive to work with education

\section{Management}

\section{Administrative skills}

The CRE is responsible for specialist training in the department. The function of the CRE concerns four areas: The department in general, the trainees, the supervisors and the clinical teachers.

\section{Tasks in relation to the department}

The CRE in your department

1. considers education in all procedural changes in the department

2. initiates new educational activities

3. makes sure that the educational programmes are in line with the educational offers in the department

4. involves relevant staff to meet the educational programmes

5. constantly coordinates the educational programmes and the working schedule

6. spreads new learning- and evaluation strategies in the department

7. follows up on results of total evaluations to optimize education in the department

\section{Tasks in relation to trainees}

The CRE in your department

8. makes sure that all educational programmes at the department are updated

9. keeps the department introduction programmes updated

10. ensures that the introduction programmes are implemented

11. is aware that the trainees have facilities for skills training 
12. helps the trainee to access necessary functions in order to obtain competence according to their individual education plan

13. makes sure that daily clinical guidance and training takes place

14. makes sure that the assessment of trainee competencies takes place

15. focus on individual learning plans to secure quality

16. invites trainees to seek relevant training opportunities

17. actively intervenes in problematic educational courses

18. can answer questions about education

\section{Tasks in relation to the supervisors}

The CRE in your department

19. points out a supervisor for all trainees

20. precisely delegates tasks to the supervisors

21. ensure that supervisors have the necessary qualifications

22. makes enquiries on the results of all appraisal meetings

23. supervises the supervisors

24. makes sure the supervisors know the learning and assessment strategies described in the educational programmes and curricula

25. keeps the supervisors updated on their responsibilities and tasks

26. sees to it that supervisors develop as supervisors

\section{Tasks in relation to clinical teachers}

The CRE in your department

27. precisely delegates tasks to the clinical teachers

28. supervises the clinical teachers

29. ensure that the clinical teachers know the learning and assessment strategies described in the educational programmes and curricula

30. sees to it that the clinical teachers develop skills as teachers

31. keeps the clinical teachers updated on their responsibilities and tasks

32. points out a supervisor for all trainees

33. precisely delegates tasks to the supervisors

34. ensure that supervisors have the necessary qualifications

35. makes enquiries on the results of all appraisal meetings

36. supervises the supervisors

37. makes sure the supervisors know the learning and assessment strategies described in the educational programmes and curricula

38. keeps the supervisors updated on their responsibilities and tasks

39. sees to it that supervisors develop as supervisors

40. precisely delegates tasks to the clinical teachers

41. supervises the clinical teachers 
42. ensure that the clinical teachers know the learning and assessment strategies described in the educational programmes and curricula

43. sees to it that the clinical teachers develop skills as teachers

44. keeps the clinical teachers updated on their responsibilities and tasks 


\section{Appendix S2}

Various respondents' ratings in a MSF process for consultants responsible for education on departmental level (CRE).

\begin{tabular}{|c|c|c|c|c|c|c|c|c|}
\hline & \multicolumn{2}{|c|}{$\begin{array}{c}\text { CRE rating } \\
\mathrm{N}=42\end{array}$} & \multicolumn{2}{|c|}{$\begin{array}{c}\text { Clinical teachers } \\
\text { rating } \\
N=224\end{array}$} & \multicolumn{2}{|c|}{$\begin{array}{l}\text { Trainees rating } \\
\qquad \mathrm{N}=235\end{array}$} & \multicolumn{2}{|c|}{$\begin{array}{l}\text { Head of departmen } \\
\text { rating } \\
\mathrm{N}=39^{*}\end{array}$} \\
\hline & Mean (SD) & Valid $\mathrm{N}$ & Mean (SD) & Valid $\mathrm{N}$ & Mean (SD) & Valid $\mathrm{N}$ & Mean (SD) & Valid $\mathrm{N}$ \\
\hline \multicolumn{9}{|l|}{ LEADERSHIP } \\
\hline \multicolumn{9}{|l|}{ Technical skills } \\
\hline $\begin{array}{l}\text { Trainee } \\
\text { counsellor }\end{array}$ & $5.95(0.91)$ & 42 & $6.07(0.93)$ & 180 & $5.92(1.05)$ & 186 & $6.02(0.85)$ & 35 \\
\hline $\begin{array}{l}\text { Performs } \\
\text { expected tasks }\end{array}$ & $5.13(1.15)$ & 42 & $5.45(1.21)$ & 182 & $5.52(1.23)$ & 183 & $6.60(0.94)$ & 34 \\
\hline $\begin{array}{l}\text { Ensures support } \\
\text { from stakeholders }\end{array}$ & $5.31(1.12)$ & 42 & $5.60(1.16)$ & 182 & $5.38(1.32)$ & 175 & $5.75(0.88)$ & 35 \\
\hline Resource allocator & $6.06(0.96)$ & 42 & $5.97(1.08)$ & 183 & $5.42(1.49)$ & 180 & $6.14(0.96)$ & 33 \\
\hline \multicolumn{9}{|l|}{ Human skills } \\
\hline $\begin{array}{l}\text { Empathic and } \\
\text { open-minded }\end{array}$ & $5.87(0.72)$ & 42 & $5.86(1.10)$ & 184 & $5.90(1.11)$ & 184 & $5.93(0.92)$ & 35 \\
\hline Shows authority & $5.32(1.04)$ & 42 & $5.67(1.23)$ & 183 & $5.83(1.18)$ & 188 & $5.87(1.07)$ & 35 \\
\hline \multicolumn{9}{|l|}{ Citizenship behaviour } \\
\hline Commitment & $5.57(0.98)$ & 42 & $5.66(1.16)$ & 186 & $5.58(1.05)$ & 189 & $5.82(0.92)$ & 36 \\
\hline $\begin{array}{l}\text { Engages } \\
\text { colleagues }\end{array}$ & $5.35(0.97)$ & 42 & $5.20(1.28)$ & 184 & $5.05(1.35)$ & 181 & $5.40(1.02)$ & 34 \\
\hline $\begin{array}{l}\text { Role-model and } \\
\text { mediator }\end{array}$ & $4.71(0.95)$ & 42 & $4.88(1.22)$ & 180 & $4.97(1.23)$ & 184 & $5.13(0.82)$ & 33 \\
\hline \multicolumn{9}{|l|}{ MANAGEMENT } \\
\hline \multicolumn{9}{|l|}{ Administrative skills } \\
\hline Implementer & $5.24(0.81)$ & 42 & $5.41(1.08)$ & 184 & $5.25(1.11)$ & 183 & $5.62(0.98)$ & 35 \\
\hline $\begin{array}{l}\text { Frames learning } \\
\text { possibilities }\end{array}$ & $5.36(0.92)$ & 42 & $5.45(1.11)$ & 178 & $5.38(1.09)$ & 181 & $5.59(0.89)$ & 34 \\
\hline $\begin{array}{l}\text { Updates } \\
\text { educational } \\
\text { programmes }\end{array}$ & $5.63(0.82)$ & 42 & $5.65(1.18)$ & 165 & $5.34(1.35)$ & 183 & $5.70(1.15)$ & 34 \\
\hline $\begin{array}{l}\text { Supervises the } \\
\text { supervisors }\end{array}$ & $3.75(1.23)$ & 42 & 4.50 (1.39) & 162 & $4.84(1.38)$ & 101 & $4.81(1.13)$ & 29 \\
\hline Quality assurance & $5.20(0.96)$ & 41 & $5.46(1.27)$ & 151 & $5.60(1.25)$ & 112 & $5.76(0.99)$ & 29 \\
\hline
\end{tabular}

Ratings shown as mean with (SD). Total numbers (N) included and number of valid ratings shown (Valid N). *3 participants were both CRE and head of department 
Curriculum vitae 
Bente Malling was born in Thisted, Denmark on the $1^{\text {st }}$ October 1954. She graduated as medical doctor from Aarhus University, Denmark in 1981, and became a specialist in anaesthesiology in 1993. From 1994 she was a consultant anaesthesiologist at Odense University Hospital, Denmark, and later at the Regional Hospital Silkeborg, Denmark. In 2003 she obtained a masters degree in Health Professions Education from Maastricht University, The Netherlands. In 2002, she was appointed assistant professor of postgraduate medical education.

In 2004, she left clinical medicine to be full time engaged in postgraduate medical education. She was director of postgraduate medical education at the Regional Hospital, Viborg, Denmark until she moved to a similar position at Aarhus University Hospital, Skejby, Denmark.

As a director of postgraduate medical education at Aarhus University Hospital, Skejby her responsibilities include research and development of postgraduate medical education as well as faculty development. Thus, she has been engaged in the development of "train the trainers" courses and has developed and managed the leadership courses for consultants responsible for education in the northern educational region in Denmark. She started the work on this thesis in Maastricht in 2004. 